NBER WORKING PAPER SERIES

\title{
THE LONG TERM IMPACTS OF GRANTS ON POVERTY: 9-YEAR EVIDENCE FROM UGANDA'S YOUTH OPPORTUNITIES PROGRAM
}

\author{
Christopher Blattman \\ Nathan Fiala \\ Sebastian Martinez \\ Working Paper 24999 \\ http://www.nber.org/papers/w24999 \\ NATIONAL BUREAU OF ECONOMIC RESEARCH \\ 1050 Massachusetts Avenue \\ Cambridge, MA 02138 \\ September 2018
}

For research assistance during this round of data collection we thank Chiara Dall'aglio, Peter Deffebach, Alex Nawar, Samuel Olweny, Harrison Pollack, field staff from Innovations for Poverty Action (IPA) Uganda, as well as the study participants for generously giving their time. In earlier rounds of the study, other IPA staff were indispensable: Filder Aryemo, Mathilde Emeriau, Benjamin Morse, Patryk Perkowski, Pia Raffler, and Alexander Segura. For comments we thank Johannes Haushofer, Joe Kaboski, Dean Karlan, Paul Niehaus, Berk Özler, Chris Udry, and numerous seminar participants. A Vanguard Charitable Trust funded the 9-year round of data collection. Prior rounds of data were funded by the same trust, the World Bank, and the Government of Uganda. Martinez's initial work on this project between 2006 and 2010 was conducted as an economist at the World Bank. All opinions in this paper are those of the authors, and do not necessarily represent the views of the Government of Uganda, the World Bank, or the IADB. The views expressed herein are those of the authors and do not necessarily reflect the views of the National Bureau of Economic Research.

NBER working papers are circulated for discussion and comment purposes. They have not been peer-reviewed or been subject to the review by the NBER Board of Directors that accompanies official NBER publications.

(C) 2018 by Christopher Blattman, Nathan Fiala, and Sebastian Martinez. All rights reserved. Short sections of text, not to exceed two paragraphs, may be quoted without explicit permission provided that full credit, including $(\odot$ notice, is given to the source. 
The Long Term Impacts of Grants on Poverty: 9-year Evidence From Uganda's Youth Opportunities Program

Christopher Blattman, Nathan Fiala, and Sebastian Martinez

NBER Working Paper No. 24999

September 2018

JEL No. C93,D13,J24,O12

\begin{abstract}
In 2008, Uganda granted hundreds of small groups \$400/person to help members start individual skilled trades. Four years on, an experimental evaluation found grants raised earnings by $38 \%$ (Blattman, Fiala, Martinez 2014). We return after 9 years to find these start-up grants acted more as a kick-start than a lift out of poverty. Grantees' investment leveled off; controls eventually increased their incomes through business and casual labor; and so both groups converged in employment, earnings, and consumption. Grants had lasting impacts on assets, skilled work, and possibly child health, but had little effect on mortality, fertility, health or education.
\end{abstract}

Christopher Blattman

Harris School of Public Policy

The University of Chicago

1155 E 60th St.

Chicago, IL 60637

and NBER

blattman@uchicago.edu

Nathan Fiala

University of Connecticut

1376 Storrs Rd

Unit 4021

Storrs, CT 06269

nathan.fiala@uconn.edu
Sebastian Martinez

Inter American Development Bank

smartinez@iadb.org

A randomized controlled trials registry entry is available at https://www.socialscienceregistry.org/trials/2187 


\section{Introduction}

To reduce poverty, governments and nonprofits commonly grant cash, livestock, or equipment to poor people who propose to start very basic businesses. These programs not only vary in the kinds of capital they grant, but also by whom they target, funding conditions, and what other services are bundled with the business capital. But the same assumptions underlie most grant-focused programs: that many of the poor have high returns to capital, but face constraints on their ability to borrow, save, or mitigate risk. ${ }^{1}$ If true, then a one-time grant of capital may help the poor overcome financial imperfections, start microenterprises (like livestock-raising or petty trading), and raise their incomes.

Broadly speaking, evaluations 1-4 years after these programs typically show that recipients raised their incomes compared to randomized control groups. ${ }^{2}$ Results vary, of course, and some programs show no impacts at all. But on the whole, these short- and medium-term results have bolstered the view that poverty, combined with start-up costs and imperfect financial markets, hold many poor people below their potential.

This includes the Youth Opportunities Program (YOP) in Uganda, the focus of this paper. YOP granted one-time cash grants to small groups that planned to set their members up as craftspersons. In an earlier follow-up, we found that 4 years after the intervention YOP increased average earnings by $38 \%$ and consumption by $10 \%$ (Blattman et al., 2014). This

\footnotetext{
${ }^{1}$ Banerjee and Duflo (2011) give one of the most comprehensive summaries of this evidence. Other recent summaries include Cho and Honorati (2014); Blattman and Ralston (2015); McKenzie (2017).

${ }^{2}$ In post-conflict northern Uganda, a program giving women $\$ 150$ grants, basic training and follow-up led to large income gains 18 months after the grants (Blattman et al., 2016). Other studies show that grants of cash and in-kind capital to less poor, existing entrepreneurs in Sri Lanka, Ghana and India lead to sustained increases in earnings 1-5 years later (de Mel et al., 2012; Fafchamps et al., 2014; Hussam et al., 2017). And cash grants to poor farmers in Mali raised farm inputs and incomes after 1 and 2 years (Beaman et al., 2018). Across seven countries, multifaceted programs that give grants of livestock alongside basic training and temporary income support show sustained increases on the incomes and consumption of the poorest rural households four years after grants (Banerjee et al., 2015; Bandiera et al., 2013, 2017). Most conditional cash transfer programs do not target (or measure) investment an earnings, but there is some evidence from a Mexican national program that cash relieves important financial constraints and leads to higher income after 1-2 years (Gertler et al., 2012; Bianchi and Bobba, 2013). Of course the effects of capital grants are not universally positive. Fiala (2018) fails to find income effects from cash grants to existing businesses in Uganda. In one of the multifaceted livestock programs, in Ghana, a grant of goats alone (without other program components) has no effect on incomes after 2 or 3 years (Banerjee et al., 2018). A cash grant programs to young men living on the streets of Monrovia and engaged in petty crime also had very shortlived impacts (less than one year) on enterprise and earnings, potentially due to the unusual instability and risk of their existence (Blattman et al., 2017). Karlan et al. (2014) find that cash grants to Ghanaian farmers had not effect without insurance, also because of the constraints from imperfect insurance. And in Kenya, a multifaceted "microfranchising" program that includes capital finds earnings gain in the first nine months but not after 1.5 years (Brudevold-Newman et al., 2017). We omit for the moment a discussion of unconditional cash transfer programs that are not designed to support business plans and raise incomes. The framing, targeting, and packaging with other conditions or services distinguishes these enterprise capital programs. We will discuss these other programs and their results below.
} 
paper returns to examine impacts 9 years after the grants.

While programs like YOP are often styled as a "lift out of poverty", theory tells us to be more cautious. In a standard model of occupational choice with financial market imperfections, one-time grants could have either temporary or lasting effects. It largely depends how serious the constraints and frictions that hold people back in the absence of grants are. For example, if credit-constrained poor people increase their work hours or have the means to save and invest some portion of their earnings over time, eventually they will be able to start similar businesses and will converge to the same level of income and investment as a grant recipient. In this case, the main question is, "how long before the control group converges?" Convergence will slow down if wages are low, saving is costly, if there are especially high start-up costs, if people are impatient or myopic, or if there are other market failures or social constraints that limit people's earnings and investment.

With enough frictions and constraints, it is possible that poor people stagnate without grants. If so, programs that grant cash, livestock or equipment could indeed be powerful tools for lifting people out of poverty. But this may be a relatively special case. In our illustrative model, for instance, a failure to converge requires extremely low initial assets, very low labor productivity in the traditional sector, and/or an inability to save. The world's poorest may face such constraints, and so it is possible that grants have lasting effects on income. So far, however, the empirical development literature has failed to find many instances of household-level poverty traps (Banerjee and Duflo, 2011; Kraay and McKenzie, 2014). Long run evidence on enterprise capital grants, from multiple sites and programs, is thus crucial information.

Long run results speak to another important empirical question: whether higher incomes have positive effects within the household over time, such as increasing children's health and education or (as we observed in the 4-year follow-up of YOP) more political engagement (Blattman et al., 2018). Even temporary income gains could have long-lasting effects through these channels.

With YOP, the Government of Uganda invited groups of about 20 poor young people to submit grant applications of roughly $\$ 400$ per person - an amount slightly greater than their annual incomes (using 2008 dollars and market exchange rates). Groups pre-specified how they would use the grants to hire their own vocational trainers, buy start-up tools and materials, and set themselves up as individual tradespersons. If selected, they received a one-time grant of roughly $\$ 8000$ into a community bank account and were left to themselves to make bulk purchases or otherwise share the funds, free of supervision or future follow-up.

YOP targeted small towns and villages in the poorer and underdeveloped periphery of the country. The districts in our sample were not directly affected by some of the region's 


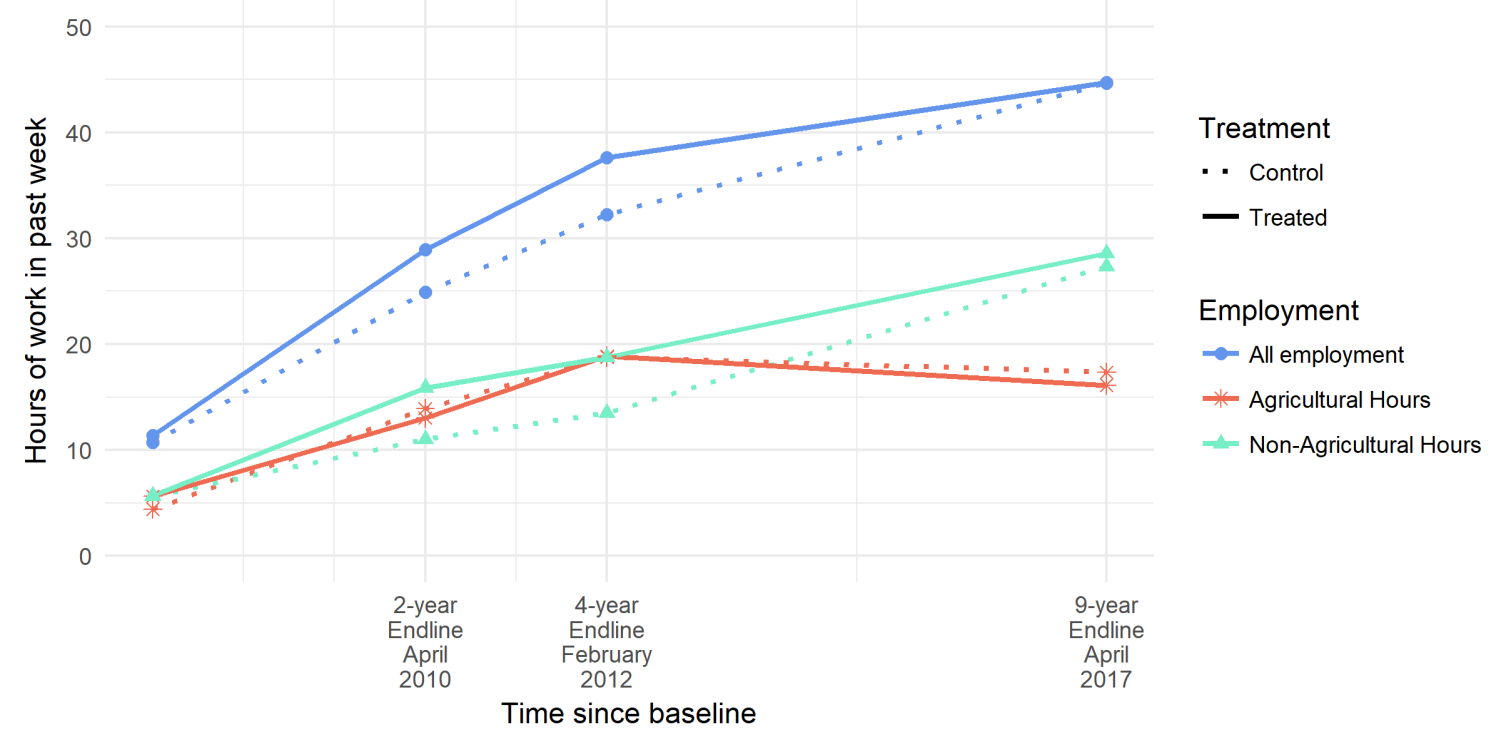

Figure 1: Progression of average weekly work hours over time, by treatment arm and sector

long-running conflicts, but they were close to unstable regions. With peace in these nearby areas, the entire region was growing economically.

We worked with the government to set YOP up as as a randomized trial, with more than 12,000 people in 535 eligible groups, 265 of which were funded. We attempted to follow a random subsample of five people in all 535 groups after 2, 4 and (in this paper) 9 years. Effective attrition is $14 \%$ in the most recent round.

Nine years after the grants were delivered we see convergence in the income and employment of treatment and control groups. Figures 1 and 2 show the progression of average weekly work hours and monthly self-reported earnings over time, by treatment status. The earnings figure also reports earnings residuals after accounting for district fixed effects (necessary for causal identification) and baseline controls (which improve precision and help account for selective attrition and mild imbalance).

Our assessment is that YOP operated more like a "kick start" for underemployed young people, rather than a sustained solution to poverty. The start-up grants helped youth with little capital to test their skills and luck in micro-entrepreneurship. But in the absence of this start-up capital, control group members eventually saved and accumulated enterprise capital and expanded their earnings opportunities. YOP's main lasting impacts after 9 years are a slight increase in fixed assets and a sustained increase in the likelihood of engaging in a skilled trade.

Four rounds of panel data and treatment effects, described in this paper, largely support this narrative. At baseline, the average person in our sample was 24 years old and had just 


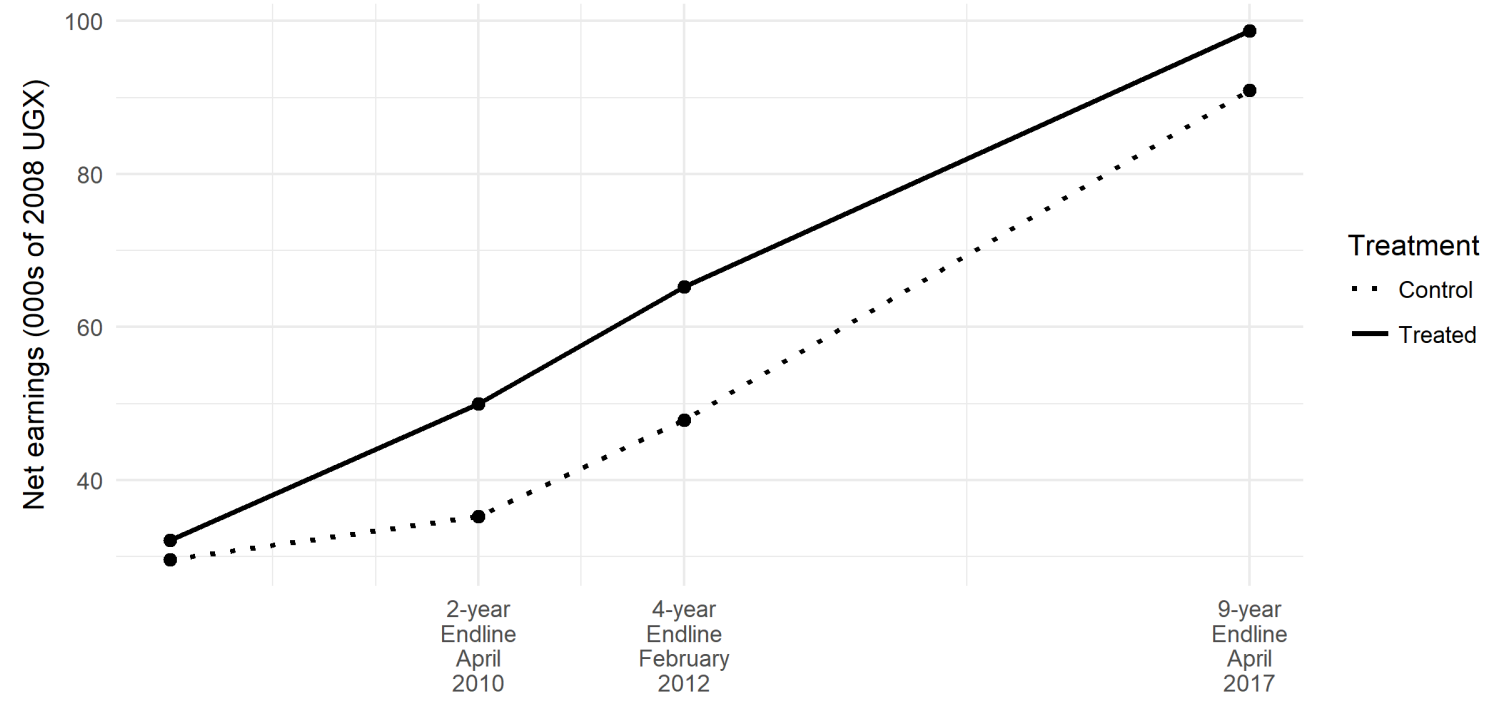

(a) Net earnings over time, disaggregated by treatment status

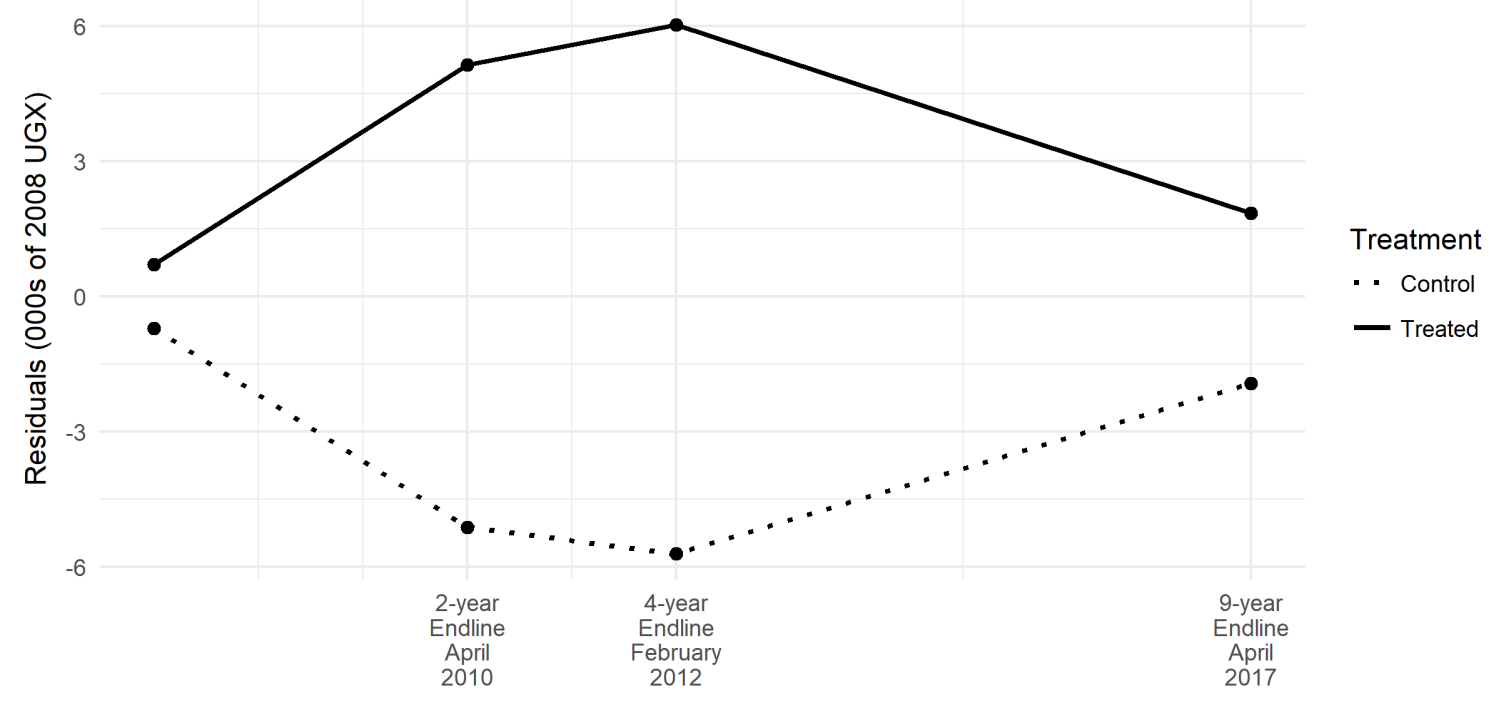

(b) Residuals from regression predicting net earnings over time, disaggregated by treatment status

Figure 2: Progression of earnings over time, by treatment arm 
11 hours of work per week. After 9 years, however, both groups reported roughly 45 hours of income-generating work per week in the past month.

In the beginning, YOP recipients invested some of their grant in skill acquisition but mostly they bought tools and materials. Treatment helped people quickly boost hours of work in a skilled trade, one generating more hours of employment and cash earnings. After 4 years, the treatment group reported $38 \%$ greater earnings and $11 \%$ greater consumption than controls. These income gains appear to come largely from more work hours. The income gains were small in relative terms - roughly $\$ 0.75$ a day in purchasing power parity terms (PPP). But given that the sample only earned about PPP $\$ 2$ a day, that extra 75 cents could be the difference between having two and three meals a day, or medicine for a sick child.

However, by the 4-year mark we were already seeing evidence of capital stocks converging, even if employment and incomes had not. On average, YOP grant recipients had stopped growing their capital stocks. We also observed the average control group member slowly accumulating capital and using it to start microenterprises, especially in petty trade and other business rather than skilled trades.

Between year 4 and 9, work hours and real incomes in the treatment group continued to grow, but control hours and incomes grew at a slightly faster rate. After 9 years, the treatment and control groups have identical work hours. Measures of income flow have also more or less converged: treatment group earnings are just 5\% larger than the control group, and treatment group consumption is just $1.4 \%$ greater. None of these differences are statistically significant.

The most persistent economic effects of YOP are on assets and occupational choice. YOP recipients have 0.12 standard deviations greater household assets such as home quality or livestock. Grant recipients are also slightly more likely to be in skilled trades rather than petty business. If we interpolate annual program effects on earnings with a $5 \%$ discount rate, we estimate a present value of total earnings gains of roughly $\$ 665$ - almost twice the size of the grant (excluding administrative costs, which are unknown).

Of course, these temporary earnings gains and greater assets can be a victory against poverty if they lead to investments in health or education, especially better outcomes for children. Yet we see relatively limited health and education effects on the YOP recipients or their children.

We asked study participants about child enrollment and grade attainment, the general health of each child, their physical functioning along a number of dimensions, and rates of miscarriage and child mortality. These parent-reported data are error-prone and noisy, especially when men live away from their children or have had children with multiple partners 
(a major reason why it is costly and difficult to survey the children directly). We expect this to affect the precision of treatment effects rather than bias impacts, however, since we see few reasons the measurement error should be correlated with treatment.

We see no program impact on the number, age, composition, or survival of children. We also see little change in child school enrollment or grade attainment. Children born after the YOP grant, however, have about 0.08 standard deviations greater physical functioning. This seems to be concentrated almost entirely among women assigned to YOP. They report children with 0.17 standard deviations greater functioning (versus 0.036 for men). Thus there is slight evidence of long run gains from the temporary income boost.

Despite the proliferation of evaluations of capital grants, such long run data are rare. Our findings, however, are consistent with a recent study in Ethiopia. Blattman et al. (2018) find that cash grants of $\$ 300$ plus basic business consulting raised incomes by a third in the first year, but that employment and earnings converged within 5 years. ${ }^{3}$ Another example, in Bangladesh, is more ambiguous. Bandiera et al. (2017) find that a multifaceted program of livestock grants plus skills and other services have 4-year impacts strikingly similar to YOP. After 7 years, some of their evidence suggests that the gains persist, though this estimate is complicated by half of the control villages beginning to be treated.

The patterns identified in this paper are consistent with our own model of investment and occupational choice, as well as more elaborate structural models and program simulations by Buera et al. $(2015,2014)$. In the absence of extreme frictions or poverty traps, these models all predict that the positive economic impacts of entrepreneurship capital grants can be short-lived if the returns to capital are diminishing and people can acquire capital in absence of the program.

These models also suggest that the largest and most sustained impacts come from targeting people with high entrepreneurial productivity and low initial wealth. For example, Hussam et al. (2017) also show that Indian microentrepreneurs and their communities have good private information about entrepreneurial productivity and returns to capital, and these returns are extremely heterogeneous. Beaman et al. (2018) also see substantial heterogeneity in returns to capital among Malian farmers, and high productivity credit constrained farmers select into loans when they become available. ${ }^{4}$ Note that, by design, YOP took many efforts

\footnotetext{
${ }^{3}$ Studying a multifaceted "microfranchising" program in Nairobi, Kenya, Brudevold-Newman et al. (2017) see income gains after 9 months but none after 1.5 years. This could imply rapid convergence, though the authors interpret the results as evidence of a savings constraint, implying that the participants' did not have high returns to capital (or, more specifically, this multifaceted program).

${ }^{4}$ In villages where farmers were eligible for loans, those who did not take out loans did not have high returns to subsequent grants, while farmers in villages ineligible for loans did have high average returns. The evidence is not always so clear; Karlan et al. (2014) experiment with cash grants to farmers in Ghana, and find some evidence that insurance market imperfections are great enough that the returns to capital alone
} 
to target this promising demographic of capital-poor, high-ability, high-initiative poor young people. More research on the effectiveness of targeting strategies could be of value.

Yet while these standard models give us many reasons to eventually expect temporary gains, it is striking how few policy analyses and papers on these programs dwell on convergence -including our own 4-year evaluation of YOP (Blattman et al 2014). We, like many others, implicitly framed the grants program as a potential solution to poverty and failed to weigh what briefer impacts would imply for theory and practice.

Convergence is especially relevant for high-cost programs. Some common intervention components - including beneficiary targeting, physical asset delivery, or skills training - can be expensive to deliver relative to the very low earnings of most microenterprises. For example, programs to deliver livestock, training, and income support to ultrapoor households in 6 countries estimated that the 3-year impacts would have to persist or grow for at least a dozen more years in order for consumption gains to outweigh program costs (Banerjee et al., 2015). Persistent gains are plausible given that the ultrapoor have such limited ability to save, and low counterfactual earnings. But clearly the pace of convergence is a firstorder question for any program model that spends large sums on targeting or other program components. (Though this was not an issue for YOP. Cumulative earnings of participants equaled program costs by the 4-year follow-up, and likely grew afterwards.)

Another strain of anti-poverty programs, not discussed so far, provide unconditional cash transfers (UCTs) to the poor. Two evaluations find short-term increases in consumption and assets, as recipients spend the money, but they find no evidence of investment or income gains over 2-4 years. ${ }^{5}$ These differ from programs like YOP in many ways, but one hypothesis that income gains are much more likely in programs that target people with high returns to investment, stated investment plans, or compulsions to invest. ${ }^{6}$

are not high.

${ }^{5}$ Baird et al. $(2017,2011)$ look at small monthly conditional cash transfers (CCTs) and UCTs to adolescent girls in Malawi, sustained over three years, where the CCT is conditioned on school attendance. At the end of this program of transfers, and 2 years afterwards, they see little effect on incomes. They also see convergence after early gains in teen pregnancy, early marriage, and sexually transmitted infections. Haushofer and Shapiro $(2016,2018)$ evaluate UCTs from GiveDirectly in Kenyan villages after 9 months and 3 years, and find sustained increases in assets between treatment and control villages, but no consumption impacts. They do find consumption differences between treated and "spillover" households within treated villages, but it is not clear if this evidence of an income gain or an adverse spillover.

${ }^{6}$ Yet another common program has been to give poor people access to cheap finance. In principle microloans should solve the credit market imperfections that constrain microentrepreneurs. But lending and banking such small sums of money for so many people can be expensive. Also, it is hard to improve institutions that reduce the loan market's information and collection problems. As a result, interest rates on micro-loans tend to be very high. That and the short time periods for repayment of most micro-loans can make them poor vehicles for business investment. This potentially one reason why some recent micro-lending experiments show little or no impact on the earnings of most loan clients. See for example Banerjee (2013); Banerjee et al. (2015). Of course, better targeted, cheaper microfinance with longer repayment periods could 
Tentatively, one might conclude that some of the poor have high returns to capital and face financial market imperfections, and grants help them start successful microenterprises. This might be especially true for the young, the poorest, in the places with the worst access to credit, and growing local economies (though these conditions are fairly speculative). If so, then the important policy and theoretical questions are in identifying who these people are, what precise constraints bind, and how to make the most difference.

\section{Setting}

Uganda, a small landlocked country in east Africa, is poor but with a stable and growing economy. $^{7}$ By the mid 2000s, however, most of that growth had been concentrated in the capital and southwest of the country. One of the government's highest priorities has been to develop the northern half of the country. ${ }^{8}$

The north is more distant from trade routes and, as an area of early opposition support, received less public investment from the 1980s onward, especially for power and roads. Partly because of this marginality, there was also virtually no access to credit for business investment in 2008. Formal insurance was unknown and the north had almost no formal lenders. Most villages had no active microfinance organizations. While village rotating savings and credit associations (ROSCAs) were commonplace, loan terms seldom extended beyond three months, with annual interest rates of 100 to 200\%. Because of high banking fees, real interest rates on formal savings are negative. In 2006 the government estimated that nearly two-thirds of northern people were unable to meet basic needs, just over half were literate, and most were under-employed in subsistence agriculture (Government of Uganda, 2007).

The north was also held back by nearby insecurity. From 1987 to 2006 a low-level insurgency destabilized districts in north-central Uganda-districts that were not part of this study, but nonetheless depressed trade and development in the north more broadly.

stimulate the same kinds of entrepreneurship as grants (see for example Feigenberg et al., 2013). Thus we view microfinance as operating under the model and assumptions as these other entrepreneurship programs. The theory and evidence of success from the Thai Million Baht Village Fund program is one example (Kaboski and Townsend, 2011).

${ }^{7}$ Shortly before the program, in 2007, it had a population of about 30 million and GDP per capita of roughly $\$ 330$. Real gross domestic product grew $6.5 \%$ per year from 1990 to 2007 , inflation was under $5 \%$, and poverty rates were falling Government of Uganda (2007). This growth puts Uganda's GDP per capita slightly above the sub-Saharan average.

${ }^{8}$ Northern development served at least two government objectives. One was economic, as the government tried to maximize growth and minimize poverty. The other is political. As multiparty elections become more and more competitive, and as ruling party support in the capital waned, the ruling National Resistance Movement appeared to be interested in building a broader base of political support in areas such as the north. To do so, they pursued a set of broad-based and relatively non-politicized programs such as the one studied in this paper. 
Moreover, wars in Sudan and Democratic Republic of Congo also led to mild insecurity in the northwest. Finally, cattle rustling and armed banditry were unusually high in the northeast.

In 2003, peace came to Uganda's neighbors, and Uganda's government increased efforts to pacify and develop the north. By 2006, the military pushed the rebels out of the country and began to disarm cattle-raiders. The government also began to improve northern infrastructure and South Sudan began to grow rapidly. With this political uncertainty resolved, by 2008 the northern economy began to catch up to the rest of the country.

From 2003 to 2010, the centerpiece of the government's northern development and security strategy was a decentralized development program, the Northern Uganda Social Action Fund, or NUSAF. NUSAF was Uganda's second-largest development program, after the national agricultural extension service. Starting in 2003, communities and groups could apply for cash grants for various purposes: various community infrastructure construction and livestock for the very poorest. Since the government wanted to do more to boost non-agricultural employment, in 2006 it introduced a third NUSAF component: YOP.

\section{The Youth Opportunities Program (YOP)}

YOP invited groups of young adults, aged roughly 16 to 35, to apply for cash grants in order to start a skilled trade such as metal fabrication, carpentry or tailoring. The program had five key elements.

1. People had to apply as a group. One reason was administrative convenience - it was easier to screen and disburse to a few hundred groups rather than thousands of people. Another reason is that officials hoped groups would be more likely to implement proposals rather than waste the cash. Finally, groups could take advantage of economies of scale in purchasing tools or hiring trainers (see below). But officials were not aiming to create cooperatives. In general, they expected that recipients would set themselves up as independent businesses, although they might share some tools or collaborate.

Groups in our sample of applications ranged from 10 to 40 people, averaging 22, mostly from the same parish (a collection of villages). Half the groups existed already, often for several years, as farm cooperatives, or sports, drama, or microfinance clubs. New groups formed specifically for YOP were often initiated by a respected community member (e.g. teachers, local leaders, or existing tradespersons) and sought members through social networks. In our sample, $5 \%$ of groups are all female and $12 \%$ are all male, but most groups are mixed - about one-third female on average. 
2. Groups had to submit a written proposal. The proposal outlined how they would use the grant for non-agricultural skills training and enterprise start-up costs. Groups could request up to $\$ 10,000$ (in 2008 market exchange rates). The proposal specified member names, a management committee of five, the proposed trade(s), and the assets to purchase. Decisions were made by member vote, and nearly all members report they had a voice in decisions. Most groups proposed a single trade for all, but a third of groups proposed that different members would train in different trades. Females and mixed groups often chose trades common to both genders, such as tailoring or hairstyling. Males and a small number of females often chose trades such as carpentry or welding.

In preparing the proposal, groups identified their own trainers, typically a local artisan or small institute. These are commonplace in Uganda (as in much of Africa) and there is a tradition of artisans taking on paying students as apprentices. Most of these artisans and institutes had been in existence more than five years, and most took students previously. In our sample, few were located in the village but the median artisan or institute was within 8 kilometers. Groups would travel to be closer to trainers, or paid transport and upkeep for trainers to come to them.

3. Proposals had to receive formal advising. Many applicants were functionally illiterate, so YOP also required "facilitators" (usually a local government employee, teacher, or community leader) to meet with the group several times, advise them on program rules, and help prepare the written proposals. Groups chose their own facilitators, and the NUSAF office paid facilitators $2 \%$ of funded proposals (up to $\$ 200$ ).

4. Several levels of government bureaucracy screened applications. Villages or parishes typically submitted one application, and that privilege may have gone to the groups with the most initiative, need, or connections. Village officials passed applications up to districts, which verified the minimum technical criteria (such as group size and a complete proposal) and were supposed to visit projects they planned to fund. Districts said they prioritized early applications and disqualified incomplete ones, but unobserved quality and political calculation could have played a role. We do not observe this process. Most of the applications were made two years before their actual selection.

5. Groups received a lump sum grant. Successful proposals received the full cash transfer to a bank account in the names of the management committee, with no government monitoring thereafter. In our sample, the average grant was UGX 12.9 million Ugandan shillings (UGX) per group, or $\$ 7,497$ (all figures in the paper are quoted in 2008 UGX 
and dollars). Per capita grant size varied across groups due to variation in group size and amounts requested. $80 \%$ of grants were between $\$ 200$ and $\$ 600$ per capita, averaging $\$ 382$.

Generally, YOP applicants did not come from the "ultra poor". For extremely poor and "vulnerable" groups, NUSAF had a separate program of group cash grants for livestock purchases. YOP was targeted to young people with at least some education and prospects for starting a skilled trade. However, most YOP group members can not be considered well off, even by international standards.

\section{Conceptual framework}

We model the effects of grants on employment and income using a simple Ramsey model of investment with occupational choice and heterogeneous individuals. We summarize the basic intuition here, and Appendix A outlines the full model. More general models and simulations, such as that by Buera et al. $(2015,2014)$, reach similar conclusions.

Consider the case where there are two riskless sectors: traditional labor-intensive work (such as subsistence agriculture) and capital-intensive small enterprise. Both use labor as an input, and production depends on a person's innate, sector-specific abilities. The enterprise sector also uses capital (physical and human), and may have a discontinuity in the production function, such as a fixed cost of start-up. People vary in their initial wealth and can either consume, save or invest their current earnings and wealth. They can also borrow and save at the market interest rate.

In this simple model, a credit-constrained young person with no start-up capital would be unable to start an enterprise. She would only work in the traditional sector. Someone with high entrepreneurial ability, or high enough local market returns, will have an incentive to save some of her earnings from traditional work. She would invest in the enterprise once she has saved the minimum capital requirement. She is less likely to save and invest in enterprise if she has low entrepreneurial ability, or is impatient, time-inconsistent, or savings constrained (e.g. has a negative interest rate or cap on savings). She will also be less likely to save or invest in enterprise if she is risk averse, has limited access to insurance, and enterprise and traditional returns are positively correlated.

Thus, credit constraints interact with initial poverty and other constraints to limit some people from entering the entrepreneurial sector, even high ability people who would enjoy high returns to capital in that sector. Under these constraints, we could expect a cash grant to be invested in an enterprise. Investment and the optimal level of capital will be lower the lower someone's entrepreneurial ability, patience, time inconsistency, or tolerance for risk 
are. If the returns to capital are high enough, we would expect to see more labor allocated to enterprise, higher incomes, and potentially more employment hours overall.

People with low enough entrepreneurial ability will not have an incentive to invest an unconditional grant. If the grant comes in the form of in-kind transfers or restricted funding, then there may be some kind of "flypaper effect" such that capital stocks are "sticky" and cannot be divested immediately. This will force people to produce above their efficient scale temporarily. But over time, if it is possible to shift capital out of the enterprise, people will divest (or depreciate) until their returns to enterprise fall to the optimal level (which may be zero). ${ }^{9}$

Consequently, the effects of a grant program like YOP depends on the population's returns to capital, the market imperfections people face, and the composition of the recipients. If YOP applicants have a mix of high and low ability, then we would expect to see the higher ability maintain or even grow the initial investment, and the others to divest over time. Adverse shocks that knock someone below the minimal capital requirement could also lead to a sustained or permanent exit from enterprise.

Longer term differences between the people who do and do not receive a grant depend on what constraints the control group faces. If people are sufficiently time inconsistent, impatient, or savings constrained then they may take a long time to start enterprises, especially if the minimum capital requirement is high. Otherwise we should expect convergence over time.

\section{$5 \quad$ Experimental design and data}

Northern Uganda's high levels of youth unemployment and poverty meant that YOP received a large number of proposals. Thus, the program was vastly oversubscribed. We worked with the government to randomize funding among a set of screened and eligible grant proposals, and track a selection of group members over time.

\subsection{Sample selection and randomization procedure}

YOP launched in 2006 and thousands of groups submitted proposals. The government funded hundreds of proposals in 2006-07, prior to our study. By 2008, 14 of the 18 NUSAFeligible districts had funds remaining for YOP. Figure 3 maps these study districts. None

\footnotetext{
${ }^{9}$ Note that, while there was no official monitoring after recipients received funds, we cannot consider YOP to be fully unconditional as there was the initial condition of people needing to prepare proposals for the funds. The groups may have also acted as enforcement devices.
} 
of the most war-affected districts (Gulu, Kitgum, and Pader) had the organization or funds remaining to participate in the final round.

Figure 3: Eligible districts and total number of study communities per parish

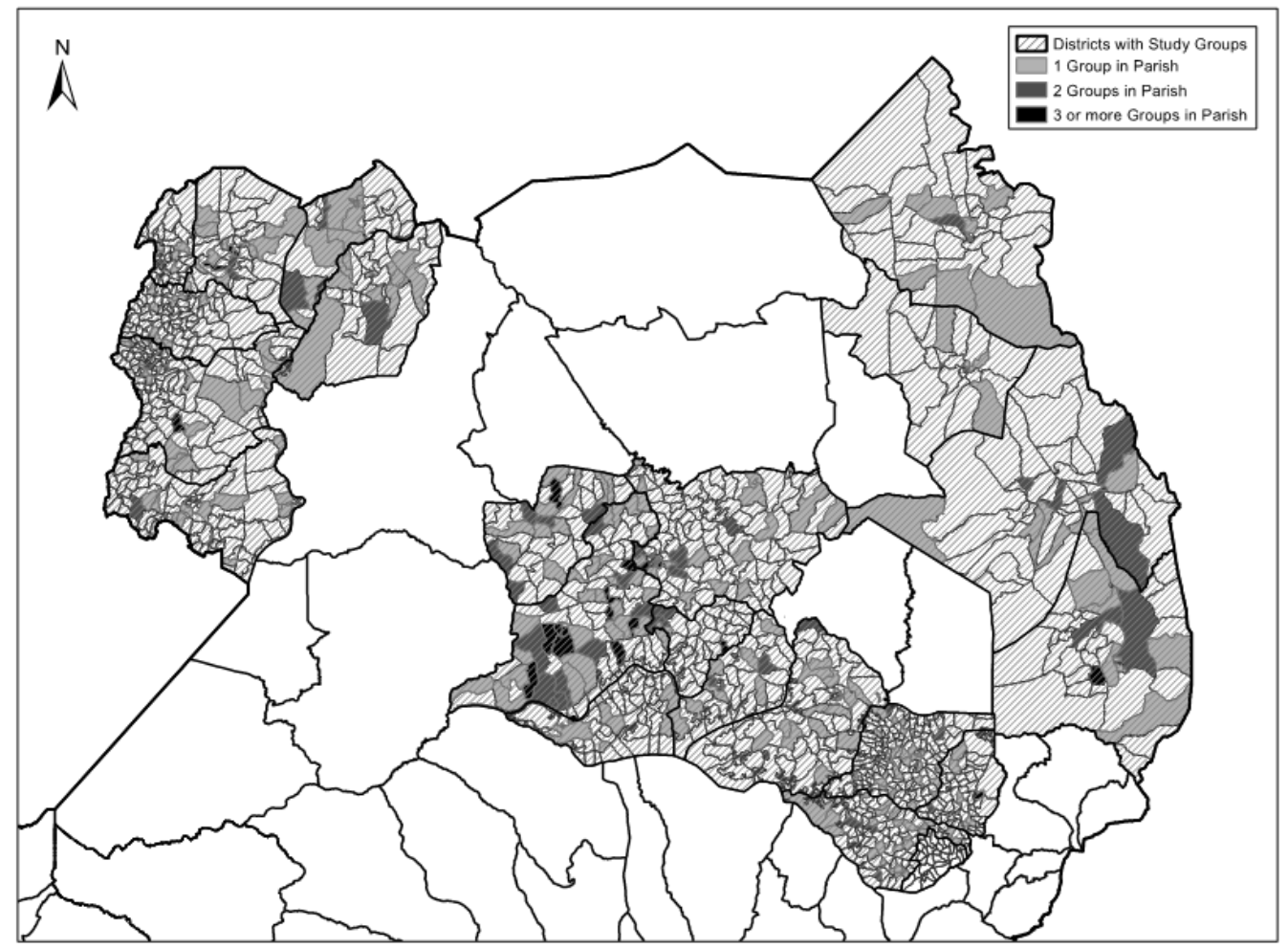

In 2007, the central government asked district governments to nominate 2.5 times the number of groups they could fund. The districts submitted roughly 625 proposals to a central government office. Based on our discussions with district officials, each district reviewed only a small fraction of the thousands of proposals they received. Most said they tried taking a "first come first serve" approach. Others described other ad hoc criteria. Local political considerations might also have come into play, although we heard very few accusations of "political pork" or favoritism.

To minimize chances of misuse and corruption, the central government reviewed proposals for completeness and validity. They also sent out audit teams to visit and verify each group. The government disqualified about 70 applications, mainly for incomplete information or ineligibility (e.g. many group members over 35 years, or a group size more than 40). The government also asked that 22 groups of underserved people (Muslims and orphans) be funded automatically.

In January 2008 the government provided us with a list of 535 remaining groups eligible for randomization, along with district budgets. These 535 groups contained nearly 12,000 
members. In February 2008, we randomly assigned 265 of the 535 groups (5,460 individuals) to treatment and 270 groups (5,828 individuals) to control, stratified by district. Spillovers between study villages were unlikely as the 535 groups were spread across 454 communities in a population of more than five million. Figure 3 displays a map of groups per parish. ${ }^{10}$

In February and March 2008 the Uganda Bureau of Statistics, with the direction of the researchers, conducted a baseline survey of all 535 groups. They gathered all group members in one place, created a full group roster, and randomly sampled five people per group to survey. This established a panel of 2,675 people. The government disbursed grants between July and September 2008.

\footnotetext{
${ }^{10}$ Gaps in administrative data mean that 20 villages are linked to a district but not a parish. Of the 26 parishes with three or more groups per parish, just six parishes have 4 or more groups.
} 
Table 1: Survey response rates by survey round

\begin{tabular}{|c|c|c|c|c|c|c|c|c|c|c|}
\hline \multirow[b]{2}{*}{ Survey } & \multicolumn{5}{|c|}{ Selection and tacking, by survey phase } & \multicolumn{5}{|c|}{ Effective response rates } \\
\hline & $\begin{array}{c}\text { Total } \\
\text { sought } \\
(1)\end{array}$ & $\begin{array}{c}\text { Found } \\
\text { phase } 1(\%) \\
(2)\end{array}$ & $\begin{array}{c}\text { Selected } \\
\text { phase } 2(\%) \\
(3)\end{array}$ & $\begin{array}{c}\text { Found } \\
\text { phase } 2(\%) \\
(4)\end{array}$ & $\begin{array}{c}\text { Final \# } \\
\text { of obs. } \\
(5)\end{array}$ & $\begin{array}{c}\text { All }(\%) \\
(6)\end{array}$ & $\begin{array}{c}\text { Control }(\%) \\
(7)\end{array}$ & $\begin{array}{c}\text { Treated }(\%) \\
(8)\end{array}$ & $\begin{array}{c}\text { Difference }(\%) \\
(9)\end{array}$ & $\begin{array}{c}\text { p-value } \\
(10)\end{array}$ \\
\hline 2008 baseline & 2,677 & 97.0 & & & 2,598 & 97.0 & 94.4 & 99.8 & 5.3 & 0.000 \\
\hline 2-year endline & 2,677 & 63.4 & 53.0 & 74.7 & 2,005 & 85.5 & 85.6 & 85.3 & -0.8 & 0.698 \\
\hline 4-year endline & 2,677 & 61.0 & 38.5 & 58.6 & 1,868 & 82.1 & 79.1 & 85.5 & 7.1 & 0.004 \\
\hline 9-year endline & 2,677 & 71.1 & 36.0 & 43.2 & 1,981 & 87.3 & 88.5 & 86.1 & -2.8 & 0.266 \\
\hline
\end{tabular}




\subsection{Survey data and attrition}

As there is no administrative data in Uganda, all outcomes are based on survey self-reports. The national statistics agency conducted the baseline survey, and Innovations for Poverty Action (IPA) and private survey firms conducted all endline surveys. The 2-year endline was conducted between August 2010 and March 2011, 24 to 30 months after disbursement, a 4-year survey between April and June 2012, 44 to 47 months after disbursement, and a 9-year endline between March and May, 2017 - 103 to 106 months after disbursement.

Table 1 reports survey response rates and sample size at each round. At baseline, enumerators and local officials mobilized group members to complete a survey of demographic data on all members as well as group characteristics. Virtually all members were mobilized. Enumerators could not locate 13 groups (3\% of the sample). Unusually, after the survey it was discovered that all 13 had been assigned to the control group. We investigated the matter and found no motive for or evidence of foul play. District officials, enumerators, and the groups themselves did not know the treatment status of the groups they were mobilizing. We were only able to find one of the 13 at endline. While we cannot confirm what happened in the other 12 groups, "ghost projects", which are fake projects developed by a local or national official with the goal of taking all of the money transferred to an account for themselves, are a common concern in such programming in Uganda. An anti-corruption experiment conducted on the second NUSAF program, which came immediately after the end of this program, found similar rates of missing projects (Fiala and Premand, 2017).

YOP applicants were young and mobile. 30-40\% of respondents had moved or were away temporarily at each endline survey. To minimize attrition, we used a two-phase tracking approach (Thomas et al., 2001). Table 1 summarizes the phases. In Phase 1, we attempted to interview all 2,675 people in their last known location. We did not find $37 \%$ in $2010,39 \%$ in 2012, and $29 \%$ in 2017. Most had migrated away from their original home. In Phase 2, we selected a random sample of the unfound $-53 \%$ in $2010,38.5 \%$ in 2012 , and $36 \%$ in $2017 .{ }^{11}$ We made at least three attempts to find this subset in their new locations.

We found $75 \%$ of the selected sample in 2010, $59 \%$ in 2012, and $74 \%$ in 2017 . Those found in Phase 1 receive unit weight, those selected in Phase 2 are weighted by the inverse of their selection probability, and those not selected in Phase 2 are dropped. Fewer than 2.5\% of people refused to answer. Our response rate was $97 \%$ at baseline, and effective response rates at endline (weighted for selection into endline tracking) were $90.7 \%$ in 2010 , $84 \%$ in 2012 , and $87 \%$ in 2017.

Overall, our attrition levels are similar to other panels of young adults in rural Africa

\footnotetext{
${ }^{11}$ The proportions mainly varied according to our available resources. The Phase 2 randomization stratified by district and by the proportion unfound in the group.
} 
(Baird et al., 2015; Friedman et al., 2011; Baird et al., 2016), though higher than some panels of existing entrepreneurs, who are typically urban, less mobile, and in some cases are screened for attrition before the experiment (de Mel et al., 2012; Udry and Anagol, 2006).

Of potentially greater concern is correlation between attrition and treatment. Largely because of the 13 "never found" control groups, attrition in 2012 and 2017 is higher among controls. If we ignore this source of non-response, there is a negligible association of treatment and attrition in 2017. If these "never found" controls had particularly high potential outcomes, we would overstate the impact of the intervention.

There is also some correlation between attrition and potential indicators of economic success. If so, and uncorrected, selective attrition could bias our treatment effects upwards. Appendix Table B.1 reports baseline correlates of attrition (excluding the $3 \%$ not found at baseline). Arguably, people with slightly more entrepreneurial potential are slightly less likely to be found: town dwellers, non-farmers, and those with higher literacy, initial employment, earnings and loan access, and members of the group management committee. To attempt to correct for any possible bias, when calculating treatment effects we will use inverse probability weights from these attrition regressions. Found members of the sample who look more like the attritors will get slightly more weight in the estimated treatment effect.

\subsection{Randomization balance}

Table 2 displays summary statistics and tests of balance for 38 baseline covariates. There is balance across a wide range of measures, but a handful show imbalance. They suggest higher levels of initial wealth among the treatment group. ${ }^{12}$

While this imbalance may be chance, the missing 13 control groups could also cause the imbalance. We estimate that if the missing control groups had baseline values just 0.05 standard deviations above the control mean, we would fail to find statistically significant imbalance. If 0.1 standard deviations above the control mean, the mean differences between the treatment and control groups would be close to zero. ${ }^{13}$ If so, this would imply that the observed control group may be poorer than the treatment group, and will lead us to overstate true program impacts. We model alternative attrition scenarios below.

\footnotetext{
${ }^{12}$ The treatment group report 2 percentage points more vocational training, 0.07 standard deviations (SD) greater wealth, $56 \%$ greater savings (though only in the linear, not in log form), and 5 percentage points more access to small loans.

${ }^{13}$ Not shown here. These results were originally reported in Blattman et al. (2014).
} 
Table 2: Balance test of all covariates at Baseline

\begin{tabular}{|c|c|c|c|c|}
\hline \multirow[b]{2}{*}{ Covariate in 2008} & \multicolumn{2}{|c|}{ Means } & \multicolumn{2}{|c|}{ Difference } \\
\hline & $\begin{array}{c}\text { Control } \\
\text { (1) }\end{array}$ & $\begin{array}{c}\text { Treated } \\
(2)\end{array}$ & $\begin{array}{l}\text { Coeff } \\
(3)\end{array}$ & $\begin{array}{c}\mathrm{p} \text {-value } \\
(4)\end{array}$ \\
\hline Age at baseline & 24.77 & 25.14 & 0.003 & 0.204 \\
\hline Age squared & 639.46 & 660.00 & 0.000 & 0.216 \\
\hline Age cubed & $17,253.38$ & $18,159.66$ & 0.000 & 0.252 \\
\hline Male & 0.67 & 0.68 & 0.009 & 0.757 \\
\hline Large town / urban area & 0.22 & 0.20 & -0.031 & 0.557 \\
\hline Risk Aversion (z-score) & 0.03 & -0.03 & -0.015 & 0.301 \\
\hline Found at baseline & 0.94 & 1.00 & 0.471 & $0.000 * * *$ \\
\hline Highest grade reached in school & 7.90 & 7.82 & -0.002 & 0.589 \\
\hline Able to read and write minimally & 0.76 & 0.71 & -0.062 & $0.028^{* *}$ \\
\hline Received prior vocational training & 0.07 & 0.08 & 0.040 & 0.331 \\
\hline Digit recall test score & 4.16 & 4.01 & -0.009 & 0.104 \\
\hline ADL index & 8.65 & 8.63 & -0.001 & 0.860 \\
\hline Durable Assets (z-score) & -0.17 & -0.07 & 0.025 & $0.067^{*}$ \\
\hline Savings (000s 2008 UGX) & 18.18 & 32.85 & 0.000 & $0.001^{* * *}$ \\
\hline Monthly gross earnings (000s 2008 UGX) & 59.59 & 67.54 & 0.000 & 0.218 \\
\hline Could obtain 100,000 UGX (58 USD) loan & 0.31 & 0.40 & 0.092 & $0.000^{* * *}$ \\
\hline Could obtain 1,000,000 UGX (580 USD) loan & 0.09 & 0.12 & 0.063 & 0.103 \\
\hline Weekly work hours: low skill & 0.97 & 1.07 & 0.001 & 0.670 \\
\hline Weekly work hours: other business & 2.11 & 2.40 & 0.002 & 0.338 \\
\hline Weekly work hours: skilled trade & 1.68 & 1.54 & -0.001 & 0.715 \\
\hline Weekly work hours: high skilled trade & 0.04 & 0.14 & 0.035 & $0.001 * * *$ \\
\hline Weekly work hours: other non-agricultural & 0.85 & 0.56 & -0.004 & $0.073^{*}$ \\
\hline Weekly work hours: agricultural & 4.40 & 5.63 & 0.003 & $0.021 * *$ \\
\hline Weekly hourshold chores, hours & 8.46 & 8.65 & 0.000 & 0.827 \\
\hline No employment hours in past month & 0.45 & 0.42 & -0.034 & 0.235 \\
\hline Main occupation is non-agricultural & 0.24 & 0.28 & 0.047 & 0.107 \\
\hline Engaged in a Skilled Trade & 0.07 & 0.08 & 0.034 & 0.438 \\
\hline Crrently in School & 0.04 & 0.04 & -0.024 & 0.646 \\
\hline Grant amount applied for (USD) & $7,497.25$ & $7,274.89$ & -0.000 & 0.220 \\
\hline Group Size & 22.52 & 21.24 & -0.007 & $0.034^{* *}$ \\
\hline Grant Amount per Member, USD & 363.39 & 381.71 & 0.000 & 0.204 \\
\hline Group existed before application & 0.43 & 0.49 & 0.065 & 0.137 \\
\hline Group age, in years & 3.76 & 3.82 & 0.004 & 0.722 \\
\hline Within-group heterogeneity (z-score) & -0.03 & 0.02 & 0.014 & 0.515 \\
\hline Quality of in-group dynamic (z-score) & -0.01 & 0.02 & 0.006 & 0.780 \\
\hline Management comittee member & 0.26 & 0.29 & 0.028 & 0.163 \\
\hline Chairperson or vice-chairperson & 0.10 & 0.12 & 0.046 & $0.067^{*}$ \\
\hline Distance to educational facilities $(\mathrm{km})$ & 6.75 & 7.27 & 0.004 & 0.354 \\
\hline Lives in Adjumani & 0.03 & 0.04 & 0.087 & 0.463 \\
\hline Lives in Apac & 0.25 & 0.18 & -0.108 & $0.038^{* *}$ \\
\hline Lives in Arua & 0.07 & 0.11 & 0.105 & 0.169 \\
\hline Lives in Kaberamaido & 0.02 & 0.03 & 0.108 & 0.417 \\
\hline Lives in Kotido & 0.05 & 0.07 & 0.072 & 0.435 \\
\hline Lives in Kumi & 0.07 & 0.10 & 0.104 & 0.183 \\
\hline Lives in Lira & 0.19 & 0.08 & -0.230 & $0.000 * * *$ \\
\hline Lives in Moroto & 0.05 & 0.05 & -0.035 & 0.729 \\
\hline Lives in Moyo & 0.05 & 0.03 & -0.137 & 0.201 \\
\hline Lives in Nakapiripirit & 0.03 & 0.04 & 0.087 & 0.463 \\
\hline Lives in Nebbi & 0.03 & 0.04 & 0.120 & 0.319 \\
\hline Lives in Pallisa & 0.07 & 0.11 & 0.120 & 0.110 \\
\hline Lives in Soroti & 0.04 & 0.06 & 0.103 & 0.299 \\
\hline
\end{tabular}

Notes: Each row represents a regression of the covariate on the indicator for assignment to treatment. Regression estimates include district fixed effects and group-level clustering of standard errors. ${ }^{*}$ implies $p<.1^{* *}$ implies $p<.05^{* * *}$ implies $p<.01$ 


\subsection{Participants}

From Table 2, members of the 535 eligible groups were generally young, rural, poor, credit constrained, and underemployed. In 2008 they were 25 years on average, mainly aged 16 to 35. Less than a quarter lived in a town, and most lived in villages of 100-2000 households. A quarter did not finish primary school, but on average they reached 8th grade.

In 2008 the sample reported 11 hours of work a week. Half these hours were low-skill labor or petty business, while the other half was in agriculture - rudimentary subsistence and cash cropping on small rain-fed plots with little equipment or inputs. Almost half of our sample reported no employment in the past month, and only $6 \%$ are engaged in a skilled trade. Cash earnings in the past month averaged a dollar a day. Savings were $\$ 15$ on average. Only 11\% reported savings. 33\% held loans, but these were small: under $\$ 7$ at the median among those who have any loans, mainly from friends and family. About $10 \%$ reported they could obtain a large loan of 1,000,000 UGX (about \$580).

Although poor by any measure, these applicants were slightly wealthier and more educated than their peers. If we compare our sample to their age group and gender a 2008 population-based household survey, our sample has 1.7 years more education, 0.15 SD more wealth, is $7.5 \mathrm{pp}$. more urban and $5.4 \mathrm{pp}$. more likely to be married, and has 1.6 fewer household members (Blattman et al. 2014).

Note that for the most part this not a post-conflict population. The three most waraffected districts did not participate in the YOP evaluation, and only $3 \%$ of the sample were involved in an armed group in any fashion.

Based on qualitative interviews, people applied to the program not because they thought it would turn into their main occupation, but rather to have a side profession that would raise cash to meet their household's direct needs. Agriculture - mainly subsistence but some cash cropping - was expected to remain the main activity. Initiative and affinity for skilled work was clearly important, but people were keen to apply even if they were poorly qualified for or had limited interest in a vocation. Most had no other government program to apply to. As a result, the sample has wide variation in wealth, education and experience, not terribly dissimilar from the general population.

\subsection{Treatment effect estimation}

Prior to collecting the 9-year data, we specified a primary interest in impacts on an index of income measures. ${ }^{14}$ We also specified a secondary interest in the recipient's health (physical and mental), in child health and education outcomes, and political attitudes and behaviors.

\footnotetext{
${ }^{14}$ See https://www.socialscienceregistry.org/trials/2187
} 
In addition, we also prespecified one heterogeneity analysis: gender.

We follow the prior empirical strategy and estimate program impacts by calculating intent-to-treat (ITT) estimates via the weighted least squares (WLS) regression:

$$
Y_{i j}=\beta_{I T T} T_{i j}+\gamma X_{i}+\alpha_{d}+\epsilon_{i j}
$$

where $Y$ denotes the outcome for person $i$ in group $j ; T$ is an indicator for assignment to treatment; $X$ is the set of baseline covariates; $\alpha$ are district fixed effects (required because the probability of assignment to treatment varies by strata); and $\epsilon$ is an individual error term, clustered by group. We weight observations by their inverse probability of selection into endline tracking and to correct for attrition.

Several outcomes have a long upper tail, and some of these large values are potentially due to enumeration errors. Extreme values will be highly influential in any treatment effect, and so we top-code all currency-denominated, hours worked, and employee variables at the 99th percentile.

Finally, since outcomes are self-reported, we will overestimate the impact if the treatment group over-reports well being due to social desirability bias, or if the controls under-report outcomes in the hope it will increase their chance of future help. This is unlikely for two reasons. First, misreporting would have to be highly systematic: income and employment was collected through more than 100 questions across 25 activities, and assets and expenditures were calculated from more than 150 questions. Second, we would also expect to see such bias appear in other outcomes, but (as we will see below) we observe no treatment effects across many measures. Misreporting would have to be confined to economic outcomes alone to bias our results.

\subsection{Dealing with multiple outcomes}

Prior to the 9-year follow up, we pre-specified income as the primary outcome of interest, combining multiple measures (earnings, consumption and assets) into one family index to reduce the number of comparisons. Secondary outcomes included children's health/education and political behavior, where again we combine multiple measures into a single family index to reduce comparisons. We registered investment, employment, and other economic outcomes principally as supporting outcomes to understand impacts on income. Because of this structure, we do not adjust standard errors for multiple comparisons. 
Table 3: Program impacts on other aid programs received since baseline

\begin{tabular}{|c|c|c|c|c|c|c|c|}
\hline \multirow{4}{*}{$\begin{array}{l}\text { Dependent Variable } \\
\mathrm{N}=1868 \text { at } 4 \text {-year endline } \\
\mathrm{N}=1981 \text { at } 9 \text {-year endline }\end{array}$} & & & \multicolumn{5}{|c|}{ Treatment effects } \\
\hline & \multirow{2}{*}{\multicolumn{2}{|c|}{ Control mean }} & 4-year & \multicolumn{4}{|c|}{ 9-year } \\
\hline & & & \multirow[b]{2}{*}{$\begin{array}{l}\text { Pooled } \\
(3)\end{array}$} & \multirow[b]{2}{*}{$\begin{array}{l}\text { Pooled } \\
\text { (4) }\end{array}$} & \multicolumn{3}{|c|}{ By gender } \\
\hline & $\begin{array}{c}\text { 4-year } \\
(1)\end{array}$ & $\begin{array}{c}9 \text {-year } \\
(2)\end{array}$ & & & $\begin{array}{c}\text { Women } \\
(5)\end{array}$ & $\begin{array}{c}\text { Men } \\
(6)\end{array}$ & $\begin{array}{c}\text { Difference } \\
(7)\end{array}$ \\
\hline Treated & 0.00 & 0.00 & 0.879 & 0.881 & 0.870 & 0.887 & 0.017 \\
\hline & & & {$[0.020]^{* * *}$} & {$[0.019]^{* * *}$} & {$[0.028]^{* * *}$} & {$[0.021]^{* * *}$} & {$[0.027]$} \\
\hline Received a non-YOP transfer in the past 12 months & 0.02 & & $\begin{array}{c}0.026 \\
{[0.009]^{* * *}}\end{array}$ & & & & \\
\hline Reported a non-minor program since 2006 & & 0.17 & & $\begin{array}{l}-0.029 \\
{[0.018]}\end{array}$ & $\begin{array}{l}-0.028 \\
{[0.032]}\end{array}$ & $\begin{array}{l}-0.029 \\
{[0.022]}\end{array}$ & $\begin{array}{l}-0.001 \\
{[0.038]}\end{array}$ \\
\hline Including all minor programs & & 0.27 & & $\begin{array}{c}0.001 \\
{[0.023]}\end{array}$ & $\begin{array}{l}-0.012 \\
{[0.037]}\end{array}$ & $\begin{array}{c}0.008 \\
{[0.028]}\end{array}$ & $\begin{array}{c}0.020 \\
{[0.044]}\end{array}$ \\
\hline Inlcuding agricultural extension in 'non-minor' & & 0.16 & & $\begin{array}{c}0.045 \\
{[0.018]^{* *}}\end{array}$ & $\begin{array}{c}0.005 \\
{[0.031]}\end{array}$ & $\begin{array}{c}0.066 \\
{[0.023]^{* * *}}\end{array}$ & $\begin{array}{c}0.060 \\
{[0.039]}\end{array}$ \\
\hline Including YOP-like programs reported by treatment group & & 0.17 & & $\begin{array}{c}0.025 \\
{[0.019]}\end{array}$ & $\begin{array}{l}0.045 \\
{[0.034]}\end{array}$ & $\begin{array}{c}0.015 \\
{[0.023]}\end{array}$ & $\begin{array}{l}-0.030 \\
{[0.040]}\end{array}$ \\
\hline Received any NUSAF, YOP, or YOP-like grant since 2006 & & 0.17 & & $\begin{array}{c}0.725 \\
{[0.022]^{* * *}}\end{array}$ & $\begin{array}{c}0.723 \\
{[0.035]^{* * *}}\end{array}$ & $\begin{array}{c}0.725 \\
{[0.024]^{* * *}}\end{array}$ & $\begin{array}{c}0.002 \\
{[0.037]}\end{array}$ \\
\hline
\end{tabular}

Notes: Each entry in columns 3 and 4 is estimated from a weighted least squares regression of the dependent variable on an indicator for assignment to treatment, district fixed effects, and a vector of baseline covariates. Standard errors are clustered at the group level (of up to 5 people). We report the coefficient on treatment only. All regressions are weighted by inverse probabilities of attrition and selection into the endline tracking sample. Columns 5 through 7 come from a single regression, where we regress treatment on an indicator for treatment, an indicator interacted with gender, and the gender indicator plus the usual controls. We use these coefficients to calculate the treatment effect on each gender separately. ${ }^{*}$ implies $p<.1,{ }^{* *}$ implies $p<.05$, *** implies $p<.01$

\section{Results}

\subsection{Program delivery}

Table 4 reports programs received since baseline, including YOP. First we consider simple receipt of the YOP grant. As discussed in Blattman et al. (2014), of the 265 groups assigned to a cash grant in 2008, 89\% received it. 21 of these 29 groups not access funds due to unsatisfactory proposals, bank complications, or collection delays. The remaining 8 groups reported they never received funds due to some form of theft or diversion. ${ }^{15}$

We would expect treatment-control convergence if control group members were more likely to receive another government or charitable program in the 9 years after YOP. Broadly speaking, we do not find any evidence that the control group received a greater number of transfers since baseline. In the 4-year survey, we asked about non-YOP programs received in the 12 months before the survey. In the 9-year survey we ask respondents to report all "major programs" they received from the government or an NGO since baseline. ${ }^{16}$

\footnotetext{
${ }^{15} \mathrm{~A}$ comparison of baseline characteristics shows that treated and untreated groups are generally similar. In a regression of receiving the grant on baseline individual and group characteristics, a joint test of significance has a p-value of 0.2. Nonetheless, some characteristics are correlated with receiving the grant. Groups were slightly more likely to be treated if they were educated and wealthier and did not have too many members. Blattman et al. (2014) expands on this analysis.

${ }^{16}$ Specifically we asked respondents to recall all major government or NGO programs they had received
} 
Our estimates vary somewhat depending on what types of programs we include or exclude, and so we report several alternative measures. Our preferred measure omits very minor programs (such as mosquito nets, vaccinations, packets of seeds, and unspecified agricultural extension) as well as any programs reported by the treatment group that sound like YOP (such as tailoring training, repair training, and business grants whose source was unspecified). In the decade before the survey, about $17 \%$ of the control group reports at least one nonminor program. Some of these are substantial (such as a goat or a training course) but most appear to be modest in nature. In the 4-year survey, for example, we calculated that the average program received by the control group was worth less than $\$ 20$, which is less than $5 \%$ of the value of the YOP grant. After 9 years, the treatment group is 2.9 percentage points less likely to report such assistance (not statistically significant).

If we change our preferred measure to include unspecified agricultural extension as "nonminor", include any YOP-like programs reported by the treatment group, or include all minor programs, the program effect shrinks or reverses. As a result, we do not regard differential treatment with other programs to be a major driver of convergence over the 9 years.

\subsection{Economic impacts}

\section{Investment}

The survey data and qualitative interviews suggest that groups commonly elected management committee members to handle procurement, making major training and tool purchases in bulk. These tools were distributed to individual members, but about half the respondents said they shared some small or large tools with other group members. In the 2-year survey, $90 \%$ of treated group members said they felt the grant was equally shared.

The majority of groups and members invested the funds in vocational training and capital, with an emphasis on capital investments. By the two-year follow-up, $53 \%$ of the treatment group had enrolled in vocational training, compared to $15 \%$ of the control group. Table 4 reports program impacts on human and physical capital investments. On average, treatment translated into 340 more hours of vocational training than controls. Among those who enrolled in any training, 38\% train in tailoring, $23 \%$ in carpentry, $13 \%$ in metalwork, $8 \%$ in hairstyling, and the remainder in miscellaneous other trades.

However, the majority of YOP funds were invested in business capital. At the median, groups estimated they spent $11 \%$ on skills training, $52 \%$ on tools, $13 \%$ on materials, and $24 \%$

since the first multiparty elections in 2006. We used this election as a starting point because it is one of the most significant and memorable events that decade, and we believed it was the best way to have a consistent recall period across respondents. 
Table 4: Program impacts on skills and capital investments after 2- and 4-years

\begin{tabular}{|c|c|c|c|c|c|}
\hline \multirow{2}{*}{$\begin{array}{l}\text { Dependent Variable } \\
N=2005 \text { in } 2 \text {-year } \\
N=1868 \text { in } 4 \text {-year }\end{array}$} & \multicolumn{2}{|c|}{ Control mean } & \multicolumn{2}{|c|}{ Treatment effects } & \multirow[b]{2}{*}{$\begin{array}{c}\text { Difference } \\
(5)\end{array}$} \\
\hline & $\begin{array}{c}\text { 2-year } \\
(1)\end{array}$ & $\begin{array}{c}\text { 4-year } \\
(2)\end{array}$ & $\begin{array}{c}\text { 2-year } \\
(3)\end{array}$ & $\begin{array}{l}\text { 4-year } \\
(4)\end{array}$ & \\
\hline Enrolled in vocational training since baseline & 0.15 & & $\begin{array}{c}0.532 \\
{[0.023]^{* * *}}\end{array}$ & & \\
\hline Returned to school since baseline & 0.10 & & $\begin{array}{c}0.026 \\
{[0.015]^{*}}\end{array}$ & & \\
\hline Hours of training received & 48.98 & & $\begin{array}{c}340.424 \\
{[22.478]^{* * *}}\end{array}$ & & \\
\hline Business assets (000s 2008 UGX) & 290.24 & 392.79 & $\begin{array}{c}377.685 \\
{[78.273]^{* * *}}\end{array}$ & $\begin{array}{c}223.186 \\
{[62.679]^{* * *}}\end{array}$ & $-154.500^{*}$ \\
\hline
\end{tabular}

Notes: Each entry in columns 3 and 4 is estimated from a weighted least squares regression of the dependent variable on an indicator for assignment to treatment, district fixed effects, and a vector of baseline covariates. Standard errors are clustered at the group level (of up to 5 people). We report the coefficient on treatment only. All regressions are weighted by inverse probabilities of attrition and selection into the endline tracking sample. ${ }^{*}$ implies $p<.1,{ }^{* *}$ implies $p<.05,{ }^{* * *}$ implies $p<.01$

on other expenses. Looking at capital stocks, after two years the treatment group reported 130\% more business capital than the control group. These are self-reported assessments of the total value of raw materials, tools, and other capital goods for respondents' enterprises.

After 4 years, however, we see evidence that the control group is catching up in terms of business capital stocks. Whereas after two years the treatment group had 2.3 times the capital stocks of the control group, after four years their capital stock level was just 1.5 times greater. This decline in the treatment effect is significant at the $10 \%$ level. (Unfortunately we did not assess capital stocks after 9 years, partly to expand room in the survey for child, health, and education outcomes.)

We see more details on convergence in Table 5, which reports levels of, program impacts on, and changes in reported capital stocks. Between the 2- and 4-year endline surveys the control group grew their business assets by $38 \%$ while the treatment group decreased theirs by $19 \%$. The control group's growth is significant at the $5 \%$ level. The bottom panel of Table 5 looks at reported asset levels and changes in (endogenous) subgroups of the treatment group. Like the control group, people in groups assigned to YOP that did not receive the grant report low levels of assets after 2 years but steep growth over time. We also see evidence of disinvestment, with the people who were funded, took training, but no longer practice report a $72 \%$ fall in assets between the 2 and 4 year surveys. Those still practicing report relatively stable assets, suggesting they are not continuing to invest retained earnings. 
Table 5: Levels of, changes in, and program impacts on business assets, after 2- and 4-years

\begin{tabular}{lccccc}
\hline & \multicolumn{3}{c}{ Business assets (000s of 2008 UGX) } \\
\hline & \multicolumn{3}{c}{ Mean } & \multicolumn{3}{c}{ Change 2010-2012 } \\
\cline { 2 - 6 } & 2010 & 2012 & $\Delta$ & $\% \Delta$ & SD \\
& $(1)$ & $(2)$ & $(3)$ & $(4)$ & $(5)$ \\
\hline Treatment & 725.8 & 607.8 & -135.02 & $-19 \%$ & $(83.3)$ \\
Control & 290.2 & 392.8 & 109.9 & $38 \%$ & $(53.5)^{* *}$ \\
ITT, with controls & 377 & 225 & & & \\
$\quad$ SD & $(78.2)^{* * *}$ & $(62.6)^{* * *}$ & & & \\
\hline Treatment subgroups (\% of total) & & & & & \\
Not funded (11\%) & 172.9 & 568.6 & 375.6 & $217 \%$ & $(121.8)$ \\
Funded, did not train (22\%) & 331.4 & 446.5 & 91.7 & $28 \%$ & $(106.4)$ \\
Funded, trained, not practicing in 2012 (29\%) & 1005.4 & 301.8 & -720.8 & $-72 \%$ & $(165.5)$ \\
Funded, trained, practicing in 2012 (38\%) & 1057.0 & 945.1 & -75.4 & $-7 \%$ & $(153.4)$ \\
\hline
\end{tabular}

Notes: Columns (1) and (2) report treatment and control group means at the 2010 and 2012 endline surveys for the full sample. Below this we report the ITT of program assignment and robust standard errors clustered by group (calculated in the same way as the previous table). Column (3) reports the coefficient on a 2012 indicator in a regression of the dependent variable on the indicator and same controls as the ITT. This coefficient represents the change in the dependent variable over time. Columns (4) and (5) report the precentage change (the coefficient relative to the 2010 endline) and robust standard errors, clustered by group. ${ }^{*}$ implies $p<.1$, ${ }^{* *}$ implies $p<.05,{ }^{* * *}$ implies $p<.01$

\section{Income}

Table 6 reports the analysis for our primary outcome, income. We report a standardized income family index composed of three measures, two of income flows and one stock measure.

1. Monthly net earnings (i.e. business profits plus wages). To measure earnings (and employment levels), survey enumerators went through a list of roughly three dozen common occupations, from farm wage work to skilled trades, asking if the person had worked in that occupation in the past year. Respondents usually answered yes to two to five occupations. For each of these affirmatives, the electronic survey guided the enumerator and respondent through a series of questions about each occupation, including days worked in the past month, average hours per day, and gross and net earnings in the previous month. We used these data to develop estimates of earnings and hours worked in the previous month. We also report a measure of monthly gross earnings (business revenues plus wages).

2. Nondurable consumption. The survey included an abbreviated consumption module, measuring the approximate value of food consumed in the past week, and less frequent expenditures (such as clothing or entertainment) in the past month. Thus the sum 
Table 6: Program impacts on Income and Savings after 4 and 9 years

\begin{tabular}{|c|c|c|c|c|c|c|c|}
\hline \multirow{4}{*}{$\begin{array}{l}\text { Dependent Variable } \\
N=1868 \text { at } 4 \text {-year endline } \\
N=1981 \text { at } 9 \text {-year endline }\end{array}$} & \multirow{3}{*}{\multicolumn{2}{|c|}{ Control mean }} & \multicolumn{5}{|c|}{ Treatment effects } \\
\hline & & & \multirow{3}{*}{$\begin{array}{l}\text { 4-year } \\
\text { Pooled } \\
(3)\end{array}$} & \multicolumn{4}{|c|}{ 9-year } \\
\hline & & & & \multirow[b]{2}{*}{$\begin{array}{c}\text { Pooled } \\
(4)\end{array}$} & \multicolumn{3}{|c|}{ By gender } \\
\hline & $\begin{array}{c}\text { 4-year } \\
(1)\end{array}$ & $\begin{array}{c}9 \text {-year } \\
(2)\end{array}$ & & & $\begin{array}{c}\text { Women } \\
\text { (5) }\end{array}$ & $\begin{array}{c}\text { Men } \\
(6)\end{array}$ & $\begin{array}{c}\text { Difference } \\
(7)\end{array}$ \\
\hline \multirow[t]{2}{*}{ Standardized Income Index } & -0.08 & -0.01 & 0.209 & 0.066 & 0.081 & 0.058 & -0.023 \\
\hline & & & {$[0.050]^{* * *}$} & {$[0.048]$} & {$[0.076]$} & {$[0.059]$} & {$[0.093]$} \\
\hline \multirow{2}{*}{ Monthly net earnings (000s of 2008 UGX) } & 47.85 & 90.97 & 18.163 & 4.172 & 7.064 & 2.664 & -4.400 \\
\hline & & & {$[4.887]^{* * *}$} & {$[8.491]$} & [13.230] & {$[10.022]$} & {$[15.457]$} \\
\hline \multirow{2}{*}{ Nondurable Consumption (000s of 2008 UGX) } & 202.22 & 190.56 & 21.688 & 2.726 & 10.728 & -1.445 & -12.172 \\
\hline & & & {$[7.946]^{* * *}$} & {$[6.298]$} & {$[10.322]$} & {$[7.528]$} & {$[12.283]$} \\
\hline \multirow[t]{2}{*}{ Durable assets } & 0.10 & 0.29 & 0.163 & 0.116 & 0.071 & 0.140 & 0.068 \\
\hline & & & {$[0.050]^{* * *}$} & {$[0.048]^{* *}$} & {$[0.081]$} & {$[0.058]^{* *}$} & {$[0.098]$} \\
\hline
\end{tabular}

Notes: Each entry in columns 3 and 4 is estimated from a weighted least squares regression of the dependent variable on an indicator for assignment to treatment, district fixed effects, and a vector of baseline covariates. Standard errors are clustered at the group level (of up to 5 people). We report the coefficient on treatment only. All regressions are weighted by inverse probabilities of attrition and selection into the endline tracking sample. Columns 5 through 7 come from a single regression, where we regress treatment on an indicator for treatment, an indicator interacted with gender, and the gender indicator plus the usual controls. We use these coefficients to calculate the treatment effect on each gender separately. ${ }^{*}$ implies $p<.1,{ }^{* *}$ implies $p<.05,{ }^{* * *}$ implies $p<.01$

of these consumed items is not a complete measure of consumption. Nonetheless, the items should account for the majority of non-durable consumption and (so long as treatment does not have a major effect on the composition of consumption) the treatment effect on the abbreviated measure should approximate the treatment effect on full consumption.

3. Durable assets. Durable assets are not just a measure of poverty, but their use also provides a flow of consumption over time. Hence we include a measure of durable goods in our prespecified income index. The survey asked people several questions about their housing quality (such as roof material or dwelling size) as well as the quantity of a number of assets, ranging from various livestock, fruit-producing trees, household goods and furnishings, electronics, and tools and equipment. We combine these into a single index using the first principal component of all these asset variables, omitting any assets that might have been directly provided by YOP (such as sewing machines). We use the same weights across all survey rounds (including baseline) and so the mean of the index at endline indicates growth in assets since baseline across the sample.

We deflate all measures by a national measure of inflation.

After 4 years, people assigned to YOP had 0.21 standard deviations higher income. ${ }^{17}$

\footnotetext{
${ }^{17}$ Due to a minor error in the earlier use of baseline data, the estimates in Table 6 are slightly different than in Blattman et al. (2014). In the earlier paper we reported an earnings ATE of 18.19 [4.898] instead of 17.94 [4.904] and an assets ATE of 0.181 [0.055] instead of 0.164 [0.051].
} 
Within the index, this corresponds to a 38.0\% increase in net monthly earnings, a 0.163 standard deviation increase in assets, and a 10.7\% increase in consumption.

After 9 years, however, we no longer observe statistically significant impacts on income. Income is 0.066 standard deviations greater in the treatment group, and this difference is driven mainly through the effect on durable assets, which are 0.116 standard deviations greater. ${ }^{18}$ Estimated program impacts on earnings and consumption are much smaller. ${ }^{19}$ Earnings are just $4.6 \%$ greater in the treatment group, and consumption just $1.4 \%$ greater (neither is statistically significant). Thus any treatment effect on income after 9 years appears to be dominated by historical earnings translated into accumulated durable assets rather than higher income flows. Some of these durable assets could yield income or consumption, such as livestock or trees. These subindices within assets increase 0.14 and 0.19 standard deviations respectively (not shown). But our earnings and consumption measures explicitly collect earning and consumption from these livelihoods, and these outcomes do not significantly differ by treatment group.

Following Blattman et al. (2014), Table 6 also reports impacts on income by gender. In general, women earn roughly half as much as men, and report fewer assets. The results after 4 years suggested that program impacts on women were proportionally greater. Men and women had roughly similar treatment effects. But control women had low enough incomes compared to control men that the program impacts were proportionally much larger. Between the 4- and 9-year surveys, however, control women began to catch up in investment, employment, and earnings. In Table 6 we see almost slightly higher treatment effects on the income for women, but the difference is not statistically significant. Additionally, there is a slight difference in patterns in the components. For men the income gains are concentrated in accumulated assets, significant at the $5 \%$ level. Women display slightly greater impacts on earnings and consumption, though neither estimate is statistically significant. Overall we cannot reject that treatment effects vary little with gender.

\footnotetext{
${ }^{18}$ The asset index does not include savings, since we only have savings and loans information at the 9-year endline, and we want the index to be comparable over time. In the control group, $69 \%$ are a member of a savings group and total savings across all sources is 125,000 UGX on average. The treatment effects (and standard errors) are -0.034 [0.023] for savings group membership and -8,759 [12,338] for savings balances. Neither is statistically significant and in neither case is there a positive treatment effect.

${ }^{19}$ Inflation rose dramatically between the 4- and 9-year surveys. For this reason real consumption levels look fairly flat over this period. These national inflation rates may exaggerate inflation in rural areas, however, though without official data it is difficult to know. But looking at the control means in Table 6, our assets measure rises 0.19 standard deviations between the 4 - and 9-year surveys.
} 


\section{Employment and occupational choice}

Table 7 reports program impacts on employment and time spent in skilled work, 4 and 9 years after the grant. Employment was measured in the same module as earnings, as described above. The results show a large, sustained increase in time spent doing skilled work, but no sustained effects on other outcomes.

After 4 years, we observed a statistically significant increase in total time spent working of 5.5 hours, a $17 \%$ increase. This effect was largely due to increases in non-agricultural work, especially skilled trades (134\% increase) and high-skilled wage labor (51\% increase). Average earnings per hour also increased by about a fifth, significant at the $10 \%$ level, implying the new work was better remunerated or higher productivity.

None of these effects were sustained 9-years after grant disbursement, save for time spent in a skilled trade. The treated sample spend twice as much time in skilled trade as the control group and are twice as likely to be working primarily in skilled trades, which we define as at least 30 hours per week in the past month. But there is no sustained effect on employment hours or earnings per hour.

As can be seen in Table 8, the control group has been increasing their overall hours worked considerably, from just under 11 hours per week at baseline to over 43 hours per week 9 years later. This growth in employment is not due to increases in skilled work or work on farm, both of which have been stagnant over the 9 years, but due to increases in non-agriculture work and petty business. The control group has thus increased time in activities that produce low income, but they have increased their time in these activities considerably.

Finally, Appendix Table B.3 reports impacts on migration, and Appendix Table B.2 examines impacts on the business itself. At baseline nearly all YOP applicants were living in a village or small town, with some in larger regional towns. By the 9 -year endline, most of the village-dwelling sample had moved to a small town or larger urban area. We see no effect of treatment on this likelihood of moving. We also see little lasting effect on business formality, including record-keeping, registration, or tax paying. We see weak indications that treated group members are more likely to have employees. The average control group member has 1.1 paid part-time employees. This is 0.26 people higher in the treatment group, significant at the $10 \%$ level only. It is mainly non-family employees, and the effects are concentrated among men. We observe a significant rise in the estimated number of hours that all employees work (a rise of 21 hours per month from the control mean of 987 hours, significant at the 1\% level). Puzzlingly we do not see a rise in total estimated payroll, however. Thus we regard this as relatively weak evidence of a positive employment externality. It seems that more non-family labor is used (about 5 hours a week) but it may be low paid or lower skill and so 
Figure 4: Estimated net present value of intervention using interpolated monthly net earnings

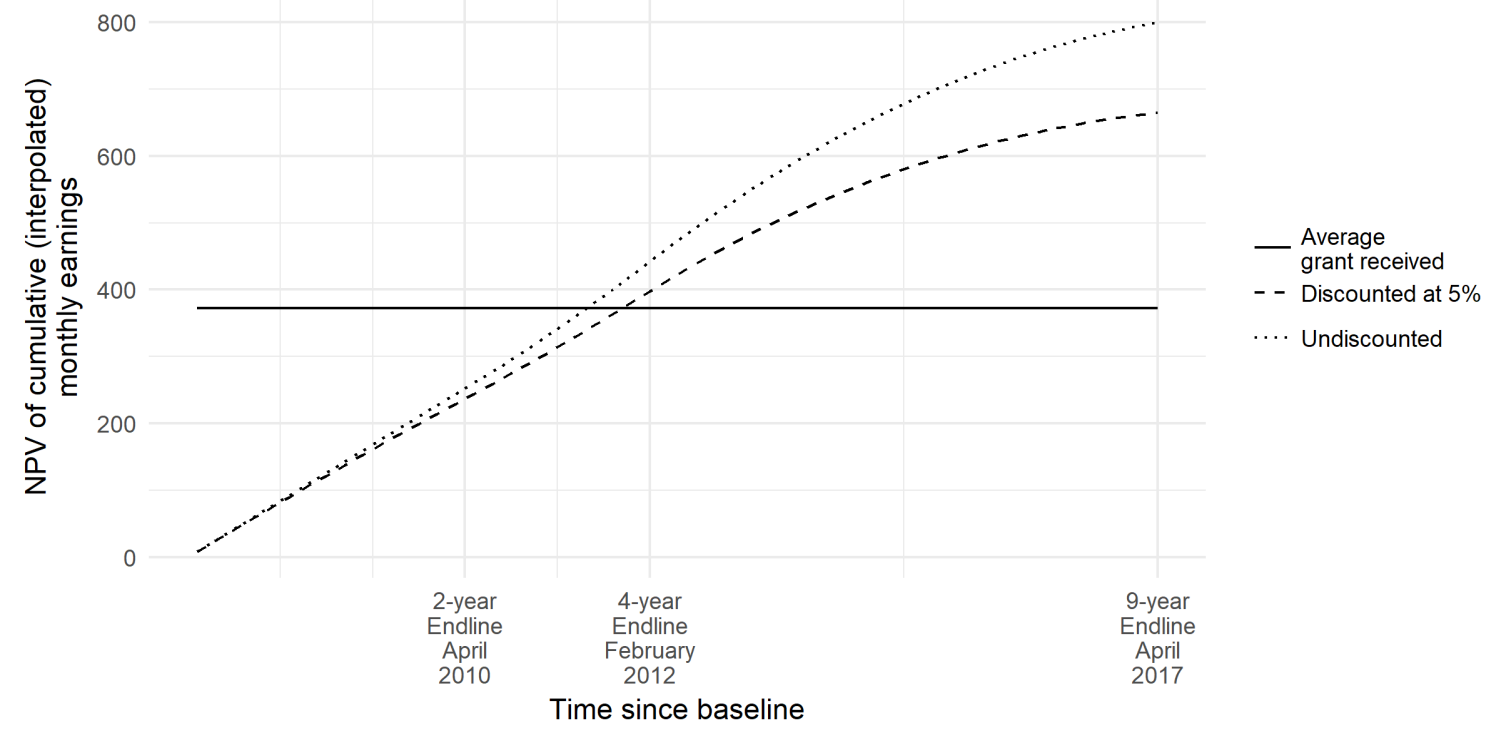

payroll is unaffected.

\section{Cumulative impact}

We estimate that this temporary earnings gain is roughly $\$ 665$ or 1.8 times the size of the grant (using 2008 USD and market exchange rates). We base this estimate on a linear interpolation of earnings treatment effects between the four survey rounds $(0,2,4$ and 9 years), discounted to the baseline year at an annualized interest rate of $5 \% .{ }^{20}$ Figure 4 illustrates this cumulative effect on earnings. While imprecise, it nonetheless implies that the program was cost-effective in the sense of cumulative earnings gains for the directly treated exceeding the average grant size.

This should not be taken as a measure of social impact for at least two reasons, however. First, the government has little to no data on NUSAF implementation costs. Judging by other aid programs, it would not be unusual for these costs to exceed the value of the grant. Second, there may have been local spillovers, and parishes are too large relative to the YOP grants to measure spillovers with any precision. Some of these employment and earnings gains could have come from displacing the work of existing craftspersons. Alternatively, the demand shock could have stimulated local economies. Thus we do not have a full measure of social impacts.

\footnotetext{
${ }^{20}$ Profits were only measured a the 4 -year endline. We model an immediate treatment effect of 18,000 UGX beginning at baseline and spanning 4 years, after which the treatment effect decreases linearly towards our 9-year estimate of 4,800 UGX.
} 
Table 7: Program impacts on employment after 4 and 9 years

\begin{tabular}{|c|c|c|c|c|c|c|c|}
\hline \multirow{4}{*}{$\begin{array}{l}\text { Dependent Variable } \\
\mathrm{N}=1868 \text { at } 4 \text {-year endline } \\
\mathrm{N}=1981 \text { at } 9 \text {-year endline }\end{array}$} & \multirow{3}{*}{\multicolumn{2}{|c|}{ Control mean }} & \multicolumn{5}{|c|}{ Treatment effects } \\
\hline & & & \multirow{3}{*}{$\begin{array}{l}\text { 4-year } \\
\text { Pooled } \\
(3)\end{array}$} & \multicolumn{4}{|c|}{ 9-year } \\
\hline & & & & \multirow[b]{2}{*}{$\begin{array}{c}\text { Pooled } \\
(4)\end{array}$} & \multicolumn{3}{|c|}{ By gender } \\
\hline & $\begin{array}{c}\text { 4-year } \\
(1)\end{array}$ & $\begin{array}{c}9 \text {-year } \\
(2)\end{array}$ & & & $\begin{array}{c}\text { Women } \\
(5)\end{array}$ & $\begin{array}{l}\text { Men } \\
(6)\end{array}$ & $\begin{array}{c}\text { Difference } \\
(7)\end{array}$ \\
\hline \multirow[t]{2}{*}{ Average employment hrs/wk } & 32.24 & 44.68 & 5.519 & 0.513 & 1.897 & -0.208 & -2.105 \\
\hline & & & {$[1.286]^{* * *}$} & {$[1.593]$} & {$[3.079]$} & {$[1.705]$} & {$[3.410]$} \\
\hline \multirow[t]{2}{*}{ Agricultural hrs/wk } & 18.77 & 17.34 & 0.422 & 0.079 & 1.354 & -0.585 & -1.940 \\
\hline & & & {$[0.945]$} & {$[0.856]$} & {$[1.342]$} & {$[1.095]$} & {$[1.728]$} \\
\hline \multirow[t]{2}{*}{ Non-agricultural hrs/wk } & 13.48 & 27.35 & 5.097 & 0.434 & 0.542 & 0.377 & -0.165 \\
\hline & & & {$[0.999]^{* * *}$} & {$[1.488]$} & {$[2.756]$} & {$[1.547]$} & {$[2.949]$} \\
\hline \multirow[t]{2}{*}{ Casual labor, low skill hrs/wk } & 2.27 & 10.93 & -0.117 & -1.206 & -1.015 & -1.306 & -0.292 \\
\hline & & & {$[0.401]$} & {$[0.990]$} & {$[1.750]$} & {$[1.095]$} & {$[1.952]$} \\
\hline \multirow[t]{2}{*}{ Petty business, low skill hrs/wk } & 3.54 & 7.59 & 0.138 & -1.589 & -3.154 & -0.773 & 2.381 \\
\hline & & & {$[0.593]$} & {$[1.069]$} & {$[1.947]$} & {$[1.077]$} & {$[2.028]$} \\
\hline \multirow[t]{2}{*}{ Skilled Trades hrs/wk } & 2.82 & 2.83 & 3.779 & 2.796 & 3.590 & 2.383 & -1.207 \\
\hline & & & {$[0.548]^{* * *}$} & {$[0.529]^{* * *}$} & {$[0.886]^{* * *}$} & {$[0.606]^{* * *}$} & {$[1.013]$} \\
\hline \multirow[t]{2}{*}{ High-skill wage labor hrs/wk } & 1.84 & 2.93 & 0.898 & 0.906 & 0.893 & 0.913 & 0.020 \\
\hline & & & {$[0.444]^{* *}$} & {$[0.582]$} & {$[0.921]$} & {$[0.712]$} & {$[1.125]$} \\
\hline \multirow[t]{2}{*}{ No employment hours in past month } & 0.05 & 0.03 & -0.022 & -0.004 & -0.009 & -0.002 & 0.006 \\
\hline & & & {$[0.009]^{* * *}$} & {$[0.008]$} & {$[0.013]$} & {$[0.010]$} & {$[0.017]$} \\
\hline \multirow[t]{2}{*}{ Main occupation is non-agricultural } & 0.19 & 0.56 & 0.011 & 0.029 & -0.016 & 0.053 & 0.069 \\
\hline & & & {$[0.010]$} & {$[0.023]$} & {$[0.039]$} & {$[0.028]^{*}$} & {$[0.047]$} \\
\hline \multirow[t]{2}{*}{ Engaged in any skilled trade } & 0.22 & 0.18 & 0.260 & 0.197 & 0.260 & 0.164 & -0.096 \\
\hline & & & {$[0.026]^{* * *}$} & {$[0.023]^{* * *}$} & {$[0.041]^{* * *}$} & {$[0.026]^{* * *}$} & {$[0.046]^{* *}$} \\
\hline \multirow[t]{2}{*}{ Works over $30 \mathrm{hrs} / \mathrm{wk}$ in skilled trade } & 0.03 & 0.03 & 0.037 & 0.029 & 0.042 & 0.023 & -0.020 \\
\hline & & & {$[0.013]^{* * *}$} & {$[0.011]^{* * *}$} & {$[0.018]^{* *}$} & {$[0.013]^{*}$} & {$[0.021]$} \\
\hline \multirow[t]{2}{*}{ Average hours of chores per week } & 9.98 & 0.48 & 0.106 & -0.117 & -0.533 & 0.100 & 0.633 \\
\hline & & & {$[0.715]$} & {$[0.164]$} & {$[0.314]^{*}$} & {$[0.203]$} & {$[0.387]$} \\
\hline \multirow[t]{2}{*}{ Average earnings/hr (000s of 2008 UGX) } & 0.39 & 0.63 & 0.071 & 0.009 & -0.032 & 0.031 & 0.063 \\
\hline & & & {$[0.037]^{*}$} & {$[0.062]$} & {$[0.092]$} & {$[0.081]$} & {$[0.122]$} \\
\hline
\end{tabular}

Notes: Each entry in columns 3 and 4 is estimated from a weighted least squares regression of the dependent variable on an indicator for assignment to treatment, district fixed effects, and a vector of baseline covariates. Standard errors are clustered at the group level (of up to 5 people). We report the coefficient on treatment only. All regressions are weighted by inverse probabilities of attrition and selection into the endline tracking sample. Columns 5 through 7 come from a single regression, where we regress treatment on an indicator for treatment, an indicator interacted with gender, and the gender indicator plus the usual controls. We use these coefficients to calculate the treatment effect on each gender separately. ${ }^{*}$ implies $p<.1,{ }^{* *}$ implies $p<.05,{ }^{* * *}$ implies $p<.01$ 
Table 8: Work opportunities without outside assitance: Progression of control group

\begin{tabular}{lcccc}
\hline \multirow{2}{*}{ Variable } & \multicolumn{4}{c}{ Control group mean (Hours) } \\
\cline { 2 - 5 } & $\begin{array}{c}\text { Baseline } \\
(1)\end{array}$ & $\begin{array}{c}2 \text {-year } \\
(2)\end{array}$ & $\begin{array}{c}\text { 4-year } \\
\text { 9-year }\end{array}$ & $(4)$ \\
\hline Average employment hr/wk & 10.7 & 24.9 & 32.2 & 44.7 \\
$\quad$ Agricultural hr/wk & 4.4 & 13.9 & 18.8 & 17.3 \\
Non-agricultural hr/wk & 5.7 & 11.0 & 13.5 & 27.3 \\
$\quad$ Casual labor, low skill hr/wk & 1.0 & 1.5 & 2.3 & 10.9 \\
$\quad$ Petty business, low skill hr/wk & 1.3 & 3.5 & 3.5 & 7.6 \\
$\quad$ Skilled Trades hr/wk & 1.7 & 2.9 & 2.8 & 2.8 \\
$\quad$ High-skill wage labor hr/wk & 0.0 & 1.2 & 1.8 & 2.9 \\
No employment hours in past month & 0.5 & 0.1 & 0.0 & 0.0 \\
Main occupation is non-agricultural & 0.2 & 0.2 & 0.2 & 0.6 \\
Engaged in any skilled trade & 0.1 & 0.2 & 0.2 & 0.2 \\
\hline
\end{tabular}

Notes: The table reports means in the control group, weighted by inverse probabilities of selection into attrition and endline tracking.

\section{Robustness and sensitivity analysis}

These conclusions are fairly robust to different estimation models and measurement decisions, including how we deal with survey attrition. Nearly all statistically significant results are driven by the persistent difference in durable assets alone. Table 9 reports the simple ITT effects from the prior tables in Column 1, and variations in subsequent columns.

If we omit the control vector, in Column 2, the program impact on income rises to 0.11 standard deviations and is significant at the $5 \%$ level. This due to the treatment-control imbalance on assets and earnings at baseline (recall Table 2 above). This change is mainly due to a rise in the treatment effect on durable assets, which were 0.06 standard deviations greater in the treatment group at baseline. We continue to see no evidence of a statistically significant rise in our flow measures of income.

Columns 3 and 4 estimate the difference-in-difference treatment effect, with Column 3 controlling for other baseline covariates and Column 4 omitting them (but both include district fixed effects). Column 4 is a form of unadjusted treatment effect that accounts for the baseline imbalance in the key outcome. We cannot calculate this for the consumption (and hence income) index because we do not have consumption data at baseline. Since earnings and durable assets were slightly higher in the treatment group at baseline, the differenced program effects are similar to Column 1 but considerably smaller than the unadjusted estimates in Column 2. We also get qualitatively similar results with a treatment on the treated 
estimate that uses assignment to treatment as an instrument for the $89 \%$ of groups that received the grant (not shown).

Our results also illustrate the importance of accounting for survey attrition. Column 4 includes control variables but no longer re-weights the sample according to probabilities of attrition. As discussed in Section 5.2, we saw some signs that attrition was higher among those with higher entrepreneurial potential. Thus, when we omit these attrition weights, our estimated treatment effects in Column 4 rise slightly to 0.080 standard deviations, though the effect remains non-statistically significant.

Indeed, these results and Column 5 illustrate the importance of our efforts to minimize attrition. Column 5 removes the sampling weights that come from our randomized tracking of migrants (described in section 5.2). These increased the weight of the migrants and other unfound people whom we tracked intensively after the initial failed attempts. Omitting them is not a "robustness check" because it explicitly biased. Rather, column 5 illustrates the bias that would arise had we not taken our approach. Our income treatment effect estimates are significantly higher, especially earnings, and the index of all three measures increases 0.11 standard deviations with treatment, significant at the $1 \%$ level. This suggests that treated migrants are more likely to be economically successful than control migrants, as expected.

Of course, we do not know for certain that unfound treatment group members are more successful than unfound control group members. Thus, as a final exercise, we model treatment effects under different assumptions about the unfound. A Manski extreme bound would impute the minimum value for unfound treated members and the maximum for unfound controls (and vice versa for the other bound). Following this method, we could in principle observe a maximal treatment effect on income of .74 standard deviations, and a minimal one of -0.667 (not shown). These are so wide and unrealistic to be unhelpful. Instead, Table 9 reports less extreme bounds. In column 6 we estimate a new ITT where we impute a high outcome for unfound controls, equal to the found mean plus 0.25 standard deviations, while for the treatment group we impute a low outcome, the found treatment mean minus 0.25 standard deviations. In column 7 we do the opposite. (In each case, this a 0.5 standard deviation gap between unfound treatment and control group members, which is quite large and would represent for more selective attrition than we observed in section 5.2 or Appendix Table B.1.) In this semi-extreme set of scenarios, our income treatment effects range from 0.009 standard deviations on the low end (obviously not statistically significant) to 0.112 standard deviations on the higher end (statistically significant at the $5 \%$ level). Importantly, note that we do not see a statistically significant rise in earnings or consumption. 
Table 9: Sensitivity analysis of 9-year program impacts to alternate models and missing data scenarios

\begin{tabular}{|c|c|c|c|c|c|c|c|c|}
\hline & \multirow{2}{*}{$\begin{array}{c}\text { Main } \\
\text { specification } \\
\text { (1) }\end{array}$} & \multirow{2}{*}{$\begin{array}{l}\text { Omit baseline } \\
\text { covariates } \\
(2)\end{array}$} & \multirow{2}{*}{$\begin{array}{c}\text { Difference in } \\
\text { Differences } \\
(3)\end{array}$} & \multirow{2}{*}{$\begin{array}{c}\mathrm{DiD}, \text { omit } \\
\text { baseline covariates } \\
(4)\end{array}$} & \multirow{2}{*}{$\begin{array}{l}\text { Omit selective } \\
\text { attrition weights } \\
\text { (5) }\end{array}$} & \multirow{2}{*}{$\begin{array}{l}\text { Ommit attrition \& } \\
\text { sampling weights } \\
\text { (6) }\end{array}$} & \multicolumn{2}{|c|}{$+/-.25 \mathrm{SD}$} \\
\hline & & & & & & & $\begin{array}{c}\text { control outperforms } \\
(7)\end{array}$ & $\begin{array}{c}\text { treated outperforms } \\
(8)\end{array}$ \\
\hline Standardized Income Index & $\begin{array}{c}0.066 \\
(0.048)\end{array}$ & $\begin{array}{c}0.111 \\
(0.053)^{* *}\end{array}$ & & & $\begin{array}{c}0.080 \\
(0.049)\end{array}$ & $\begin{array}{c}0.122 \\
(0.042)^{* * *}\end{array}$ & $\begin{array}{c}0.009 \\
(0.043)\end{array}$ & $\begin{array}{c}0.112 \\
(0.047)^{* *}\end{array}$ \\
\hline Monthly net earnings (000s of $2008 \mathrm{UGX}$ ) & $\begin{array}{l}4.172 \\
(8.491)\end{array}$ & $\begin{array}{l}7.712 \\
(8.843)\end{array}$ & $\begin{array}{l}4.318 \\
(8.501)\end{array}$ & $\begin{array}{l}5.698 \\
(9.848)\end{array}$ & $\begin{array}{c}4.764 \\
(8.325)\end{array}$ & $\begin{array}{l}14.212 \\
(7.128)^{* *}\end{array}$ & $\begin{array}{l}-5.344 \\
(7.326)\end{array}$ & $\begin{array}{c}9.478 \\
(7.983)\end{array}$ \\
\hline Nondurable Consumption (000s of 2008 UGX) & $\begin{array}{c}2.726 \\
(6.298)\end{array}$ & $\begin{array}{l}8.015 \\
(6.645)\end{array}$ & & & $\begin{array}{l}4.685 \\
(6.465)\end{array}$ & $\begin{array}{l}8.274 \\
(5.731)\end{array}$ & $\begin{array}{l}-3.851 \\
(5.726)\end{array}$ & $\begin{array}{c}9.848 \\
(6.144)\end{array}$ \\
\hline Durable assets & $\begin{array}{c}0.116 \\
(0.048)^{* *}\end{array}$ & $\begin{array}{c}0.164 \\
(0.054)^{* * *}\end{array}$ & $\begin{array}{c}0.108 \\
(0.048)^{* *}\end{array}$ & $\begin{array}{c}0.090 \\
(0.062)\end{array}$ & $\begin{array}{c}0.132 \\
(0.047)^{* * *}\end{array}$ & $\begin{array}{c}0.146 \\
(0.043)^{* * *}\end{array}$ & $\begin{array}{c}0.051 \\
(0.043)\end{array}$ & $\begin{array}{c}0.162 \\
(0.045)^{* * *}\end{array}$ \\
\hline Average employment hrs/wk & $\begin{array}{c}0.513 \\
(1.593)\end{array}$ & $\begin{array}{c}0.879 \\
(1.645)\end{array}$ & $\begin{array}{c}0.489 \\
(1.595)\end{array}$ & $\begin{array}{l}-0.433 \\
(1.875)\end{array}$ & $\begin{array}{c}0.962 \\
(1.526)\end{array}$ & $\begin{array}{c}2.302 \\
(1.332)^{*}\end{array}$ & $\begin{array}{l}-0.946 \\
(1.367)\end{array}$ & $\begin{array}{l}1.725 \\
(1.443)\end{array}$ \\
\hline
\end{tabular}

Notes: Each entry is estimated from a weighted least squares regression of the dependent variable on an indicator for assignment to treatment and district fixed effects. Column 1 reports the estimated ITT program effects from the previous tables. Subsequent columns omit baseline covariates, calculate difference-in-difference ITTs, or omit regression weights to account for selective attrition or selection into the endline tracking sample. Finally, the last two columns omit attrition weights and instead impute semi-extreme values of the dependent variable, so that missing treatment and control group members have a 0.5 standard deviation difference in their outcomes (as we impute a mean +.25 standard deviation dependent variable, so that missing treatment and control group members have a 0.5 standard deviation difference in their outcomes (as we imp
outcome for treatment and mean -.25 standard deviatioon for controls, or vice versa). ${ }^{*}$ implies $p<.1,{ }^{* *}$ implies $p<.05,{ }^{* * *}$ implies $p<.01$ 


\subsection{Human capital impacts}

We next turn to secondary outcomes, which could arise from temporary economic gains. We begin with the respondent's own health and then consider the health and education of their children.

\section{Respondent's own health}

Table 10 reports program impacts on the respondent's physical and mental health. As this is a young population, mortality rates were just $0.55 \%$ over the nine years. YOP reduced mortality by 0.4 percentage points, an $80 \%$ improvement, but one that is not statistically significant.

Among those alive and interviewed, the health and education of the treatment and control groups are broadly similar. We have three measures of physical health: (1) an index of physical functioning that averages self-reported performance at four activities of daily life (such as standing and running) plus self-reported tiredness and general health problems; (2) an index for whether they reported a disability, injury, illness or another inability to work; and (3) number of days unable to work in the last month. We also asked respondents a lengthy symptom checklist for various mental health issues, including: depression/emotional distress; pro-social behavior; and hostility/aggression. ${ }^{21}$

To reduce the number of hypotheses tested, we combine these secondary outcomes into two family indexes of physical and mental health. We also report treatment effects on the component measures for transparency. We see no substantively large or statistically significant differences between the treatment and control group, either in the two family indexes or their components. The estimated coefficients on the family indexes are less than 0.06 standard deviations.

\section{Child health and education}

Most YOP recipients were in their twenties, and bearing or raising small children, when they received the grants. At baseline, the average member of the sample was 25 years old, had 1.5 children on average. In the first 4 years of the grant, the average sample had 1.6 children, when income gains were highest.

As a result, we hypothesized that YOP recipients would invest more in their children at a young age, and as a result the children would have better child health and education

\footnotetext{
${ }^{21}$ We asked respondents about the same depression, distress, and aggression/hostility symptoms at baseline. At endline we add a set of new, more nationally-comparable symptoms. Whether we include these additional symptoms or not, or look at changes in symptoms over time, our results and qualitative conclusions do not change.
} 


\section{Table 10: 9-year program impacts on respondent's own physical and mental health}

\begin{tabular}{|c|c|c|c|c|c|c|c|}
\hline \multirow{3}{*}{$\begin{array}{l}\text { Dependent Variable } \\
\mathrm{N}=2086\end{array}$} & \multirow{2}{*}{\multicolumn{3}{|c|}{ Control mean }} & \multicolumn{4}{|c|}{ Treatment effects } \\
\hline & & & & \multirow[b]{2}{*}{$\begin{array}{c}\text { Pooled } \\
(4)\end{array}$} & \multicolumn{3}{|c|}{ By gender } \\
\hline & $\begin{array}{l}\text { Pooled } \\
\text { (1) }\end{array}$ & $\begin{array}{l}\text { Women } \\
(2)\end{array}$ & $\begin{array}{c}\text { Men } \\
(3)\end{array}$ & & $\begin{array}{c}\text { Women } \\
(5)\end{array}$ & $\begin{array}{c}\text { Men } \\
(6)\end{array}$ & $\begin{array}{c}\text { Difference } \\
(7)\end{array}$ \\
\hline Respondent passed away & 0.006 & 0.000 & 0.008 & $\begin{array}{l}-0.004 \\
(0.006)\end{array}$ & $\begin{array}{c}0.001 \\
0.007\end{array}$ & $\begin{array}{l}-0.007 \\
0.006]\end{array}$ & $\begin{array}{l}-0.009 \\
0.006]\end{array}$ \\
\hline Physical health index (z-score) & -0.03 & 0.26 & -0.17 & $\begin{array}{l}-0.028 \\
(0.047)\end{array}$ & $\begin{array}{l}-0.017 \\
{[0.092]}\end{array}$ & $\begin{array}{l}-0.034 \\
{[0.051]}\end{array}$ & $\begin{array}{l}-0.017 \\
{[0.102]}\end{array}$ \\
\hline Difficulty in hysical functioning at activities of daily life (z-score) & -0.01 & 0.32 & -0.18 & $\begin{array}{l}-0.048 \\
(0.048)\end{array}$ & $\begin{array}{c}0.005 \\
{[0.088]}\end{array}$ & $\begin{array}{l}-0.075 \\
{[0.052]}\end{array}$ & $\begin{array}{l}-0.080 \\
{[0.097]}\end{array}$ \\
\hline Inability perform activities of daily life index (z-score) & 0.00 & 0.22 & -0.11 & $\begin{array}{l}-0.077 \\
(0.049)\end{array}$ & $\begin{array}{l}0.007 \\
{[0.095]}\end{array}$ & $\begin{array}{c}-0.121 \\
{[0.050]^{* *}}\end{array}$ & $\begin{array}{l}-0.127 \\
{[0.103]}\end{array}$ \\
\hline Tiredness index (z-score) & -0.02 & 0.31 & -0.19 & $\begin{array}{l}-0.003 \\
(0.048)\end{array}$ & $\begin{array}{c}0.001 \\
{[0.080]}\end{array}$ & $\begin{array}{l}-0.006 \\
{[0.057]}\end{array}$ & $\begin{array}{l}-0.007 \\
{[0.095]}\end{array}$ \\
\hline Illness and injury index (z-score) & -0.01 & 0.16 & -0.10 & $\begin{array}{l}-0.036 \\
(0.049)\end{array}$ & $\begin{array}{l}-0.124 \\
{[0.089]}\end{array}$ & $\begin{array}{c}0.009 \\
{[0.058]}\end{array}$ & $\begin{array}{c}0.133 \\
{[0.106]}\end{array}$ \\
\hline Days unable to work in past month & 1.29 & 1.75 & 1.06 & $\begin{array}{c}0.080 \\
(0.155)\end{array}$ & $\begin{array}{c}0.292 \\
{[0.322]}\end{array}$ & $\begin{array}{l}-0.031 \\
{[0.171]}\end{array}$ & $\begin{array}{l}-0.323 \\
{[0.371]}\end{array}$ \\
\hline Mental health index (z-score) & 0.01 & 0.33 & -0.16 & $\begin{array}{l}-0.056 \\
(0.047)\end{array}$ & $\begin{array}{l}-0.122 \\
{[0.082]}\end{array}$ & $\begin{array}{l}-0.023 \\
{[0.055]}\end{array}$ & $\begin{array}{c}0.099 \\
{[0.097]}\end{array}$ \\
\hline Depression and distress index (z-score) & -0.05 & 0.36 & -0.26 & $\begin{array}{l}-0.034 \\
(0.046)\end{array}$ & $\begin{array}{l}-0.110 \\
{[0.080]}\end{array}$ & $\begin{array}{c}0.005 \\
{[0.055]}\end{array}$ & $\begin{array}{c}0.115 \\
{[0.095]}\end{array}$ \\
\hline Depression index (z-score) & -0.05 & 0.32 & -0.24 & $\begin{array}{l}-0.040 \\
(0.045)\end{array}$ & $\begin{array}{l}-0.118 \\
{[0.076]}\end{array}$ & $\begin{array}{c}0.000 \\
{[0.055]}\end{array}$ & $\begin{array}{c}0.118 \\
{[0.091]}\end{array}$ \\
\hline Distress index (z-score) & -0.04 & 0.34 & -0.23 & $\begin{array}{l}-0.023 \\
(0.047)\end{array}$ & $\begin{array}{l}-0.083 \\
{[0.081]}\end{array}$ & $\begin{array}{c}0.009 \\
{[0.057]}\end{array}$ & $\begin{array}{c}0.092 \\
{[0.097]}\end{array}$ \\
\hline Pro-social behavior index (z-score) & -0.05 & -0.21 & 0.04 & $\begin{array}{c}0.022 \\
(0.050)\end{array}$ & $\begin{array}{l}-0.021 \\
{[0.088]}\end{array}$ & $\begin{array}{c}0.044 \\
{[0.059]}\end{array}$ & $\begin{array}{c}0.065 \\
{[0.104]}\end{array}$ \\
\hline Hostility index (z-score & 0.02 & 0.13 & -0.04 & $\begin{array}{l}-0.064 \\
(0.046)\end{array}$ & $\begin{array}{c}-0.170 \\
{[0.082]^{* *}}\end{array}$ & $\begin{array}{l}-0.009 \\
{[0.055]}\end{array}$ & $\begin{array}{c}0.161 \\
{[0.099]}\end{array}$ \\
\hline
\end{tabular}

Notes: Each entry in columns 3 and 4 is estimated from a weighted least squares regression of the dependent variable on an indicator for assignment to treatment, district fixed effects, and a vector of baseline covariates. Standard errors are clustered at the group level (of up to 5 people). We report the coefficient on treatment only. All regressions are weighted by inverse probabilities of attrition and selection into the endline tracking sample. Columns 5 through 7 come from a single regression, where we regress treatment on an indicator for treatment, an indicator interacted with gender, and the gender indicator plus the usual controls. We use these coefficients to calculate the treatment effect on each gender separately. For each index, missing values were imputed to be the row median of the measures that compose the index, per respondent. Maximum $\mathrm{N}$ across all regressions is 2086 because the outcome Has died is measured for individuals found, including those who did not complete the full survey. $N=1981$ for all other regressions. ${ }^{*}$ implies $p<.1,{ }^{* *}$ implies $p<.05,{ }^{* * *}$ implies $p<.01$ 


\section{Table 11: 9-year program impacts on child mortality and fertility}

\begin{tabular}{|c|c|c|c|c|c|c|c|}
\hline \multirow{4}{*}{$\begin{array}{l}\text { Dependent Variable } \\
N=1868 \text { at } 4 \text {-year endline } \\
\mathrm{N}=1981 \text { at } 9 \text {-year endline }\end{array}$} & \multirow{3}{*}{\multicolumn{2}{|c|}{ Control mean }} & \multicolumn{5}{|c|}{ Treatment effects } \\
\hline & & & \multicolumn{5}{|c|}{$\begin{array}{r}\text { 1reatment efrects } \\
9 \text {-year }\end{array}$} \\
\hline & & & \multirow[b]{2}{*}{$\begin{array}{l}\text { Pooled } \\
\text { (3) }\end{array}$} & \multirow[b]{2}{*}{$\begin{array}{l}\text { Pooled } \\
\text { (4) }\end{array}$} & \multicolumn{3}{|c|}{ By gender } \\
\hline & $\begin{array}{c}\text { 4-year } \\
(1)\end{array}$ & $\begin{array}{c}\text { 9-year } \\
(2)\end{array}$ & & & $\begin{array}{c}\text { Women } \\
(5)\end{array}$ & $\begin{array}{c}\text { Men } \\
(6)\end{array}$ & $\begin{array}{c}\text { Difference } \\
(7)\end{array}$ \\
\hline \multicolumn{8}{|l|}{ Panel A: fertility, household size, and child expenditures } \\
\hline Number of pregnancies 2007 or later & & 2.47 & & $\begin{array}{c}0.097 \\
{[0.101]}\end{array}$ & $\begin{array}{l}-0.031 \\
{[0.152]}\end{array}$ & $\begin{array}{c}0.164 \\
{[0.121]}\end{array}$ & $\begin{array}{c}0.195 \\
{[0.182]}\end{array}$ \\
\hline Pct. of births that were live 2007 or later & & 0.92 & & $\begin{array}{c}0.013 \\
{[0.010]}\end{array}$ & $\begin{array}{c}0.019 \\
{[0.019]}\end{array}$ & $\begin{array}{c}0.011 \\
{[0.012]}\end{array}$ & $\begin{array}{l}-0.008 \\
{[0.022]}\end{array}$ \\
\hline Pct. of pregnancies 2007 or later where child still living & & 0.89 & & $\begin{array}{c}0.009 \\
{[0.012]}\end{array}$ & $\begin{array}{c}0.017 \\
{[0.020]}\end{array}$ & $\begin{array}{c}0.005 \\
{[0.014]}\end{array}$ & $\begin{array}{l}-0.012 \\
{[0.025]}\end{array}$ \\
\hline Pct. of successful pregnancies 2007 or later where child still living & & 0.96 & & $\begin{array}{l}-0.006 \\
{[0.006]}\end{array}$ & $\begin{array}{l}-0.001 \\
{[0.010]}\end{array}$ & $\begin{array}{l}-0.008 \\
{[0.008]}\end{array}$ & $\begin{array}{l}-0.006 \\
{[0.013]}\end{array}$ \\
\hline Number of biological children alive born 2007 or later & & 2.14 & & $\begin{array}{c}0.075 \\
{[0.083]}\end{array}$ & $\begin{array}{l}-0.006 \\
{[0.121]}\end{array}$ & $\begin{array}{c}0.116 \\
{[0.100]}\end{array}$ & $\begin{array}{c}0.122 \\
{[0.144]}\end{array}$ \\
\hline Size of household & 7.74 & 5.86 & $\begin{array}{l}-0.102 \\
{[0.222]}\end{array}$ & $\begin{array}{l}-0.127 \\
{[0.162]}\end{array}$ & $\begin{array}{l}-0.192 \\
{[0.269]}\end{array}$ & $\begin{array}{l}-0.093 \\
{[0.183]}\end{array}$ & $\begin{array}{c}0.099 \\
{[0.301]}\end{array}$ \\
\hline Mean age of children $(0-15)$ & & 7.50 & & $\begin{array}{c}0.014 \\
{[0.138]}\end{array}$ & $\begin{array}{l}-0.007 \\
{[0.233]}\end{array}$ & $\begin{array}{c}0.025 \\
{[0.164]}\end{array}$ & $\begin{array}{c}0.032 \\
{[0.277]}\end{array}$ \\
\hline Mean age of biological children $(0-15)$ & & 7.08 & & $\begin{array}{c}0.095 \\
{[0.147]}\end{array}$ & $\begin{array}{l}-0.084 \\
{[0.243]}\end{array}$ & $\begin{array}{c}0.189 \\
{[0.173]}\end{array}$ & $\begin{array}{c}0.273 \\
{[0.286]}\end{array}$ \\
\hline \multicolumn{8}{|l|}{ Panel B: Child educational outcomes } \\
\hline Child's age-adjusted educational attainment (6-15) & & 0.03 & & $\begin{array}{l}-0.017 \\
{[0.043]}\end{array}$ & $\begin{array}{c}0.082 \\
{[0.071]}\end{array}$ & $\begin{array}{l}-0.071 \\
{[0.053]}\end{array}$ & $\begin{array}{c}-0.152 \\
{[0.086]^{*}}\end{array}$ \\
\hline Child's age-adjusted educational attainment, (6-15, biological) & & 0.06 & & $\begin{array}{l}-0.036 \\
{[0.048]}\end{array}$ & $\begin{array}{c}0.058 \\
{[0.077]}\end{array}$ & $\begin{array}{l}-0.086 \\
{[0.057]}\end{array}$ & $\begin{array}{l}-0.144 \\
{[0.092]}\end{array}$ \\
\hline Mean of child's enrollment & & 0.91 & & $\begin{array}{l}-0.016 \\
{[0.013]}\end{array}$ & $\begin{array}{l}-0.019 \\
{[0.021]}\end{array}$ & $\begin{array}{l}-0.015 \\
{[0.016]}\end{array}$ & $\begin{array}{c}0.005 \\
{[0.026]}\end{array}$ \\
\hline Mean of child's enrollment, biological & & 0.91 & & $\begin{array}{l}-0.018 \\
{[0.013]}\end{array}$ & $\begin{array}{l}-0.028 \\
{[0.022]}\end{array}$ & $\begin{array}{l}-0.013 \\
{[0.017]}\end{array}$ & $\begin{array}{c}0.016 \\
{[0.027]}\end{array}$ \\
\hline Current child expenditures (clothes and school) & 28.23 & 42.14 & $\begin{array}{c}4.935 \\
{[2.382]^{* *}}\end{array}$ & $\begin{array}{c}0.411 \\
{[2.784]}\end{array}$ & $\begin{array}{l}-2.241 \\
{[5.190]}\end{array}$ & $\begin{array}{l}1.793 \\
{[2.974]}\end{array}$ & $\begin{array}{c}4.034 \\
{[5.698]}\end{array}$ \\
\hline Current child expenditures per child & & 14.00 & & $\begin{array}{c}0.502 \\
{[1.071]}\end{array}$ & $\begin{array}{l}-0.587 \\
{[2.275]}\end{array}$ & $\begin{array}{c}1.081 \\
{[1.139]}\end{array}$ & $\begin{array}{l}1.668 \\
{[2.573]}\end{array}$ \\
\hline \multicolumn{8}{|l|}{ Panel C: Child health outcomes } \\
\hline Mean health index per child, ages 3-9, family average & & -0.03 & & $\begin{array}{c}0.078 \\
{[0.043]^{*}}\end{array}$ & $\begin{array}{c}0.166 \\
{[0.076]^{* *}}\end{array}$ & $\begin{array}{c}0.036 \\
{[0.051]}\end{array}$ & $\begin{array}{l}-0.130 \\
{[0.092]}\end{array}$ \\
\hline Mean parent-reported health score per child, for ages 3-9, family average & & 0.00 & & $\begin{array}{c}0.071 \\
{[0.047]}\end{array}$ & $\begin{array}{c}0.144 \\
{[0.087]^{*}}\end{array}$ & $\begin{array}{c}0.036 \\
{[0.055]}\end{array}$ & $\begin{array}{l}-0.108 \\
{[0.101]}\end{array}$ \\
\hline Mean malaria cases in past year, ages 3-9, family average & & 2.96 & & $\begin{array}{l}-0.125 \\
{[0.087]}\end{array}$ & $\begin{array}{l}-0.163 \\
{[0.153]}\end{array}$ & $\begin{array}{l}-0.107 \\
{[0.108]}\end{array}$ & $\begin{array}{c}0.055 \\
{[0.190]}\end{array}$ \\
\hline Mean normalized ADL score per child, ages 3-9, family average & & 0.01 & & $\begin{array}{c}0.045 \\
{[0.041]}\end{array}$ & $\begin{array}{c}0.145 \\
{[0.071]^{* *}}\end{array}$ & $\begin{array}{l}-0.003 \\
{[0.049]}\end{array}$ & $\begin{array}{c}-0.149 \\
{[0.085]^{*}}\end{array}$ \\
\hline
\end{tabular}

Notes: Each entry in columns 3 and 4 is estimated from a WLS regression of the dependent variable on an indicator for assignment to treatment, district fixed effects, and a vector of baseline covariates. Standard errors are clustered at the group level (of up to 5 people). We report the coefficient on treatment only. All regressions are weighted by inverse probabilities of attrition and selection into the endline tracking sample. Columns 5 through 7 come from a single regression, where we regress treatment on an indicator for treatment, an indicator interacted with gender, and the gender indicator plus the usual controls. N's vary across variables because: not all respondents were ever pregnant, causing there to be $N<1982$; current child expenditures are meaasured for all respondents, while current expenditures per child is only measured for respondents with children; and health measures for children were only measured for respondents with children between the ages of 3 and 9. Child educational measures and child health measures stem from different portions of the survey, which may have led to inconsistencies in which children were discussed. ${ }^{*}$ implies $p<.1,{ }^{* *}$ implies $p<.05,{ }^{* * *}$ implies $p<.01$ 
outcomes after 9 years. This is consistent with a wide literature on anti-poverty programs.

${ }^{22}$ We collected survey data on three main kinds of outcomes:

A. Fertility and child mortality. We first asked each respondent to recall and report each of their pregnancies, and followed these through to birth and currentl status. We use these data to construct approximate measures of fertility (number of pregnancies), percentage of births that were live, percentage of children still living, and the number of biological children. Men typically had multiple partners, and so only report pregnancies about which they were aware. This has obvious sources of error, which we will discuss in a moment. Panel A Table 11 reports program impacts on these measures for all respondents.

B. Educational outcomes. From a list of all biological children, plus non-biological children living in the household, we then asked respondents to report the child's current grade attainment and enrollment status. Panel B of Table 11 reports program impacts on these outcomes for all children and biological children only. We report results for children currently aged 6-15 (age 6 or less at the time of the grant), but the conclusions are similar for children currently aged 6-24 (not shown). The table also reports impacts on expenditures on children's clothing and education from the consumption portion of the 9-year survey.

C. Child current health outcomes. Finally, we collected health information on biological children who were aged 3-9 at the time of the survey (and hence unborn at the time of the grant). ${ }^{23}$ Many survey respondents did not live with all their children, and for this (and other reasons of cost and logistics) we did not collect anthropomorphic data on living children. Instead, we asked parents to report the physical functioning of their child along three dimensions: (i) 6 measures of physical functioning, including activities of daily life such as using the toilet, washing themselves, and walking and running; (b) an overall subjective assessment of the child's general healthiness; and (iii) the number of reported malaria cases in the previous year. We assemble these into three sub-indices and use them to construct an overall index of child health, reported in Panel C of Table 11.

\footnotetext{
${ }^{22}$ Aizer et al. (2016) find that welfare income to U.S. mothers increase the longevity of children by one year. Paxson and Schady (2010) find that cash transfers to Ecuadorian women had positive impacts on child physical and cognitive health after two years.

${ }^{23}$ We do not have physical assessments on children currently aged $0-2$ or $10+$ because the daily activities of life do not apply to children under 3 , and a survey error meant that children over 9 were no asked the questions.
} 
All of these outcomes are respondent-reported and hence error-prone. Noise and systematic underreporting of health will tend to bias treatment effects downwards, and make them less precise (i.e. bias us towards failing to reject the null). We might be especially worried about men's reports, especially because they may be less likely to live or spend time with their children. The main threat to identification is if such measurement error is correlated with treatment status. While possible, it is not obvious why treated men should be more knowledgable of their children's health than control men, especially when we see no signs of a change in the number of children or their ages. The chief possibility - that one group is more likely to migrate away from their family than the other-shows no treatment-control difference (see Appendix Table B.3). Hence, to a first approximation, we think these are reasonable estimates of the mean effects of the program.

We see almost no evidence of a change in fertility or children's well-being. Most of the estimated coefficients are not only statistically insignificant, but they are also small in the sense of being less than $5 \%$ of the control group mean. Moreover, most $95 \%$ confidence intervals exclude changes more than roughly $10 \%$. The education coefficients generally point in the wrong direction. Hence, even if the outcomes were significantly less noisy, there is little reason to believe that we could observe substantively important improvement's in children's well being.

The one exception is the health index among children alive today. Child mortality was roughly $4 \%$ of live births (and 11\% of any pregnancy) among the control group, and there is no statistically significant difference in the treatment group (indeed the sign is negative for child mortality conditional on being born). But a health index for children is 0.08 standard deviations greater in the treatment group, significant at the $10 \%$ level. This effect is concentrated among women, where treated women report children who are 0.17 standard deviations healthier, significant at the $5 \%$ level. None of these standard errors are adjusted for multiple comparisons, however, and so we must take these results with caution, especially because they are concentrated in a single family index and a single subgroup. Nonetheless, the result is consistent with a largely observational literature that has found that, compared to income or assets in the hands of men, income or assets in the hands of women is associated with larger improvements in child health (Thomas, 1990; Duflo, 2012).

\subsection{Political impacts}

Table 12 reports program impacts on political behavior after 4 and 9 years. In Blattman et al. (2018), we found that during the 2011 national elections (3 years after YOP), those assigned to treatment reported that they were no more likely to engage in non-partisan 


\section{Table 12: 9-year program impacts on political behavior}

\begin{tabular}{|c|c|c|c|c|c|c|c|}
\hline \multirow{4}{*}{$\begin{array}{l}\text { Dependent Variable } \\
N=1858 \text { at } 4 \text {-year endline } \\
N=1981 \text { at } 9 \text {-year endline }\end{array}$} & \multirow{3}{*}{\multicolumn{2}{|c|}{ Control mean }} & \multicolumn{5}{|c|}{ Treatment effects } \\
\hline & & & \multirow{3}{*}{$\begin{array}{c}\text { 4-year } \\
\text { Pooled } \\
(3)\end{array}$} & \multicolumn{4}{|c|}{ 9-year } \\
\hline & & & & \multirow[b]{2}{*}{$\begin{array}{c}\text { Pooled } \\
\text { (4) }\end{array}$} & \multicolumn{3}{|c|}{ By gender } \\
\hline & $\begin{array}{l}\text { 4-year } \\
\text { (1) }\end{array}$ & $\begin{array}{c}\text { 9-year } \\
(2)\end{array}$ & & & $\begin{array}{c}\text { Women } \\
(5)\end{array}$ & $\begin{array}{c}\text { Men } \\
(6)\end{array}$ & $\begin{array}{c}\text { Difference } \\
(7)\end{array}$ \\
\hline \multirow[t]{2}{*}{ Index of political action (z-score) } & -0.02 & -0.06 & 0.013 & 0.056 & 0.076 & 0.045 & -0.030 \\
\hline & & & {$[0.012]$} & {$[0.050]$} & {$[0.085]$} & {$[0.063]$} & {$[0.107]$} \\
\hline \multirow[t]{2}{*}{ Attended voter education meeting } & 0.48 & 0.54 & 0.026 & 0.030 & 0.062 & 0.013 & -0.048 \\
\hline & & & {$[0.026]$} & {$[0.024]$} & {$[0.041]$} & {$[0.029]$} & {$[0.049]$} \\
\hline \multirow[t]{2}{*}{ Discussed Vote } & 0.56 & 0.69 & -0.028 & -0.003 & -0.018 & 0.005 & 0.023 \\
\hline & & & {$[0.025]$} & {$[0.024]$} & {$[0.042]$} & {$[0.028]$} & {$[0.049]$} \\
\hline \multirow[t]{2}{*}{ Reported campaign malpractice or incident } & 0.10 & 0.08 & 0.024 & -0.013 & 0.011 & -0.026 & -0.037 \\
\hline & & & {$[0.017]$} & {$[0.012]$} & {$[0.015]$} & {$[0.017]$} & {$[0.023]$} \\
\hline \multirow[t]{2}{*}{ Voted in presidential election } & 0.91 & 0.92 & 0.001 & 0.007 & 0.026 & -0.002 & -0.028 \\
\hline & & & {$[0.014]$} & {$[0.013]$} & {$[0.024]$} & {$[0.015]$} & {$[0.029]$} \\
\hline \multirow[t]{2}{*}{ Attended political rally } & 0.68 & 0.69 & 0.002 & 0.012 & 0.007 & 0.015 & 0.008 \\
\hline & & & {$[0.024]$} & {$[0.025]$} & {$[0.041]$} & {$[0.030]$} & {$[0.048]$} \\
\hline \multirow[t]{2}{*}{ Participated in political primary } & 0.43 & 0.47 & 0.011 & 0.014 & 0.013 & 0.015 & 0.002 \\
\hline & & & {$[0.025]$} & {$[0.024]$} & {$[0.042]$} & {$[0.029]$} & {$[0.051]$} \\
\hline \multirow[t]{2}{*}{ Worked to get a candidate/party elected } & 0.34 & 0.50 & 0.045 & 0.037 & -0.019 & 0.065 & 0.084 \\
\hline & & & {$[0.024]^{*}$} & {$[0.025]$} & {$[0.043]$} & {$[0.030]^{* *}$} & {$[0.054]$} \\
\hline \multirow[t]{2}{*}{ Member of a political party } & 0.49 & 0.56 & -0.001 & 0.045 & 0.054 & 0.041 & -0.013 \\
\hline & & & {$[0.026]$} & {$[0.024]^{*}$} & {$[0.042]$} & {$[0.029]$} & {$[0.051]$} \\
\hline \multirow[t]{2}{*}{ Index of NRM/Presidential support (z-score) } & -0.05 & -0.04 & -0.041 & 0.030 & 0.094 & -0.003 & -0.097 \\
\hline & & & {$[0.052]$} & {$[0.052]$} & {$[0.081]$} & {$[0.066]$} & {$[0.103]$} \\
\hline \multirow[t]{2}{*}{ Would vote for NRM if election were tomorrow } & 0.75 & 0.77 & -0.019 & -0.009 & 0.002 & -0.015 & -0.017 \\
\hline & & & {$[0.022]$} & {$[0.021]$} & {$[0.036]$} & {$[0.026]$} & {$[0.044]$} \\
\hline \multirow{2}{*}{ Like or strongly like NRM } & 0.81 & 0.81 & -0.023 & 0.014 & 0.055 & -0.007 & -0.062 \\
\hline & & & {$[0.020]$} & {$[0.020]$} & {$[0.031]^{*}$} & {$[0.025]$} & {$[0.040]$} \\
\hline Feels close to the NRM & 0.55 & & 0.011 & & & & \\
\hline & & & {$[0.024]$} & & & & \\
\hline Worked to get the NRM elected & 0.29 & 0.43 & 0.014 & 0.020 & -0.026 & 0.044 & 0.070 \\
\hline & & & {$[0.023]$} & {$[0.025]$} & {$[0.042]$} & {$[0.031]$} & {$[0.053]$} \\
\hline Member of the NRM & 0.40 & 0.51 & -0.017 & 0.037 & 0.058 & 0.026 & -0.032 \\
\hline & & & {$[0.026]$} & {$[0.024]$} & {$[0.040]$} & {$[0.029]$} & {$[0.049]$} \\
\hline Voted or supported the president in the last election & 0.88 & 0.81 & -0.038 & -0.006 & 0.056 & -0.038 & -0.094 \\
\hline & & & {$[0.018]^{* *}$} & {$[0.020]$} & {$[0.032]^{*}$} & {$[0.025]$} & {$[0.040]^{* *}$} \\
\hline Approve or strongly approve of President & 0.85 & & -0.020 & & & & \\
\hline & & & {$[0.018]$} & & & & \\
\hline Index of opposition support (z-score) & -0.00 & 0.01 & 0.117 & 0.082 & 0.047 & 0.100 & 0.053 \\
\hline & & & {$[0.053]^{* *}$} & {$[0.044]^{*}$} & {$[0.073]$} & {$[0.058]^{*}$} & {$[0.096]$} \\
\hline Would vote for opposition if election were tomorrow & 0.17 & 0.12 & 0.010 & 0.017 & -0.004 & 0.029 & 0.033 \\
\hline & & & {$[0.020]$} & {$[0.016]$} & {$[0.024]$} & {$[0.020]$} & {$[0.031]$} \\
\hline Like or strongly like any opposition party & 0.36 & 0.35 & 0.030 & 0.029 & 0.010 & 0.039 & 0.029 \\
\hline & & & {$[0.023]$} & {$[0.022]$} & {$[0.038]$} & {$[0.026]$} & {$[0.045]$} \\
\hline Feels close to any opposition party & 0.10 & & 0.032 & & & & \\
\hline & & & {$[0.016]^{* *}$} & & & & \\
\hline Worked to get the opposition elected & 0.04 & 0.06 & 0.031 & 0.014 & 0.018 & 0.012 & -0.006 \\
\hline & & & {$[0.011]^{* * *}$} & {$[0.010]$} & {$[0.015]$} & {$[0.014]$} & {$[0.021]$} \\
\hline Member of an opposition party & 0.05 & 0.53 & 0.025 & 0.040 & 0.060 & 0.029 & -0.031 \\
\hline & & & {$[0.013]^{* *}$} & {$[0.024]$} & {$[0.041]$} & {$[0.029]$} & {$[0.050]$} \\
\hline Voted or supported an election party in the past election & 0.12 & 0.28 & 0.038 & -0.006 & -0.029 & 0.005 & 0.034 \\
\hline & & & {$[0.018]^{* *}$} & {$[0.022]$} & {$[0.034]$} & {$[0.027]$} & {$[0.041]$} \\
\hline
\end{tabular}

Notes: Each entry in columns 3 and 4 is estimated from a weighted least squares regression of the dependent variable on an indicator for assignment to treatment, district fixed effects, and a vector of baseline covariates. Standard errors are clustered at the group level (of up to 5 people). We report the coefficient on treatment only. All regressions are weighted by inverse probabilities of attrition and selection into the endline tracking sample. Columns 5 through 7 come from a single regression, where we regress treatment on an indicator for treatment, an indicator interacted with gender, and the gender indicator plus the usual controls. We use these coefficients to calculate the treatment effect on each gender separately. ${ }^{*}$ implies $p<.1,{ }^{* *}$ implies $p<.05,{ }^{* * *}$ implies $p<.01$ 
political actions, but they were significantly more likely to have supported and voted for opposition candidates in elections the previous year. We hypothesized that this was partly due to clientelistic election tactics, where villagers are commonly offered small sums of money to vote, especially on behalf of the ruling party (Larreguy et al., 2018). By earning more income, individuals in the treatment group were freed to publicly demonstrate their support for the opposition.

We see largely similar but less statistically significant patterns in the 2016 elections, held 8 years after YOP grants were disbursed. We asked a broadly similar set of questions on nonpartisan and partisan actions and attitudes. Once again, we see little treatment-control difference in political actions that are either nonpartisan or not specific to a party, and we see no change in self-reported support for the ruling party. But the treatment group was 0.08 standard deviations more likely to support the opposition party, such as join the party, vote for the opposition candidate, or actively work to get an opposition candidate elected. This family index is significant at the 10 percent level only, and slightly smaller than the previous effect of 0.12 standard deviations. Nonetheless, some of the component treatment effects are very large: actively working to get an opposition candidate elected rises $62 \%$ relative to the control mean, and voting for the opposition rises $14 \%$ relative to the control mean. Longer term research will be need to see if the opposition support is more persistent than the earnings impact.

\section{Discussion and conclusions}

The main effect of giving underemployed, poor young people one-time grants averaging $\$ 384$ per person appears to have been an increase in earnings that lasted at most 9 years, plus a relatively small increase in fixed assets due to accumulated earnings.

Most grant recipients used the funds to train in and start the vocational enterprise that they and their groups proposed. This helped them to get a few additional hours of employment per week, usually at relatively low wages. Nonetheless, this was a large amount of new cash earnings given their poor alternatives and underemployment. Over time, however, both the treatment and control groups were able to accumulate more capital and expand their employment, usually in a mix of farm and non-farm activities. By the end of the 9 years, the control group appears to have reached the same level of investment, employment, and earnings as those who received the grant.

These temporary gains are not unexpected. Although most studies of entrepreneurship programs do not highlight this prediction, most studies (including this one) have been rooted in models of financial market imperfections that allow for convergence over time. For ex- 
ample, in models of credit constraints and fixed start-up costs to enterprise, people above some minimum levels of initial assets and earnings, with access to a savings technology, will eventually save past the minimal capital constraint and start the enterprise. Convergence will be faster if there are frictions that prevent the YOP group from rapidly accumulating more and more capital. This could be in the form of other constraints on enterprise (such as an absence of insurance, or limited ability), or constraints on capital accumulation such as families "taxing" successful kin (Jakiela and Ozier, 2015).

We estimate that this temporary earnings gain was roughly $\$ 665$ or 1.8 times the size of the grant (using 2008 USD and market exchange rates). While this an imprecise estimate of the cumulative income gain, it still implies that the program was cost-effective compared to direct outlays. We do not know the government's program implementation costs, however.

This figure does not include the gains in assets and children's health. Besides being difficult to value, we also take with some caution given that the effects are confined to a single dimension of child well-being in a single subgroup (women). Nonetheless, the pattern is consistent with an extensive literature on women using income to invest in their children's long run well being.

What we do not know is what effects the intervention had on local markets and prices, or the earnings of pre-existing entrepreneurs in the village or parish. Elsewhere in Uganda, Blattman et al. (2016) were able to estimate the spillovers of cash grants to ultrapoor women, and showed that the petty trading businesses they opened lowered the price of outside goods in the village, raising the general standard of living. Pre-existing traders were crowded out of the business, but mostly managed to shift to farm enterprises and maintain their earnings. Hence there were positive spillovers on net. We do not have the same closely-knit set of villages and data on non-treated villagers, and so we cannot estimate the same treatment effects. It is possible that the net spillovers of YOP are positive as well. Yet it is equally possible that the cumulative earnings gain likely overestimates the social impact, since the new entrants may have taken some of the business from preexisting vocational tradespersons. In that case, it makes even more sense to think of YOP as a social insurance program or kickstart, one where the costs could be borne in part by more successful, older people in the industry.

If these patterns are borne out by more long term studies, such as the parallel findings in Ethiopia in Blattman et al. (2018), then there are both theoretical and policy implications for poverty. Theoretically, it would bolster the view that there are relatively few cases of household poverty traps, and promote a more marginalized view of poverty alleviation (Banerjee and Duflo, 2011). It should also start to focus academic attention on the other frictions and constraints besides missing credit markets. After all, a big part of the convergence story was 
the sharply diminishing returns to capital we observed in the treatment group. What seems important is understanding the interactive effects between grants and efforts to relieve other constraints.

As a policy measure, it may make sense for governments to compare the costs and benefits of enterprise capital grant programs to other temporary social insurance schemes, such as guaranteed employment schemes. This would also affect how programs are targeted and on what basis they are evaluated. If government and charitable agencies sell these programs on the basis of permanent poverty relief, they may be setting up perfectly successful programs to fail at an outcome they are unlikely to ever deliver.

\section{References}

Aizer, A., S. Eli, J. Ferrie, and A. Lleras-Muney (2016). The long-run impact of cash transfers to poor families. The American Economic Review 106(4), 935-971.

Baird, S., J. H. Hicks, M. Kremer, and E. Miguel (2015). Worms at Work: Long-run Impacts of Child Health Gains. Working paper.

Baird, S., J. H. Hicks, M. Kremer, and E. Miguel (2016). Worms at work: Long-run impacts of a child health investment. The quarterly journal of economics 131(4), 1637-1680.

Baird, S., C. McIntosh, and B. Özler (2011). Cash or condition? Evidence from a cash transfer experiment. The Quarterly Journal of Economics 126(4), 1709-1753.

Baird, S., C. T. McIntosh, and B. Özler (2017). When the Money Runs out: Do Cash Transfers Have Sustained Effects on Human Capital Accumulation? Working Paper.

Bandiera, O., R. Burgess, N. Das, S. Gulesci, I. Rasul, and M. Sulaiman (2013). Can entrepreneurship programs transform the economic lives of the poor? Working paper.

Bandiera, O., R. Burgess, N. Das, S. Gulesci, I. Rasul, and M. Sulaiman (2017). Labor markets and poverty in village economies. The Quarterly Journal of Economics 132(2), $811-870$.

Banerjee, A., D. Karlan, R. D. Osei, H. Trachtman, and C. Udry (2018). Unpacking a Multi-Faceted Program to Build Sustainable Income for the Very Poor. Working paper.

Banerjee, A., D. Karlan, and J. Zinman (2015). Six Randomized Evaluations of Microcredit: Introduction and Further Steps. American Economic Journal: Applied Economics 7(1), $1-21$. 
Banerjee, A. V. (2013). Microcredit Under the Microscope: What Have We Learned in the Past Two Decades, and What Do We Need to Know? Annual Review of Economics 5(1), $487-519$.

Banerjee, A. V. and E. Duflo (2011). Poor economics: A radical rethinking of the way to fight global poverty. New York: Public Affairs.

Banerjee, A. V., E. Duflo, N. Goldberg, D. Karlan, R. Osei, W. Parienté, J. Shapiro, B. Thuysbaert, and C. Udry (2015). A Multi-faceted Program Causes Lasting Progress for the Very Poor: Evidence from Six Countries. Science 348(6236), 772-737.

Beaman, L., D. Karlan, B. Thuysbaert, and C. Udry (2018). Selection into Credit Markets: Evidence from Agriculture in Mali. Working paper.

Bianchi, M. and M. Bobba (2013). Liquidity, Risk, and Occupational Choices. Review of Economic Studies 80(2), 491-511.

Blattman, C., J. Annan, E. P. Green, C. Lehmann, and J. Jamison (2016). The returns to microenterprise support among the ultra-poor: A field experiment in postwar Uganda. American Economic Journal: Applied Economics 8(2), 35-64.

Blattman, C., S. Dercon, and S. Franklin (2018). The long run effects of industrial and entreprenerial jobs: 5-year evidence from Ethiopia. Working paper.

Blattman, C., M. Emeriau, and N. Fiala (2018). Do anti-poverty programs sway voters? Experimental evidence from Uganda. Review of Economics and Statistics.

Blattman, C., N. Fiala, and S. Martinez (2014). Generating skilled employment in developing countries: Experimental evidence from Uganda. Quarterly Journal of Economics 129(2), $697-752$.

Blattman, C., J. Jamison, and M. Sheridan (2017). Reducing crime and violence: Experimental evidence on cognitive behavioral therapy in Liberia. American Economic Review 107(4), 1165-1206.

Blattman, C. and L. Ralston (2015). Generating employment in poor and fragile states: A review of the evidence from labor market and entrepreneurship programs. Working paper.

Brudevold-Newman, A. P., M. Honorati, P. Jakiela, and O. W. Ozier (2017). A firm of one's own: experimental evidence on credit constraints and occupational choice. Working paper. 
Buera, F. J., J. P. Kaboski, and Y. Shin (2014). Macro-perspective on asset grants programs: Occupational and wealth mobility. American Economic Review 104 (5), 159-64.

Buera, F. J., J. P. Kaboski, and Y. Shin (2015). Entrepreneurship and financial frictions: A macrodevelopment perspective. economics 7(1), 409-436.

Cho, Y. and M. Honorati (2014). Entrepreneurship programs in developing countries: a meta regression analysis. Labour Economics 28, 110-130.

de Mel, S., D. J. McKenzie, and C. Woodruff (2012). One-Time Transfers of Cash or Capital Have Long-Lasting Effects on Microenterprises in Sri Lanka. Science 335(6071), 962-966.

Duflo, E. (2012). Women Empowerment and Economic Development. Journal of Economic Literature 50(4), 1051-1079.

Fafchamps, M., D. J. McKenzie, S. Quinn, and C. Woodruff (2014). When is capital enough to get female microenterprises growing? Evidence from a randomized experiment in Ghana. Journal of Development Economics 106(1), 211-226.

Feigenberg, B., E. Field, and R. Pande (2013). The economic returns to social interaction: Experimental evidence from microfinance. The Review of Economic Studies 80(4), 14591483.

Friedman, W., M. Kremer, E. Miguel, and R. Thornton (2011). Education as Liberation? Technical report, National Bureau of Economic Research.

Gertler, P., S. Martinez, and M. Rubio (2012). Investing Cash Transfers to Raise Long Term Living Standards. American Economic Journal: Applied Economics 4(1), 164-192.

Government of Uganda (2007). National Peace, Recovery and Development Plan for Northern Uganda: 2006-2009. Reoirt.

Haushofer, J. and J. Shapiro (2016). The short-term impact of unconditional cash transfers to the poor: Experimental evidence from Kenya. The Quarterly Journal of Economics 131 (4), 1973-2042.

Haushofer, J. and J. Shapiro (2018). The Long-Term Impact of Unconditional Cash Transfers: Experimental Evidence from Kenya. Working paper.

Hussam, R., N. Rigol, and B. Roth (2017). Targeting high ability entrepreneurs using community information: Mechanism design in the field. Working paper. 
Jakiela, P. and O. Ozier (2015). Does Africa need a rotten kin theorem? Experimental evidence from village economies. The Review of Economic Studies 83(1), 231-268.

Kaboski, J. P. and R. M. Townsend (2011). A Structural Evaluation of a Large-Scale QuasiExperimental Microfinance Initiative. Econometrica 79(5), 1357-1406.

Karlan, D., R. Osei, I. Osei-Akoto, and C. Udry (2014). Agricultural decisions after relaxing credit and risk constraints. The Quarterly Journal of Economics 129(2), 597-652.

Kraay, A. and D. McKenzie (2014). Do poverty traps exist? Assessing the evidence. Journal of Economic Perspectives 28(3), 127-48.

Larreguy, H., B. Marx, O. Reid, and C. Blattman (2018). A Market Equilibrium Approach to Reduce the Incidence of Vote-Buying: Evidence from Uganda. Working paper.

McKenzie, D. (2017). How effective are active labor market policies in developing countries? A critical review of recent evidence. The World Bank Research Observer 32(2), 127-154.

Paxson, C. and N. Schady (2010). Does money matter? The effects of cash transfers on child development in rural Ecuador. Economic development and cultural change 59(1), $187-229$.

Thomas, D. (1990). Intra-Household Resource Allocation An Inferential Approach. Journal of human resources 25(4).

Thomas, D., E. Frankenberg, and J. P. Smith (2001). Lost but Not Forgotten: Attrition and Follow-up in the Indonesia Family Life Survey. The Journal of Human Resources 36, 556-92. 3.

Udry, C. and S. Anagol (2006). The return to capital in Ghana. American Economic Review 96(2), 388-393. 


\section{Appendix for online publication}

\section{A Ramsey model of investment and occupational choice}

Our conceptual framework is rooted in a simple Ramsey model of investment and occupational choice with heterogeneous individuals, originally developed in Blattman et al. (2014). ${ }^{24}$ We consider the effects of a cash windfall on investment, savings, occupational choice, earnings and consumption in the short run and long run. We also consider the effects of a windfall where the recipient is constrained to make an initial capital investment. We examine the comparative statics in perfect financial markets as well as under a variety of missing markets (credit, savings, and insurance) and behavioral considerations such as impatient or hyperbolic discounters.

\section{A.1 Setup}

Consider an individual who can spend time working in one of two sectors: enterprise or traditional labor. Production functions for enterprise and traditional labor are $f^{E}\left(k, l^{E}, \theta\right)$ and $f^{T}\left(l^{T}, \omega\right)$, where $k$ is accumulated physical and human capital used in enterprise, $l^{E}$ is hours spent on enterprise, $l^{T}$ is hours on traditional labor, and $\theta$ is individual specific talent in enterprise, and $\omega$ is individual specific talent in traditional labor. Working in enterprise requires a minimum capital stock $\underline{k} \geq 0$, while traditional labor has no capital requirement. We assume positive but diminishing marginal returns to inputs, $f_{k}^{E}>0>f_{k k}^{E}, f_{l}^{E}>0>f_{l l}^{E}$; inputs are complements, $f_{k l}^{E}>0$; and the returns to inputs are increasing in ability, $f_{k \theta}^{E}>0$, $f_{l \theta}^{E}>0$ and $f_{l \omega}^{T}>0 .^{25}$ Also, note that $l_{t}=l_{t}^{E}+l_{t}^{T} \in[0,1]$.

\footnotetext{
${ }^{24}$ This model drew on a one sector model from Fafchamps et al (2012) and introduced occupational choice and labor supply. The model was developed by the authors in collaboration with Julian Jamison and Xing Xia for a suite of experimental studies of microenterprise and cash transfer interventions.

${ }^{25}$ We also assume the minimum capital requirement means that $f^{E}\left(k, l^{E}, \theta\right) \equiv 0$ as long as $k<\underline{k}$, and that for any ability level, at very low levels of $k$, marginal product of the first unit of labor is always higher in traditional labor than in enterprise, while at higher levels of $k$ it is the opposite, $\lim _{k \downarrow 0} \frac{f_{l}^{E}(k, 0, \theta)}{f_{l}^{T}(0, \omega)}=0$ and $\lim _{k \uparrow+\infty} \frac{f_{l}^{E}(k, 0, \theta)}{f_{l}^{T}(0, \omega)}=+\infty$. For simplicity, we assume $f^{E}\left(k, l^{E}, \theta\right)$ is homogeneous of degree 1 in $\left(k, l^{E}\right)$.
} 
The individual thus faces the problem:

$$
\begin{aligned}
\max _{c_{t}>0, l_{t} \geq 0, k_{t+1} \geq 0, a_{t+1}} & \sum_{t=0} \delta^{t} u\left(c_{t}, l_{t}\right) \\
\text { s.t. } c_{t}+a_{t+1}+k_{t+1}= & \left(1+r_{t}\right) a_{t}+k_{t}+f^{E}\left(k_{t}, l_{t}^{E}, \theta\right)+f^{T}\left(l_{t}^{T}, \omega\right) \\
l_{t}= & l_{t}^{E}+l_{t}^{T} \leq 1 \\
k_{0}= & 0 \\
a_{0} & \text { given }
\end{aligned}
$$

where $a_{t}$ is any financial assets other than capital invested in enterprise and $r_{t}$ is the returns to these alternative financial assets at time $t . a_{t}$ is any financial assets other than capital invested in enterprise and $r_{t}$ is the returns to these alternative financial assets at time $t$. Without loss of generality, we assume $k_{0}=0$ and all initial wealth is in the financial asset, $a_{0}$. To make analysis simple, we fix $r_{t}=r>0$. Finally, to fully characterize the equilibrium we add a transversality condition: $\lim _{t \rightarrow \infty} \delta^{t} u_{c}^{\prime}\left(c_{t}, l_{t}\right) a_{t}=0$.

This benchmark case considers perfect financial markets and consistent time preferences. In this case, individuals will allocate assets between the enterprise and savings until the returns of capital are equal, and will allocate their time across sectors until the marginal disutility is equal. The solution to the problem is characterized as time-paths of quantities $\left\{c_{t}, l_{t}^{E}, l_{t}^{T}, k_{t+1}, a_{t+1}\right\}_{t=0}^{\infty}$ that satisfy the following set of conditions given $k_{0}=0$ and $a_{0}>0$ :

$$
\begin{aligned}
\frac{u_{c}^{\prime}\left(c_{t}, l_{t}\right)}{u_{c}^{\prime}\left(c_{t+1}, l_{t+1}\right)} & =\delta(1+r) \\
-\frac{u_{l}^{\prime}\left(c_{t}, l_{t}\right)}{u_{c}^{\prime}\left(c_{t}, l_{t}\right)} & =f_{l}^{E^{\prime}}\left(k_{t}, l_{t}^{E}, \theta\right) \quad \text { if } l_{t}^{E}>0 \\
-\frac{u_{l}^{\prime}\left(c_{t}, l_{t}\right)}{u_{c}^{\prime}\left(c_{t}, l_{t}\right)} & =f_{l}^{T^{\prime}}\left(l_{t}^{T}, \omega\right) \quad \text { if } l_{t}^{T}>0 \\
\frac{u_{c}^{\prime}\left(c_{t}, l_{t}\right)}{u_{c}^{\prime}\left(c_{t+1}, l_{t+1}\right)} & =\delta\left(1+f_{k}^{E^{\prime}}\left(k_{t+1}, l_{t+1}^{E}, \theta\right)\right) \quad \text { if } k_{t+1}>0 \\
c_{t}+a_{t+1}+k_{t+1} & =(1+r) a_{t}+k_{t}+f^{E}\left(k_{t}, l_{t}^{E}, \theta\right)+f^{T}\left(l_{t}^{T}, \omega\right) \\
\lim _{t \rightarrow \infty} \delta^{t} u_{c}^{\prime}\left(c_{t}, l_{t}\right) a_{t} & =0
\end{aligned}
$$

Conditions 1 and 4 imply that whenever investment in enterprise is positive the individual always produces at efficient scale, i.e. $f_{k}^{E^{\prime}}\left(k_{t+1}, l_{t+1}^{E}, \theta\right)=r$. For simplicity, we focus on interior solutions only throughout. 


\section{Who runs an enterprise?}

For $\underline{k}>0$, there will be low $\theta$ types who cannot reach efficient scale because their returns to capital are lower than $r$. We can define a minimum ability before enterprise is feasible, $\underline{\theta}=\underline{\theta}(r, \underline{k})$ for $f_{k}^{E^{\prime}}(\underline{k}, 1, \underline{\theta})=r .{ }^{26}$ Note that $\underline{\theta}$ does not depend on $a_{0}$.

As $\theta$ rises above $\underline{\theta}$, the returns to capital and labor increase in enterprise, and enterprise becomes a better alternative than saving all assets in $a_{t}$. This does not guarantee that the individual will invest, since time could be allocated instead to traditional labor. Not surprisingly, those with high values of $\omega$ and low values of $\theta$ will only engage in traditional labor. Specifically, there will be a second threshold, $\tilde{\theta}$, above which individuals will invest in enterprise if $\theta>\underline{\theta}$ is also satisfied. $\tilde{\theta}$ is a function of the relative marginal products of labor. The marginal product of labor in enterprise, $M P L^{E}(r, \theta)$, is decreasing in $r$ and increasing in $\theta{ }^{27}$ In the traditional sector, $M P L^{T}\left(\omega, a_{0}, r\right)$ is determined by the equilibrium level of $l^{T}$, and is increasing in $\omega, a_{o}$ and $r .^{28}$ For high enough $\omega, M P L^{T}\left(\omega, a_{0}, r\right) \geq M P L^{E}(r, \theta)$, and these individuals will engage only in traditional labor and save all their assets in $a_{t}$. $M P L^{T}\left(\omega, a_{0}, r\right)=M P L^{E}(r, \theta)$ defines a threshold level of $\tilde{\theta}=\tilde{\theta}\left(\omega, r, a_{o}\right)$ where $\theta>\tilde{\theta}$ if and only if $M P L^{T}\left(\omega, a_{0}, r\right)<M P L^{E}(r, \theta)$. $\tilde{\theta}\left(\omega, r, a_{0}\right)$ is increasing in all three arguments $r, \omega$ and $a_{o}$. However, the effect of $a_{o}$ on $\tilde{\theta}$ will be negligible and so we simplify to $\tilde{\theta}(\omega, r)$.

Finally, in the steady state ${ }^{29}$, occupational choice is determined by the threshold $\theta^{*}=$ $\theta^{*}(r, \underline{k}, \omega)=\max \{\underline{\theta}(r, \underline{k}), \tilde{\theta}(\omega, r)\}$. Low ability individuals whose $\theta<\theta^{*}(r, \underline{k}, \omega)$ will set $k=0$ and $l^{E}=0$. $c$ and $l^{T}$ will be determined by $a_{o}, r$ and $w$. High ability individuals

\footnotetext{
${ }^{26}$ Since hours working in the enterprise are upward bounded by 1 while capital invested in skilled trade must be higher than $\underline{k}$, for any individual that invests in the enterprise, $\frac{k}{l^{E}}$ must be higher than $\underline{k}$. Then for any $\theta<\underline{\theta}, k \geq \underline{k}$, and $l^{s}<1, f_{k}^{E^{\prime}}\left(k, l^{E}, \theta\right)<f_{k}^{E^{\prime}}(\underline{k}, 1, \underline{\theta})=r$. The inequality arises because $f_{k}^{E^{\prime}}$ is decreasing in $k$ but increasing in $l^{E}$ and $\theta$. Therefore, for individuals with $\theta<\underline{\theta}$, their returns to capital in enterprise is below $r$ regardless of the level of $l^{E}$ and $k$. Note that $\underline{\theta}$ is an increasing function of $\underline{k}, r$ and other parameters in the production function $f^{E}$.

${ }^{27}$ If there is positive investment in enterprise, condition $f_{k}^{E^{\prime}}\left(k, l^{E}, \theta\right)=r$ pins down the level of $\frac{k}{l^{E}}$ (this because we assumed $f^{E}$ is homogenous of degree one in $\left.\left(k, l^{E}\right)\right) \cdot \frac{k}{l^{E}}$ then pins down the marginal product of labor on the right hand side of condition $3:-\frac{u_{l}^{\prime}\left(c_{t}, l_{t}\right)}{u_{c}^{\prime}\left(c_{t}, l_{t}\right)}=f_{l}^{E^{\prime}}\left(k_{t}, l_{t}, \theta\right)$.

${ }^{28}$ If an individual does not invest in enterprise and only engages in traditional labor, conditions $1,3,5$ and 6 will pin down a level of $l^{T}$.

${ }^{29}$ Note that we cannot have growth on the steady state because total hours available to the individual is 1 , and we assume there is no exogenous growth in productivity or individual ability. Therefore, we characterize a steady state where $c_{t}, k_{t}, l_{t}$ and $a_{t}$ are all constant. From optimal condition 1 , we can see that, without any restraints on savings or borrowing, the existence of a steady state requires $\delta(1+r)=1$, otherwise we cannot keep consumption constant. Notice that this because we assumed there is free lending and free borrowing, both at the same rate $r$. Patient individuals whose $\delta>\frac{1}{1+r}$ would over save and accumulate infinite wealth when $t \rightarrow \infty$; impatient individuals whose $\delta<\frac{1}{1+r}$ would borrow too much today and their assets would approach negative infinity as $t \rightarrow \infty$. In both of these cases, the transversality condition would be violated. While this condition $\delta(1+r)=1$ seems restrictive, we could argue that in reality, there will bounds for borrowing and savings. As long as there is lending and borrowing within some bounds at the rate $r$, our results would hold. We do not need $\delta(1+r)=1$ for our comparative analysis.
} 
whose $\theta \geq \theta^{*}$ will invest in enterprise and set $k^{*}>0$ and $l^{E *}>0$ such that $f_{k}^{E^{\prime}}\left(k^{*}, l^{E *}, \theta\right)=r$

and $-\frac{u_{l}^{\prime}\left(c^{*}, l^{*}\right)}{u_{c}^{\prime}\left(c^{*}, l^{*}\right)}=f_{l}^{E^{\prime}}\left(k^{*}, l^{E *}, \theta\right)=f_{l}^{T^{\prime}}\left(l^{T *}, \omega\right)$. Their returns to capital will be $r$ regardless of their level of wealth. The ratio $\frac{k^{*}}{l^{E *}}$ will be determined by $\theta$ and $r$, while hours in traditional labor $l^{T *}$ will be determined by $w$ and $r$. Initial wealth $a_{o}$ will have a small effect on the level of $k^{*}, l^{E *}, c$ and $a$. Without any constraints, all individuals will immediately jump to these efficient steady state levels of production and consumption at time $t=1$.

\section{Impact of a windfall}

With perfect financial markets, an unrestricted windfall will have no effect on entry into enterprise and little effect on earnings because it does not change $\theta, \omega$ or $r$. The individual will immediate jump to a new steady state with higher level of savings $a$ and consumption $c$, and will slightly reduce investment $k$ and hours in enterprise $l^{E}$ because of greater wealth.

Suppose instead the windfall is granted in the form of in-kind transfers or restricted funding and there is some minimal "flypaper effect" such that capital stocks are "sticky" and cannot be divested immediately. This "restricted windfall" will force individuals to produce above their efficient scale, $f_{k}^{E^{\prime}}(k, l, \theta)<r$. $c$ will increase as output increases in the enterprise. $l^{T}$ will decrease and $l^{E}$ could go either direction, depending on parameter values. In the longer run, if it is possible to shift capital to $a$, individuals will divest until the returns in enterprise drops back to $r$.

\section{A.2 Cash windfalls in imperfect financial markets}

\section{A.2.1 Credit constraint $a_{t} \geq 0$}

For simplicity, we consider an extreme credit constraint, $a_{t} \geq 0$. The intuition and comparative statics are similar for other less restrictive credit constraints. The credit constraint affects optimality conditions 1, which becomes:

$$
\frac{u_{c}^{\prime}\left(c_{t}, l_{t}\right)}{u_{c}^{\prime}\left(c_{t+1}, l_{t+1}\right)} \geq \delta(1+r) \quad \text { with equality if } a_{t+1}>0
$$

Initially wealthy entrepreneurs tend to operate at efficient scale, with marginal returns equal to $r$. The less wealthy, more impatient and higher ability do not have savings, will satisfy 7 with equality, and will invest below efficient scale with marginal returns are higher than $r$.

Credit constraints also change the steady state level of investments, returns to investments, and threshold $\theta^{*}$. Define $\rho=\frac{1-\delta}{\delta}$, where a high level of $\rho$ indicates impatience. Define $k^{* *}$ and $l^{E * *}$ such that $f_{k}^{s^{\prime}}\left(k^{* *}, l^{E * *}, \theta\right)=\rho$. For impatient individuals whose $\rho>r$, the steady state level of capital and hours in the enterprise would be $k^{* *}<k^{*}$ and $l^{E * *}$, and 
their returns to capital will be $\rho$. These individuals are investing below the efficient scale. For those whose $\rho<r$, the steady state level of returns will still be $r$ and investments will still be $k^{*}$ as before. To sum up, the steady state returns to capital will be $\max \{r, \rho\}$. For simplicity we will still refer to the threshold as $\theta^{*}$, while here $\theta^{*}=\theta^{*}(r, \underline{k}, \omega, \rho)$ and $\theta^{*}$ is increasing in $\rho$ whenever $\rho>r$. This means that with a credit constraint, more impatient individuals will find enterprise undesirable than in the benchmark case.

Not surprisingly, with a credit constraint, not all whose $\theta>\theta^{*}$ will immediately engage in enterprise. Specifically, if there is a credit constraint, $a_{t} \geq 0$, then compared to the benchmark case with no constraints at all then occupational choice and investment will vary by type and initial wealth in the following manner:

1. Low ABility individuals, $\theta<\theta^{*}$. A credit constraint will not change occupational choice, consumption or labor supply as they would not invest in the enterprise even if they are allowed to borrow.

2. High ABility And High wealth, $\theta \geq \theta^{*}$ AND $a_{0} \geq k^{* *}$. A credit constraint will not change occupational choice. However, investment levels and returns will depend on time preferences:

(a) Patient types $(\rho<r)$ will invest $k^{*}$, with marginal returns $r$.

(b) Impatient types $(\rho>r)$ will invest $k^{* *}<k^{*}$, with marginal returns $\rho$.

3. High Ability And Below Steady State Wealth $\left(\theta \geq \theta^{*}\right.$ AND $\left.\underline{k} \leq a_{0} \leq k^{* *}\right)$. A credit constraint will reduce initial investment in enterprise only. They will start with an enterprise below efficient scale and over time will accumulate enough capital to reach the steady state level of investment.

4. High ability and Below minimum scale Wealth $\left(\theta \geq \theta^{*}\right.$ AND $\left.a_{0} \leq \underline{k}\right)$. A credit constraint will change initial occupational choice, but whether this effect is long-term or not depends on $a_{0}, \delta$ and abilities in each sector:

(a) if $a_{0}$ is close to $\underline{k}$ or $\omega$ is very high, and $\delta$ is close to one, the individual would be able to save in the initial periods and eventually accumulate enough wealth to invest in enterprise. In this case, the credit constraint only temporarily alters the individual's occupational choice. Individuals will not invest in enterprise until $a_{t+1}$ is above $\underline{k}$, after which they start investing in enterprise and reach the steady state level of investment over time. 
(b) if $a_{0}$ is far below $\underline{k}$ or $\omega$ is very low, and $\delta$ is close to zero, the individual would remain in traditional labor forever. In this case, the credit constraint has a permanent effect on the individual's occupational choice.

Impact of a windfall We first consider an unrestricted cash windfall. In cases 1 and 2(a), individuals are in their optimal steady state and the windfall will increase consumption and savings, and slightly reduce labor supplied, but will not affect entry into enterprise or resulting earnings. In case 2(b), individuals will increase investments in enterprise temporarily above $k^{* *}$, increase total earnings but reduce marginal returns to capital to a level below $\rho$ but not lower than $r$; over time they will reduce capital in the enterprise until capital returns in the enterprise rise up to $\rho$ again. Consumption will rise in the long run, but savings will be zero in the long run.

The most relevant cases are 3 and 4 . In case 3 , the windfall will immediately increase their investments in enterprise and earnings, and they will continue to increase capital and earnings over time until they reach $k^{*}$. Likewise, in case 4 , individuals will start and sustain an enterprise if the windfall is enough to cover the capital requirement $\underline{k}$. For those with extremely low level of initial wealth $a_{0}<\underline{k}-M$, the windfall will not immediately affect their involvement in enterprises, but it does increase the chances of their engaging in enterprise in the long run. Whether they will eventually engage in the enterprise will again depend on their patience and productivity in traditional labor.

The impacts of a windfall may be temporary. Note that, in both cases 3 and 4 , for a wide range of $a_{0}$ a non-windfall recipient will eventually reach their optimal capital stock. In case 3 , where $\underline{k} \leq a_{0} \leq k^{* *}$, individuals will accumulate enough capital to reach the steady state level of investment. In case $4(\mathrm{a})$, if $a_{0}$ is close to $\underline{k}$ or $\omega$ is very high, and $\delta$ is close to one, the individual will increase $a$ in the initial periods and eventually accumulate enough asset to invest in enterprise, once $a_{t+1}$ is above $\underline{k}$. Only in case $4(\mathrm{~b})$, for a sufficiently low initial asset stock or labor productivity, the individual will be "trapped" at very low levels of income.

Next we consider a restricted windfall with some flypaper effect. In cases 1 and 2, individuals are in their optimal steady state and the results are the same as in the case of perfect financial markets: they will be forced to invest above efficient scale in the short run, earnings will increase, but returns will be low. In the long-run, they will divest and go back to the their steady state level of production, merely saving and consuming divested funds. In cases 3 and 4 , individuals are below steady state and the impact will be similar to the case of the unrestricted windfall. 


\section{A.2.2 Savings constraint $a_{t} \leq 0$}

Now we consider the case of a savings constraint where individuals do not have any alternative means to invest other than enterprise. They are, however, still allowed to borrow at rate $r$. Condition 1 now becomes

$$
\frac{u_{c}^{\prime}\left(c_{t}, l_{t}\right)}{u_{c}^{\prime}\left(c_{t+1}, l_{t+1}\right)} \leq \delta(1+r) \quad \text { with equality if } a_{t+1}<0
$$

Savings constraints can lead to investment above the efficient scale. For those with debts $a_{t+1}<0$ (the impatient and poor ones), the first order conditions require their returns to capital to be the same as $r$; however, for those without debts $a_{t+1}=0$ (the patient and savings constrained ones), these conditions mean marginal returns are lower than $r$.

Among those who do invest in the enterprise, for the patient individuals whose $\rho<r$, the steady state level of capital and hours are $k^{* *}$ and $l^{E * *}$, and their returns will be $\rho$. Notice $k^{* *} / l^{E * *}>k^{*} / l^{E *}$. For those impatient ones whose $\rho>r$, steady state returns are still $r$ and investments are still $k^{*}$ as before. Thus the steady state returns to capital are $\min \{r, \rho\}$. Because individuals are still allowed to borrow, any individual with $\theta \geq \theta^{*}$ would invest in enterprise, though this $\theta^{*}$ is lower than in the benchmark and credit constraint cases for patient individuals whose $\rho<r .{ }^{30}$ Thus, under a savings constraint, more people run an enterprise at any $t>0$, before and after everyone reaches their steady state. However, the average rate of returns among entrepreneurs will be lower than $r$.

Impact of a windfall An unrestricted windfall will not change any individual's decision to engage in enterprise, since all those with $\theta \geq \theta^{*}$ will be already engage in enterprise at the outset. However, in the short run, since individuals cannot save, the windfall will increase consumption and capital stocks, and thus further reduce the marginal returns to capital in the enterprise below $\min \{r, \rho\}$. In the long run, however, capital and consumption will drop back to the steady state level and rate of returns will rise back to $\min \{r, \rho\}$.

A restricted cash transfer with a flypaper effect will immediately increase capital stocks and lower the rate of return while having no immediate impact on consumption. Over time, the individual will consume these transfers until consumption and capital stock falls back to the steady state level. The average impact on earnings will not be as high as under a credit

\footnotetext{
${ }^{30}$ Savings constraints will lower the threshold level of $\theta^{*}$ for those whose $\rho<r$. This because now we would need to define $\theta^{*}$ based on the new level of returns to capital $\min \{r, \rho\}$ instead of $r$. For simplicity of discussion, we will still refer to the threshold as $\theta^{*}$, while here $\theta^{*}=\theta^{*}(r, \underline{k}, \omega, \rho)$ and $\theta^{*}$ is increasing in $\rho$ whenever $\rho<r$. This means that with a credit constraint, more individuals will be engaging in enterprise than in the benchmark case.
} 
constraint.

\section{A.2.3 Savings and credit constraints $a_{t}=0$}

Finally we consider the effect of a savings constraint on top of a credit constraint. For those who do invest in the enterprise, their rate of returns will be $f_{k}^{E^{\prime}}\left(k, l^{E}, \theta\right)=\frac{1-\delta}{\delta}=\rho$. This means the less patient will be investing below the efficient scale while the more patient will be investing above the efficient scale. This also changes the threshold level $\theta^{*}$ for all individuals. We would need to define $\theta^{*}$ using $f_{k}^{E^{\prime}}\left(k, l^{E}, \theta\right)=\rho$ instead of $r$. For impatient people whose $\rho>r, \theta^{*}$ would be higher than in the benchmark case; while for patient ones whose $r>\rho, \theta^{*}$ would be lower than in the benchmark case. This means, compared to the benchmark case, there will be more patient individuals and less impatient ones investing in enterprise. Individuals with $\theta<\theta^{*}$ (case 1 above) will be engaging in traditional labor only, as are those with high ability and below minimum scale wealth (case 4(a) and (b)).

Cash windfalls, restricted or unrestricted, will be invested in all cases. ${ }^{31}$ Those at or near their optimal steady state level of capital (including no enterprise) will have an average return below $\min \{r, \rho\}$, and those below their steady state will have average returns higher than this level. Individuals in case 4, however, who do not receive a windfall and have low initial capital stocks, will not gradually save and accumulate enough capital to start an enterprise.

\section{A.2.4 Risk and missing insurance markets}

Next we consider the case of risky enterprise and risky traditional labor but a riskless financial alternative. It is possible to model risk in several ways. To incorporate uncertainty, we illustrate the case where the productivity measures $\theta_{t}$ and $\omega_{t}$ are uncertain and vary over time.

Specifically, we assume that realizations of ability are normally distributed around average expected productivity $\bar{\theta}$ and $\bar{\omega}, \theta_{t} \sim N\left(\bar{\theta}, \delta_{\theta}\right)$ and $\omega_{t} \sim N\left(\bar{\omega}, \delta_{\omega}\right)$. Hours in enterprise and traditional labor are determined after the realization of $\theta_{t}$ and $\omega_{t}$. Investment decisions $k_{t}$ and $a_{t}$, however, are made in time $t-1$, before the realization of productivity $\theta_{t}$ and $\omega_{t}$. We can view the individual as having a stochastic income stream delivered by the stochastic wage from traditional labor. At the same time, the individual has the option of investing his asset in either the risky enterprise with expected return $\mathbb{E}_{t}\left(1+f_{k}^{E^{\prime}}\left(k_{t+1}, l_{t+1}^{E}, \theta\right)\right)$ or the riskless asset with return $1+r$.

\footnotetext{
${ }^{31}$ The sole exception is the very poor with initial wealth $a_{0}<\underline{k}-M$. They will no longer pass a point where they have incentives to save in order to accumulate $\underline{k}$. This a moot point if $M>\underline{k}$.
} 
The solution to the problem is characterized as time-paths of quantities $\left\{c_{t}, l_{t}^{E}, l_{t}^{T}, k_{t+1}, a_{t+1}\right\}_{t=0}^{\infty}$ that satisfy the following set of conditions for all time periods $t$ and for all states of the world at time $t$ :

$$
\begin{aligned}
& \mathbb{E}_{t}\left[\frac{\delta u_{c}^{\prime}\left(c_{t+1}, l_{t+1}\right)}{u_{c}^{\prime}\left(c_{t}, l_{t}\right)}(1+r)\right]=1 \\
& -\frac{u_{l}^{\prime}\left(c_{t}, l_{t}\right)}{u_{c}^{\prime}\left(c_{t}, l_{t}\right)}=f_{l}^{E^{\prime}}\left(k_{t}, l_{t}^{E}, \theta_{t}\right) \quad \text { if } l_{t}^{E}>0 \\
& -\frac{u_{l}^{\prime}\left(c_{t}, l_{t}\right)}{u_{c}^{\prime}\left(c_{t}, l_{t}\right)}=f_{l}^{T^{\prime}}\left(l_{t}^{T}, \omega_{t}\right) \quad \text { if } l_{t}^{T}>0 \\
& \mathbb{E}_{t}\left[\frac{\delta u_{c}^{\prime}\left(c_{t+1}, l_{t+1}\right)}{u_{c}^{\prime}\left(c_{t}, l_{t}\right)}\left(1+f_{k}^{E}\left(k_{t+1}, l_{t+1}^{E}, \theta_{t}\right)\right)\right]=1 \text { if } k_{t+1}>0 \\
& (1+r) a_{t}+k_{t}+f^{E}\left(k_{t}, l_{t}^{E}, \theta_{t}\right)+f^{T}\left(l_{t}^{T}, \omega_{t}\right)=c_{t}+a_{t+1}+k_{t+1} \\
& \lim _{j \rightarrow \infty} \mathbb{E}_{t} \beta^{j} u_{c}^{\prime}\left(c_{t+j}, l_{t+j}\right) a_{t+j}=0
\end{aligned}
$$

given $k_{0}=0$ and $a_{0}>0$.

Following the asset pricing literature, we define $M_{t}=\frac{\delta u_{c}^{\prime}\left(c_{t+1}, l_{t+1}\right)}{u_{c}^{\prime}\left(c_{t}, l_{t}\right)}$ as the stochastic discount factor. Condition 9 and 12 imply that investment in the enterprise, if positive, must satisfy the usual asset pricing equation:

$$
\mathbb{E}_{t} f_{k}^{E^{\prime}}\left(k_{t+1}, l_{t+1}^{E}, \theta_{t}\right)-r=-(1+r) \operatorname{Cov}_{t}\left(f_{k}^{E^{\prime}}\left(k_{t+1}, l_{t+1}^{E}, \theta_{t}\right), M_{t+1}\right)
$$

Risk neutral individuals will invest until $\mathbb{E} f_{k}^{E^{\prime}}\left(k, l^{E}, \theta\right)=r$. As in the case without risk, we refer to the level of investment that corresponds to $\mathbb{E} f_{k}^{E^{\prime}}\left(k, l^{E}, \theta\right)=r$ as the efficient scale of investment.

For any risk averse individual, if $\theta_{t+1}$ and $\omega_{t+1}$ are positively correlated or uncorrelated, then $\operatorname{Cov}_{t}\left(f_{k}^{E^{\prime}}\left(k_{t+1}, l_{t+1}^{E}, \theta_{t}\right), M_{t+1}\right)<0$ and $\mathbb{E}_{t} f_{k}^{E^{\prime}}\left(k_{t+1}, l_{t+1}^{E}, \theta_{t}\right)>r$. This saying that if the returns to enterprise and traditional labor are positively correlated, then the riskless asset will deliver higher expected utility than the risky enterprise, and the individual will invest below the efficient scale in the enterprise as long as he is risk averse. In this case, the more risk averse the individual is, the less he invests in risky enterprise, and the higher the returns to the enterprise. Similarly, the higher the variability of $\theta$ or $w$, the less the individual invests in risky enterprise,

If instead, $\theta_{t+1}$ and $\omega_{t+1}$ are negatively correlated, i.e. the returns to enterprise and traditional labor are negatively correlated, then the enterprise and traditional labor are a good hedge against each other. The individual will invest more in the enterprise, or even invest above the efficient scale. The returns to enterprise $\mathbb{E}_{t} f_{k}^{E^{\prime}}\left(k_{t+1}, l_{t+1}^{s E}, \theta_{t}\right)$ will be close to 
$r$, or even lower than $r$ if the variability of $\omega$ is high.

Here the optimal level of investment is a function of interest rate $r$, the mean and variance of productivity $\bar{\theta}, \delta_{\theta}, \bar{\omega}, \delta_{\omega}$, the correlation between $\theta$ and $\omega$, patience $\delta$ and the degree of risk aversion. The optimal choice of whether to invest in enterprise or not then depends on all these parameters, as well as the minimum scale of production $\underline{k}$.

Impact of a windfall We ask the same question as before: Under what conditions will the cash windfall have a sustained effect on individuals' investment in enterprise and/or returns to investment in enterprise?

Even absent a credit constraint a windfall may induce some individuals to enter into enterprise, and change investment levels for those who do invest in enterprise, simply through the wealth effect. If utility displays constant absolute risk aversion (CARA) wealth would not have any effect on the optimal level of investment, and no effect on entry into enterprise. If, however, utility displays constant relative risk aversion (CRRA) then a windfall increases the level of wealth, which then increases the optimal level of investment in the risky enterprise.

Note that there will be individuals with either very low initial wealth, or very high risk aversion, who would not invest in the risky enterprise (because of $\underline{k}$ ) but would do so after receiving the cash windfall. Unless the amount of the windfall is very large (relative of the minimum scale $\underline{k}$ ) or the individual is very risk averse, we would not expect the windfall to have a large long-run average effect on investment across many individuals.

So long as both sectors are risky, for a windfall to result in high levels of investment and high returns, there must be some other form of imperfection on top of an environment with risk. Again, a credit constraint is a likely candidate in the setting described. This conclusion rests on the assumption that there are roughly similar levels of uncertainty in the two sectors. We turn to that assumption next.

Relative uncertainty Intuitively, the relative volatility of traditional trade and enterprise matter for investments in enterprise. More importantly, the impact of their relative volatility depends on initial wealth, the degree of risk aversion, as well as the correlation between enterprise and traditional labor.

In general terms, if either enterprise or traditional labor is relative safe (i.e. either $\sigma_{\theta}$ or $\sigma_{\omega}$ is low), then investment in enterprise $k$ falls as $\sigma_{\theta} / \sigma_{\omega}$ increases; and the more risk averse the individual is, the steeper the slope of the fall is. If $\sigma_{\theta}$ is low while $\sigma_{\omega}$ is high, the individual will very likely engage in the enterprise, as long as she is not bounded by a credit constraint. If $\sigma_{\theta}$ is high while $\sigma_{\omega}$ is low, the individual will likely not engage in the enterprise. In both cases, a windfall will have little impact on investments and earnings. 
If, however, productivity in traditional labor and enterprise are both very volatile $\left(\sigma_{\theta}\right.$ and $\sigma_{\omega}$ both high), then the relationship between $k$ and $\sigma_{\theta} / \sigma_{\omega}$ would also depend on initial wealth $a_{0}$, the degree of risk aversion, as well as the correlation between $\theta$ and $\omega$. First, consider the case where traditional labor and enterprise are uncorrelated or positively correlated. Holding everything else constant, if an individual has very low (or negative) initial wealth, then given a highly volatile income stream from traditional labor, the safety asset would be much more appealing to her than the enterprise even if the enterprise is less volatile than traditional labor. In this case, the individual may not enter into enterprise even if she faces no credit constraint - she might fear that she would never be able to repay the debt with her earnings. The same happens if the individual is very risk averse - she would not enter the enterprise and instead use the safety asset to smooth consumption over time. In both of these cases, a large windfall might pull the individual out of these situations and allow her to invest in the enterprise. However, if the returns from traditional labor and enterprise are negatively correlated, then again $k$ increases as $\sigma_{\theta} / \sigma_{\omega}$ falls, and the individual will likely invest in the enterprise as long as she is not bounded by a credit constraint. In this case, a windfall will have a long term effect on those with high levels of risk aversion and low levels of initial wealth . Again, this because a windfall increases wealth and lead the risk averse to invest more in risky assets - the enterprise.

\section{A.3 Cash windfalls and time-inconsistency}

We introduce quasi-hyperbolic $(\beta, \delta)$ preferences to see what predictions they hold for investment and earnings. The problem becomes:

$$
\begin{array}{rl}
\max _{c_{t}>0, l_{t} \geq 0, k_{t+1} \geq 0, a_{t+1}} & u\left(c_{t}, l_{t}\right)+\beta \sum_{s=t+1}^{\infty} \delta^{s} u\left(c_{s}, l_{s}\right) \\
\text { s.t. } \quad c_{t}+a_{t+1}+k_{t+1}= & W_{t} \\
l_{t}= & l_{t}^{E}+l_{t}^{T} \leq 1 \\
W_{t} & \equiv\left(1+r_{t}\right) a_{t}+k_{t}+f^{E}\left(k_{t}, l_{t}^{E}, \theta\right)+f^{T}\left(l_{t}^{T}, \omega\right)
\end{array}
$$

We consider the case of a "naive" type, or "naif", who makes investment decisions under the false belief that future selves will act in the interest of the current self, and a "sophisticate" who knows exactly what her future selves' preferences will be. 


\section{A.3.1 Perfect financial markets}

Optimal conditions 1 and 4 will now change into the general Euler equation for hyperbolic preferences:

$$
\frac{u_{c}^{\prime}\left(c_{t}, l_{t}\right)}{u_{c}^{\prime}\left(c_{t+1}^{P}, l_{t+1}\right)}=\left[\frac{\partial c_{t+1}}{\partial W_{t+1}} \beta \delta+\left(1-\frac{\partial c_{t+1}}{\partial W_{t+1}}\right) \delta\right] \cdot(1+r)
$$

and

$$
\frac{u_{c}^{\prime}\left(c_{t}, l_{t}\right)}{u_{c}^{\prime}\left(c_{t+1}^{P}, l_{t+1}\right)}=\left[\frac{\partial c_{t+1}}{\partial W_{t+1}} \beta \delta+\left(1-\frac{\partial c_{t+1}}{\partial W_{t+1}}\right) \delta\right] \cdot\left(1+f_{k}^{E^{\prime}}\left(k_{t+1}, l_{t+1}^{E}, \theta\right)\right) \quad \text { if } k_{t+1}>0
$$

These resemble the Euler equations 1 and 4 under exponential discounting, except that the discount factor $\delta$ is replaced by the effective discount factor $\frac{\partial c_{t+1}}{\partial W_{t+1}} \beta \delta+\left(1-\frac{\partial c_{t+1}}{\partial W_{t+1}}\right) \delta$, a weighted average of the short-run and long-run discount factors $\beta \delta$ and $\delta$ where the weights are the next period marginal propensity to consume out of total wealth. Here $W_{t}$ denotes total wealth at time $t . c_{t+1}^{P}$ denotes the individual's predicted future decision about $c_{t+1}$ at time $t$.

The differences between the naif and the sophisticate lie in the predicted consumption $c_{t+1}^{P}$ and the marginal propensity to consume $\frac{\partial c_{t+1}}{\partial W_{t+1}}$. Sophisticates are aware of the timeinconsistency problem and will correctly anticipate future consumption. For them, $c_{t+1}^{P}=$ $c_{t+1}$. Naifs, however, mistakenly believe that future selves will act as if their discount factor remains unchanged at all future dates. For them $c_{t+1}^{P}<c_{t+1}$. Time-inconsistency will affect both consumption and savings.

Time-inconsistency should not affect the optimal use of a cash windfall. For those with $\theta \geq \theta^{*}$, they will still invest until the returns to capital are equal between the enterprise and alternative financial options, or $f_{k}^{E^{\prime}}\left(k, l^{E}, \theta\right)=r$. Note that consumption, hours and savings will all be different under time-inconsistency compared to our benchmark case without time-inconsistency. Thus threshold value of $\theta^{*}$ is different than in the benchmark case. However, the effect of a windfall will be similar to that in the benchmark case without timeinconsistency. This because absent of any credit market imperfections, everyone will already be at their efficient scale.

\section{A.3.2 Time-inconsistency with credit constraints}

For a windfall to be invested and produce high average returns, some other constraint must be present. Similar to the case without time-inconsistency, credit constraints will suffice. To see this, we turn to the Euler equations again. Those who are credit constrained will put every additional dollar they get into consumption (not savings), because they are present- 
biased. Therefore $\frac{\partial c_{t+1}}{\partial W_{t+1}}=1$ and the Euler equations become

$$
\frac{u_{c}^{\prime}\left(c_{t}, l_{t}\right)}{u_{c}^{\prime}\left(c_{t+1}^{P}, l_{t+1}\right)}=\beta \delta\left(1+f_{k}^{E^{\prime}}\left(k_{t+1}, l_{t+1}^{E}, \theta\right)\right) \quad \text { if } k_{t+1}>0
$$

for those who are bounded by the credit constraint, i.e. $a_{t+1}=0$.

With time inconsistency, all credit constrained individuals will invest less than if they were time-consistent. To see this, define $\tau$ such that $\frac{1}{1+\tau}=\beta \delta$, i.e. $\tau=\frac{1}{\beta \delta}-1$. Since the sophisticates can correctly anticipate their future consumptions, in their steady state $c_{t+1}^{P}=c_{t+1}=c_{t}$, and the marginal rate of return will be $f_{k}^{E^{\prime}}\left(k_{\text {sophisticate }}, l^{E}, \theta\right)=\tau$. Naifs will naively expect themselves to have more self-control tomorrow, and expect $c_{t+1}^{P}<c_{t}$. For them $\frac{u_{c}^{\prime}\left(c_{t}, l_{t}\right)}{u_{c}^{\prime}\left(c_{t+1}^{P}, l_{t+1}\right)}<1$ and $\rho<f_{k}^{E^{\prime}}\left(k_{\text {naive }}, l^{E}, \theta\right)<\tau$. Therefore, for those who are credit constrained $\left(a_{t+1}=0\right)$, their steady state level of investment satisfies $\rho<f_{k}^{E^{\prime}}\left(k_{\text {naive }}, l^{E}, \theta\right)<\tau=$ $f_{k}^{E^{\prime}}\left(k_{\text {sophisticate }}, l^{E}, \theta\right)$. They also work less and consume a larger portion of their income.

Somewhat counter-intuitively, given the levels of $\beta$ and $\delta$, the sophisticates invest even less than the naifs. This because the naifs believe (incorrectly) that they will consume less tomorrow and eventually grow to $k=k^{* *}$ just like a time-consistent type. Thus they think their average future marginal utility of consumption is low (i.e. high consumption) and therefore are willing to consume less than the sophisticates. In practice, however, we might expect $\beta$ and $\delta$ to be positively correlated, or sophisticates to have both higher $\beta$ and $\delta$ than the naive. In this case, sophisticates would invest more than naifs.

Impact of a windfall The impact of a cash windfall is similar to the case with timeconsistent preferences. Credit constraints (but not savings constraints) are needed in this simple model to expect investment and high returns. High investment and returns, moreover, will only be seen where people start below their steady state. The steady state levels of capital to which the time-inconsistent will move, however, are lower than the case without time inconsistency. Thus the average returns will be lower than the benchmark case, but still greater than $r$.

Recall, however, that in the time consistent case the average impact was expected to increase in patience (at least amongst those below their optimal steady state capital). With time inconsistency, holding patience constant, we expect the impacts to be larger among the more time-inconsistent. In practice, however, this comparative static will be difficult to identify, partly because $\beta$ and $\delta$ may be correlated and partly because they may be difficult to measure separately.

More importantly, restricted windfalls with a flypaper effect have the potential to increase investment levels to $k^{*}$, at least temporarily. Eventually as long as they can divert, 
both types will return to their steady state level of investment.. However, if there is a commitment device, for example an in-kind transfer that cannot be diverted over time, then the sophisticates will more likely be the ones who apply for and use this in-kind transfer. Such a transfer will not only help some constrained individuals to enter into enterprise or get closer to their steady state level of investment, it will also change the steady state level of investment for the sophisticates from $k_{\text {sophisticate }}$ to $k^{* *}$. A naive type, on the other hand, would not want to tie their hands to such a transfer; they would prefer a transfer that can be diverted over time. Intuitively, time inconsistency makes the sophisticates act like a person with very low discount rate $\beta \delta$ every period, when in fact their real discount rate for the far future is $\delta$. So a windfall that also act as a commitment device could push them into a new equilibrium that it wouldn't do for someone who was time-consistent but merely impatient. 


\title{
B Supplementary tables and figures
}

\author{
Table B.1: Correlates of survey attrition
}

\begin{tabular}{|c|c|c|c|c|c|c|}
\hline & \multicolumn{6}{|c|}{ Dependent variable: indicator for being unable to find in round } \\
\hline & \multicolumn{2}{|c|}{ 2-year endline } & \multicolumn{2}{|c|}{ 4-year endline } & \multicolumn{2}{|c|}{ 9-year endline } \\
\hline & $\begin{array}{l}\text { Coeff } \\
\text { (1) }\end{array}$ & $\begin{array}{l}\text { SE } \\
(2)\end{array}$ & $\begin{array}{c}\text { Coeff } \\
(3)\end{array}$ & $\begin{array}{l}\text { SE } \\
(4)\end{array}$ & $\begin{array}{c}\text { Coeff } \\
(5)\end{array}$ & $\begin{array}{l}\text { SE } \\
(6)\end{array}$ \\
\hline Assigned to treatment & 0.02 & 0.02 & -0.03 & 0.02 & 0.04 & 0.02 \\
\hline Grant amount applied for (USD) & -0.00 & 0.00 & 0.00 & 0.00 & -0.00 & 0.00 \\
\hline Group Size & 0.00 & 0.00 & -0.00 & 0.00 & -0.00 & 0.00 \\
\hline Grant Amount per Member, USD & 0.00 & 0.00 & -0.00 & 0.00 & -0.00 & 0.00 \\
\hline Group existed before application & -0.02 & 0.02 & -0.01 & 0.03 & -0.01 & 0.03 \\
\hline Group age, in years & 0.00 & 0.01 & -0.00 & 0.01 & -0.00 & 0.01 \\
\hline Within-group heterogeneity (z-score) & 0.01 & 0.01 & 0.03 & $0.01^{*}$ & -0.00 & 0.01 \\
\hline Quality of in-group dynamic (z-score) & 0.01 & 0.01 & -0.02 & 0.02 & -0.01 & 0.01 \\
\hline Distance to educational facilities $(\mathrm{km})$ & 0.00 & 0.00 & 0.00 & 0.00 & 0.00 & 0.00 \\
\hline Age at baseline & -0.00 & $0.00^{*}$ & -0.01 & $0.00^{* * *}$ & -0.01 & $0.00^{* * *}$ \\
\hline Large town / urban area & 0.08 & $0.03^{* * *}$ & 0.17 & $0.04^{* * *}$ & 0.12 & $0.03^{* * *}$ \\
\hline Risk Aversion (z-score) & 0.04 & $0.01^{* * *}$ & 0.02 & $0.01^{* *}$ & 0.04 & $0.01 * * *$ \\
\hline Management comittee member & -0.04 & $0.02 * *$ & -0.03 & 0.02 & -0.01 & 0.03 \\
\hline Chairperson or vice-chairperson & 0.01 & 0.03 & 0.02 & 0.04 & -0.05 & 0.03 \\
\hline Weekly work hours: low skill & 0.00 & $0.00^{*}$ & 0.00 & 0.00 & 0.00 & 0.00 \\
\hline Weekly work hours: other business & 0.00 & 0.00 & -0.00 & 0.00 & -0.00 & 0.00 \\
\hline Weekly work hours: skilled trade & 0.00 & $0.00^{*}$ & -0.00 & 0.00 & -0.00 & 0.00 \\
\hline Weekly work hours: high skilled trade & 0.00 & 0.01 & -0.02 & 0.01 & -0.00 & 0.01 \\
\hline Weekly work hours: other non-agricultural & 0.00 & 0.00 & -0.00 & 0.00 & -0.00 & 0.00 \\
\hline Weekly work hours: agricultural & -0.01 & $0.00 * * *$ & -0.00 & 0.00 & 0.00 & 0.00 \\
\hline Weekly hourshold chores, hours & -0.00 & 0.00 & -0.00 & 0.00 & 0.00 & 0.00 \\
\hline No employment hours in past month & -0.13 & $0.03^{* * *}$ & -0.02 & 0.03 & 0.06 & $0.03^{* *}$ \\
\hline Main occupation is non-agricultural & -0.17 & $0.04 * * *$ & 0.03 & 0.05 & 0.10 & $0.04^{* *}$ \\
\hline Engaged in a Skilled Trade & -0.06 & $0.04^{*}$ & -0.03 & 0.05 & 0.02 & 0.05 \\
\hline Crrently in School & -0.08 & $0.03^{* *}$ & -0.04 & 0.05 & -0.06 & 0.05 \\
\hline Highest grade reached in school & -0.00 & 0.00 & 0.00 & 0.00 & 0.00 & 0.00 \\
\hline Able to read and write minimally & 0.06 & $0.02 * * *$ & 0.02 & 0.03 & -0.04 & 0.02 \\
\hline Received prior vocational training & -0.04 & 0.03 & -0.04 & 0.04 & -0.10 & $0.03^{* * *}$ \\
\hline Digit recall test score & -0.01 & $0.00^{* *}$ & 0.02 & $0.01^{* * *}$ & -0.00 & 0.01 \\
\hline ADL index & -0.01 & $0.00^{* * *}$ & -0.00 & 0.00 & -0.00 & 0.00 \\
\hline Durable Assets (z-score) & 0.02 & 0.01 & -0.01 & 0.01 & -0.01 & 0.01 \\
\hline Savings (000s 2008 UGX) & 0.00 & 0.00 & 0.00 & $0.00^{* * *}$ & 0.00 & 0.00 \\
\hline Monthly gross earnings (000s 2008 UGX) & -0.00 & $0.00^{*}$ & -0.00 & 0.00 & 0.00 & 0.00 \\
\hline Could obtain 100,000 UGX (58 USD) loan & -0.02 & 0.02 & 0.01 & 0.02 & 0.03 & 0.02 \\
\hline Could obtain 1,000,000 UGX (580 USD) loan & -0.01 & 0.03 & 0.01 & 0.04 & -0.06 & $0.03^{* *}$ \\
\hline Lives in Adjumani & -0.02 & 0.06 & -0.09 & 0.09 & -0.06 & 0.06 \\
\hline Lives in Apac & 0.06 & 0.05 & -0.07 & 0.08 & 0.07 & 0.06 \\
\hline Lives in Arua & 0.12 & $0.06^{* *}$ & -0.02 & 0.08 & 0.17 & $0.07^{* *}$ \\
\hline Lives in Kaberamaido & -0.03 & 0.05 & 0.04 & 0.10 & 0.03 & 0.08 \\
\hline Lives in Kotido & 0.24 & $0.08^{* * *}$ & 0.10 & 0.10 & 0.06 & 0.08 \\
\hline Lives in Kumi & 0.01 & 0.05 & -0.07 & 0.08 & -0.01 & 0.06 \\
\hline Lives in Lira & 0.10 & $0.06^{*}$ & -0.09 & 0.08 & 0.10 & 0.08 \\
\hline Lives in Moroto & 0.26 & $0.08^{* * *}$ & 0.17 & 0.11 & 0.06 & 0.08 \\
\hline Lives in Moyo & 0.05 & 0.06 & -0.16 & $0.08^{* *}$ & 0.13 & 0.09 \\
\hline Lives in Nakapiripirit & 0.09 & 0.06 & 0.02 & 0.10 & 0.11 & 0.08 \\
\hline Lives in Nebbi & 0.02 & 0.07 & -0.10 & 0.09 & -0.00 & 0.06 \\
\hline Lives in Pallisa & 0.01 & 0.05 & -0.17 & $0.08^{* *}$ & 0.04 & 0.06 \\
\hline Lives in Soroti & -0.06 & 0.06 & -0.05 & 0.09 & 0.06 & 0.07 \\
\hline Mean & 0.15 & & 0.18 & & 0.12 & \\
\hline $\mathrm{P}$-value of F-test & 0.00 & & 0.00 & & 0.00 & \\
\hline$N$ & $2,322.00$ & & $2,035.00$ & & $2,086.00$ & \\
\hline R-squared & 0.13 & & 0.16 & & 0.11 & \\
\hline
\end{tabular}

Each pair of columns report the results from a WLS regression of an attrition indicator on baseline covariates and district fixed effects. Standard errors are clustered at the group level. ${ }^{*}$ implies $p<.1^{* *}$ implies $p<.05{ }^{* * *}$ implies $p<.01$. Observations are weighted by the probability into selection of endline tracking, and errors are clustered by group. 
Table B.2: Program impacts on additional business measures after 9 years

\begin{tabular}{|c|c|c|c|c|c|c|c|}
\hline \multirow{3}{*}{$\begin{array}{l}\text { Dependent Variable } \\
\mathrm{N}=1981\end{array}$} & \multirow{2}{*}{\multicolumn{3}{|c|}{ Control mean }} & \multicolumn{4}{|c|}{ Treatment effects } \\
\hline & & & & \multirow[b]{2}{*}{$\begin{array}{l}\text { Pooled } \\
\quad(4)\end{array}$} & \multicolumn{3}{|c|}{ By gender } \\
\hline & $\begin{array}{c}\text { Pooled } \\
\text { (1) }\end{array}$ & $\begin{array}{c}\text { Women } \\
(2)\end{array}$ & $\begin{array}{c}\text { Men } \\
(3)\end{array}$ & & $\begin{array}{c}\text { Women } \\
(5)\end{array}$ & $\begin{array}{c}\text { Men } \\
(6)\end{array}$ & $\begin{array}{c}\text { Difference } \\
(7)\end{array}$ \\
\hline Business index (sum) & 0.47 & 0.36 & 0.52 & $\begin{array}{c}0.044 \\
(0.040)\end{array}$ & $\begin{array}{c}0.041 \\
{[0.061]}\end{array}$ & $\begin{array}{c}0.045 \\
{[0.050]}\end{array}$ & $\begin{array}{c}0.004 \\
{[0.076]}\end{array}$ \\
\hline Business maintains formal records & 0.21 & 0.16 & 0.24 & $\begin{array}{c}0.030 \\
(0.021)\end{array}$ & $\begin{array}{l}-0.004 \\
{[0.032]}\end{array}$ & $\begin{array}{c}0.047 \\
{[0.026]^{*}}\end{array}$ & $\begin{array}{c}0.052 \\
{[0.040]}\end{array}$ \\
\hline Business is formally registered & 0.09 & 0.05 & 0.11 & $\begin{array}{l}-0.005 \\
(0.013)\end{array}$ & $\begin{array}{c}0.016 \\
{[0.021]}\end{array}$ & $\begin{array}{l}-0.016 \\
{[0.017]}\end{array}$ & $\begin{array}{l}-0.032 \\
{[0.027]}\end{array}$ \\
\hline Business payes taxes & 0.16 & 0.15 & 0.16 & $\begin{array}{c}0.019 \\
(0.018)\end{array}$ & $\begin{array}{c}0.029 \\
{[0.031]}\end{array}$ & $\begin{array}{c}0.014 \\
{[0.022]}\end{array}$ & $\begin{array}{l}-0.016 \\
{[0.036]}\end{array}$ \\
\hline Has any employees (dummy) & 0.57 & 0.48 & 0.61 & $\begin{array}{c}0.032 \\
(0.023)\end{array}$ & $\begin{array}{c}0.023 \\
{[0.042]}\end{array}$ & $\begin{array}{c}0.037 \\
{[0.028]}\end{array}$ & $\begin{array}{c}0.015 \\
{[0.050]}\end{array}$ \\
\hline Number of employees, all trades & 2.17 & 1.76 & 2.39 & $\begin{array}{c}0.320 \\
(0.165)^{*}\end{array}$ & $\begin{array}{c}0.119 \\
{[0.265]}\end{array}$ & $\begin{array}{c}0.425 \\
{[0.210]^{* *}}\end{array}$ & $\begin{array}{c}0.306 \\
{[0.339]}\end{array}$ \\
\hline Number of employees, non-agricultural & 0.48 & 0.25 & 0.60 & $\begin{array}{c}0.154 \\
(0.083)^{*}\end{array}$ & $\begin{array}{c}0.033 \\
{[0.086]}\end{array}$ & $\begin{array}{c}0.217 \\
{[0.112]^{*}}\end{array}$ & $\begin{array}{c}0.184 \\
{[0.132]}\end{array}$ \\
\hline Number of employees, skilled & 0.12 & 0.02 & 0.17 & $\begin{array}{c}0.139 \\
(0.042)^{* * *}\end{array}$ & $\begin{array}{c}0.035 \\
{[0.028]}\end{array}$ & $\begin{array}{c}0.193 \\
{[0.063]^{* * *}}\end{array}$ & $\begin{array}{c}0.158 \\
{[0.069]^{* *}}\end{array}$ \\
\hline Number of paid employees, all trades & 1.14 & 0.88 & 1.27 & $\begin{array}{c}0.257 \\
(0.136)^{*}\end{array}$ & $\begin{array}{c}0.102 \\
{[0.232]}\end{array}$ & $\begin{array}{c}0.338 \\
{[0.163]^{* *}}\end{array}$ & $\begin{array}{c}0.237 \\
{[0.279]}\end{array}$ \\
\hline Number of paid employees, non-agricultural & 0.33 & 0.14 & 0.43 & $\begin{array}{c}0.113 \\
(0.067)^{*}\end{array}$ & $\begin{array}{c}0.018 \\
{[0.076]}\end{array}$ & $\begin{array}{c}0.163 \\
{[0.090]^{*}}\end{array}$ & $\begin{array}{c}0.145 \\
{[0.113]}\end{array}$ \\
\hline Number of paid employees, skilled & 0.10 & 0.00 & 0.15 & $\begin{array}{c}0.098 \\
(0.034)^{* * *}\end{array}$ & $\begin{array}{c}0.034 \\
{[0.025]}\end{array}$ & $\begin{array}{c}0.131 \\
{[0.051]^{* * *}}\end{array}$ & $\begin{array}{c}0.097 \\
{[0.057]^{*}}\end{array}$ \\
\hline Number of family employees & 0.93 & 0.76 & 1.02 & $\begin{array}{c}0.088 \\
(0.096)\end{array}$ & $\begin{array}{c}0.119 \\
{[0.159]}\end{array}$ & $\begin{array}{c}0.072 \\
{[0.112]}\end{array}$ & $\begin{array}{l}-0.047 \\
{[0.182]}\end{array}$ \\
\hline Number of non-family employees & 1.24 & 1.00 & 1.37 & $\begin{array}{c}0.254 \\
(0.144)^{*}\end{array}$ & $\begin{array}{c}0.047 \\
{[0.239]}\end{array}$ & $\begin{array}{c}0.362 \\
{[0.177]^{* *}}\end{array}$ & $\begin{array}{c}0.315 \\
{[0.293]}\end{array}$ \\
\hline Employee hours in past month, all trades & 87.15 & 58.30 & 102.00 & $\begin{array}{c}20.754 \\
(8.909)^{* *}\end{array}$ & $\begin{array}{c}7.595 \\
{[12.720]}\end{array}$ & $\begin{array}{c}27.614 \\
{[11.097]^{* *}}\end{array}$ & $\begin{array}{c}20.019 \\
{[15.930]}\end{array}$ \\
\hline Employee hours in past month, non-agricultural & 37.88 & 19.92 & 47.12 & $\begin{array}{c}6.305 \\
(6.830)\end{array}$ & $\begin{array}{l}-3.225 \\
{[7.766]}\end{array}$ & $\begin{array}{l}11.273 \\
{[8.823]}\end{array}$ & $\begin{array}{c}14.498 \\
{[10.628]}\end{array}$ \\
\hline Employee hours in past month, skilled & 9.19 & 1.06 & 13.37 & $\begin{array}{c}9.690 \\
(3.763)^{* *}\end{array}$ & $\begin{array}{c}2.477 \\
{[2.588]}\end{array}$ & $\begin{array}{c}13.450 \\
{[5.255]^{* *}}\end{array}$ & $\begin{array}{c}10.973 \\
{[5.322]^{* *}}\end{array}$ \\
\hline Total payroll in past month (000s of 2008 UGX) & 44.67 & 20.09 & 57.32 & $\begin{array}{c}0.846 \\
(6.162)\end{array}$ & $\begin{array}{l}-4.832 \\
{[6.534]}\end{array}$ & $\begin{array}{c}3.806 \\
{[8.584]}\end{array}$ & $\begin{array}{c}8.638 \\
{[10.569]}\end{array}$ \\
\hline Total payroll in past month, non-agricultural & 24.38 & 5.49 & 34.11 & $\begin{array}{c}0.401 \\
(5.020)\end{array}$ & $\begin{array}{l}-2.272 \\
{[3.606]}\end{array}$ & $\begin{array}{c}1.794 \\
{[7.208]}\end{array}$ & $\begin{array}{c}4.066 \\
{[7.727]}\end{array}$ \\
\hline Total payroll in past month, skilled & 6.59 & 0.13 & 9.93 & $\begin{array}{c}3.054 \\
(2.326)\end{array}$ & $\begin{array}{c}0.672 \\
{[1.425]}\end{array}$ & $\begin{array}{l}4.295 \\
{[3.357]}\end{array}$ & $\begin{array}{c}3.623 \\
{[3.472]}\end{array}$ \\
\hline
\end{tabular}

Notes: Each entry in columns 3 and 4 is estimated from a weighted least squares regression of the dependent variable on an indicator for assignment to treatment, district fixed effects, and a vector of baseline covariates. Standard errors are clustered at the group level (of up to 5 people). We report the coefficient on treatment only. All regressions are weighted by inverse probabilities of attrition and selection into the endline tracking sample. Columns 5 through 7 come from a single regression, where we regress treatment on an indicator for treatment, an indicator interacted with gender, and the gender indicator plus the usual controls. We use these coefficients to calculate the treatment effect on each gender separately. ${ }^{*}$ implies $p<.1,{ }^{* *}$ implies $p<.05,{ }^{* * *}$ implies $p<.01$ 


\section{Table B.3: Program impacts on migration and urbanization after 9 years}

\begin{tabular}{|c|c|c|c|c|c|c|c|}
\hline \multirow{3}{*}{$\begin{array}{l}\text { Dependent Variable } \\
\mathrm{N}=1981\end{array}$} & \multirow{2}{*}{\multicolumn{3}{|c|}{ Control mean }} & \multicolumn{4}{|c|}{ Treatment effects } \\
\hline & & & & \multirow[b]{2}{*}{$\begin{array}{l}\text { Pooled } \\
\quad(4)\end{array}$} & \multicolumn{3}{|c|}{ By gender } \\
\hline & $\begin{array}{c}\text { Pooled } \\
(1)\end{array}$ & $\begin{array}{l}\text { Women } \\
(2)\end{array}$ & $\begin{array}{c}\text { Men } \\
(3)\end{array}$ & & $\begin{array}{l}\text { Women } \\
(5)\end{array}$ & $\begin{array}{c}\text { Men } \\
(6)\end{array}$ & $\begin{array}{l}\text { Difference } \\
\quad(7)\end{array}$ \\
\hline Lives in a town or city & 0.73 & 0.71 & 0.74 & $\begin{array}{c}0.013 \\
(0.021)\end{array}$ & $\begin{array}{c}0.022 \\
{[0.034]}\end{array}$ & $\begin{array}{c}0.008 \\
{[0.025]}\end{array}$ & $\begin{array}{l}-0.014 \\
{[0.040]}\end{array}$ \\
\hline Moved from a village to a town/city since Baseline & 0.65 & 0.65 & 0.66 & $\begin{array}{c}0.015 \\
(0.017)\end{array}$ & $\begin{array}{c}0.042 \\
{[0.028]}\end{array}$ & $\begin{array}{l}-0.000 \\
{[0.020]}\end{array}$ & $\begin{array}{l}-0.042 \\
{[0.033]}\end{array}$ \\
\hline Population of town (categorical variable) & 3.75 & 3.71 & 3.78 & $\begin{array}{l}-0.006 \\
(0.045)\end{array}$ & $\begin{array}{c}0.040 \\
{[0.076]}\end{array}$ & $\begin{array}{l}-0.029 \\
{[0.054]}\end{array}$ & $\begin{array}{l}-0.069 \\
{[0.090]}\end{array}$ \\
\hline
\end{tabular}

Notes: The categorial Population of town variable ranges from 1-6, with one being "less than 50 people", and six being "more than 5,000 people". $75 \%$ of the sample lives a town of category three or four: towns between 200 and 1000 people. Each entry in columns 3 and 4 is estimated from a weighted least squares regression of the dependent variable on an indicator for assignment to treatment, district fixed effects, and a vector of baseline covariates. Standard errors are clustered at the group level (of up to 5 people). We report the coefficient on treatment only. All regressions are weighted by inverse probabilities of attrition and selection into the endline tracking sample. Columns 5 through 7 come from a single regression, where we regress treatment on an indicator for treatment, an indicator interacted with gender, and the gender indicator plus the usual controls. We use these coefficients to calculate the treatment effect on each gender separately. ${ }^{*}$ implies $p<.1,{ }^{* *}$ implies $p<.05,{ }^{* * *}$ implies $p<.01$ 